Cómo citar este trabajo: Mayordomo Maya, S., \& Hermosilla Pla, J. (2019). Evaluación del patrimonio cultural: la Huerta de Valencia como recurso territorial. Boletín de la Asociación de Geógrafos Españoles, 82, 2790, 1-57. http://dx.doi.org/10.21138/bage.2790

\title{
Evaluación del patrimonio cultural: la Huerta de Valencia como recurso territorial
}

Cultural heritage evaluation: the Huerta de Valencia as a territorial resource

\author{
Sandra Mayordomo Maya \\ Sandra.Mayordomo@uv.es \\ Jorge Hermosilla Pla \\ Jorge.Hermosilla@uv.es \\ ESTEPA. Estudios del Territorio, Paisaje y Patrimonio \\ Departamento de Geografía \\ Universitat de València (España)
}

\section{Resumen}

El concepto de patrimonio cultural ha evolucionado a lo largo de la historia mediante un complejo proceso de atribución de valores. En la actualidad se define como la herencia de una comunidad, y comprende una amplia diversidad de bienes que nos remiten a nuestra identidad. La identificación y evaluación de estos elementos y expresiones constituyen acciones fundamentales para su gestión y restitución. En este artículo se desarrolla y aplica una metodología de evaluación del patrimonio cultural en 257 bienes de la Huerta de Valencia. Se trata de un método cuantitativo, reproducible para las diferentes tipologías de inmuebles y en cualquier territorio. Está conformado por múltiples criterios basados en parámetros objetivos. Asimismo, contempla acciones complementarias de participación mediante la realización de encuestas a los habitantes. La aplicación del método ha permitido la jerarquización de los bienes según su interés patrimonial. Se han detectado numerosos inmuebles de extraordinario valor. No obstante, una proporción significativa del inventario ha obtenido puntuaciones escasas, derivadas del progresivo deterioro del espacio agrario de la Huerta. La implementación efectuada constata que la metodología propuesta constituye una herramienta eficaz de evaluación patrimonial para la toma de decisiones y el diseño de acciones de gestión y puesta en valor. 
Palabras clave: patrimonio cultural; metodología de evaluación; Huerta de Valencia; participación pública; gestión patrimonial.

\begin{abstract}
The concept of cultural heritage has evolved throughout history through a complex process of attribution of values. Nowadays, it is defined as the inheritance of a community, with a wide diversity of assets that speak about our identity. The identification and evaluation of these elements and expressions are fundamental actions for their management and restitution. This article develops and applies a methodology of evaluation of the cultural heritage in 257 assets of the Huerta de Valencia. It is a quantitative method, reproducible for the different types of properties and in any territory. It is built upon multiple criteria based on objective parameters. It also contemplates complementary participation actions by conducting surveys to the inhabitants. The application of the method has allowed the hierarchy of the assets according to their patrimonial interest. Numerous properties of extraordinary value have been detected. However, a significant proportion of the inventory has obtained low scores, because of the deterioration of the agricultural space of La Huerta. The implementation validates the proposed methodology as an important tool regarding the decisionmaking and the design of management actions and evaluation.
\end{abstract}

Key words: cultural heritage; evaluation methodology; Huerta de Valencia; public participation; heritage management.

\title{
1 Introducción
}

El patrimonio cultural adquiere una importancia cada vez más evidente en las sociedades debido a sus múltiples significados, valores y usos. Se trata de un concepto abierto y en constante reelaboración, sometido a continuas modificaciones a lo largo de la historia. No es una esencia inmutable, ya que su definición depende de las valoraciones sociales, ideológicas e intelectuales de cada época y contexto, así como de las relaciones mantenidas con la memoria y la historia (González-Varas, 2015).

La noción actual de patrimonio cultural se ha construido durante siglos, y ha evolucionado desde un planteamiento particularista, relacionado con la propiedad privada e individual, hacia una difusión de los bienes como elementos de identidad colectiva (Llull, 2005). Es una propiedad comunitaria, la herencia común de una cultura (García, 2012). En la actualidad, el concepto continúa su expansión e incluye una extensa variedad de bienes y manifestaciones. Contempla expresiones escasamente reconocidas hasta el momento y aparecen nuevas tipologías, como el patrimonio inmaterial, los itinerarios culturales o los paisajes (García, Soto \& Martínez, 2017). 
Las discusiones y reflexiones relacionadas con los valores patrimoniales se han convertido en uno de los temas más relevantes tratados en los discursos vinculados con el patrimonio cultural y su conservación (Labadi, 2007). La Convención sobre la Protección del Patrimonio Mundial, Cultural y Natural aprobada en 1972 por la UNESCO establece que los valores atribuidos a los bienes no se limitan a su contenido histórico o artístico, sino que incluyen otros aspectos como los económicos, ambientales, sociales, tecnológicos o simbólicos (Siguencia \& Rey, 2016).

Desde hace décadas, numerosos especialistas de diferentes disciplinas han desarrollado teorías y metodologías de evaluación patrimonial basadas en múltiples atributos. En 1903, Riegl publica el ensayo "El culto moderno a los monumentos. Caracteres y origen", en el que considera el monumento como una suma de valores. Otro antecedente significativo es la Carta Burra (Australia Internacional Council on Monuments and Sites [ICOMOS], 1979), que incluye el aspecto social. Desde finales del siglo XX se acentúa el diseño de métodos de evaluación como resultado del progresivo interés en la gestión patrimonial. Se trata de sistemas aplicados en diversas escalas territoriales y para diferentes tipos de patrimonio, como el arqueológico (Sirovica \& Kudelić, 2019), arquitectónico (Zhang \& Wang, 2017), geológico (Ibáñez, Ahumada, Toledo \& Páez, 2018), hidráulico (Mayordomo, Antequera, \& Hermosilla, 2018), paisajístico (Iranzo, 2009; Brunetta, Monaco, Salizzoni \& Salvarani, 2018) o paleontológico (Morey, 2018).

En este estudio se desarrolla y aplica un método de evaluación del patrimonio cultural inmueble,1 una modalidad determinada por la diversidad de tipologías. Es un sistema multicriterio y cuantitativo, constituido por parámetros objetivos. El sistema permite su aplicación a los diferentes bienes culturales inmuebles y en cualquier ámbito territorial, por lo que constituye un método común y reproducible.

Los valores que constituyen el sistema metodológico atienden a factores propios del patrimonio cultural y a criterios exógenos, y comprenden aspectos relacionados con la dimensión histórica, artística, simbólica, social o educativa de los elementos. La cuantificación del valor o interés patrimonial de los bienes permite establecer su jerarquización y, por tanto, el diseño de medidas orientadas a su gestión y conservación. Además de la evaluación técnica, el método considera actuaciones adicionales vinculadas con la participación de los habitantes y otros actores del territorio. Es fundamental involucrar a la comunidad en la evaluación y gestión de sus bienes culturales (Mydland \& Grahn, 2012; Fitri, Ahmad \& Ahmad, 2015).

1 Este sistema forma parte de un modelo general de evaluación del patrimonio cultural, constituido por tres metodologías independientes. La primera, desarrollada en este estudio, permite la evaluación de los bienes inmuebles. La segunda evalúa los bienes inmateriales, y la tercera los paisajes. Conscientemente no se ha procedido a la aplicación de la segunda y tercera metodología en este estudio. 


\section{2 Área de estudio y objetivos}

La implementación del método se efectúa en una selección de bienes situados en la comarca de I'Horta de Valencia, un complejo espacio metropolitano conformado administrativamente por tres subcomarcas -l'Horta Nord, I'Horta Oest y l'Horta Sud- y el municipio de Valencia. Este espacio abarca 44 términos. No obstante, la denominada de manera estricta como Huerta de Valencia histórica o l'Horta comprende el territorio agrícola irrigado por las siete acequias del Tribunal de las Aguas de la Vega de Valencia, la Real Acequia de Moncada, la Acequia Real del Júcar y varias fuentes y pozos históricos (Iranzo, 2014). La Huerta de Valencia es una de las seis huertas mediterráneas milenarias que perduran en Europa, como se desprende del Informe Dobris, realizado por la Agencia Europea de Medio Ambiente (Stanners \& Bourdeau, 1995). La Figura 1 delimita la comarca administrativa de l'Horta y los municipios que la integran, así como la superficie histórica regada de la Huerta de Valencia.

Figura 1. Área de estudio
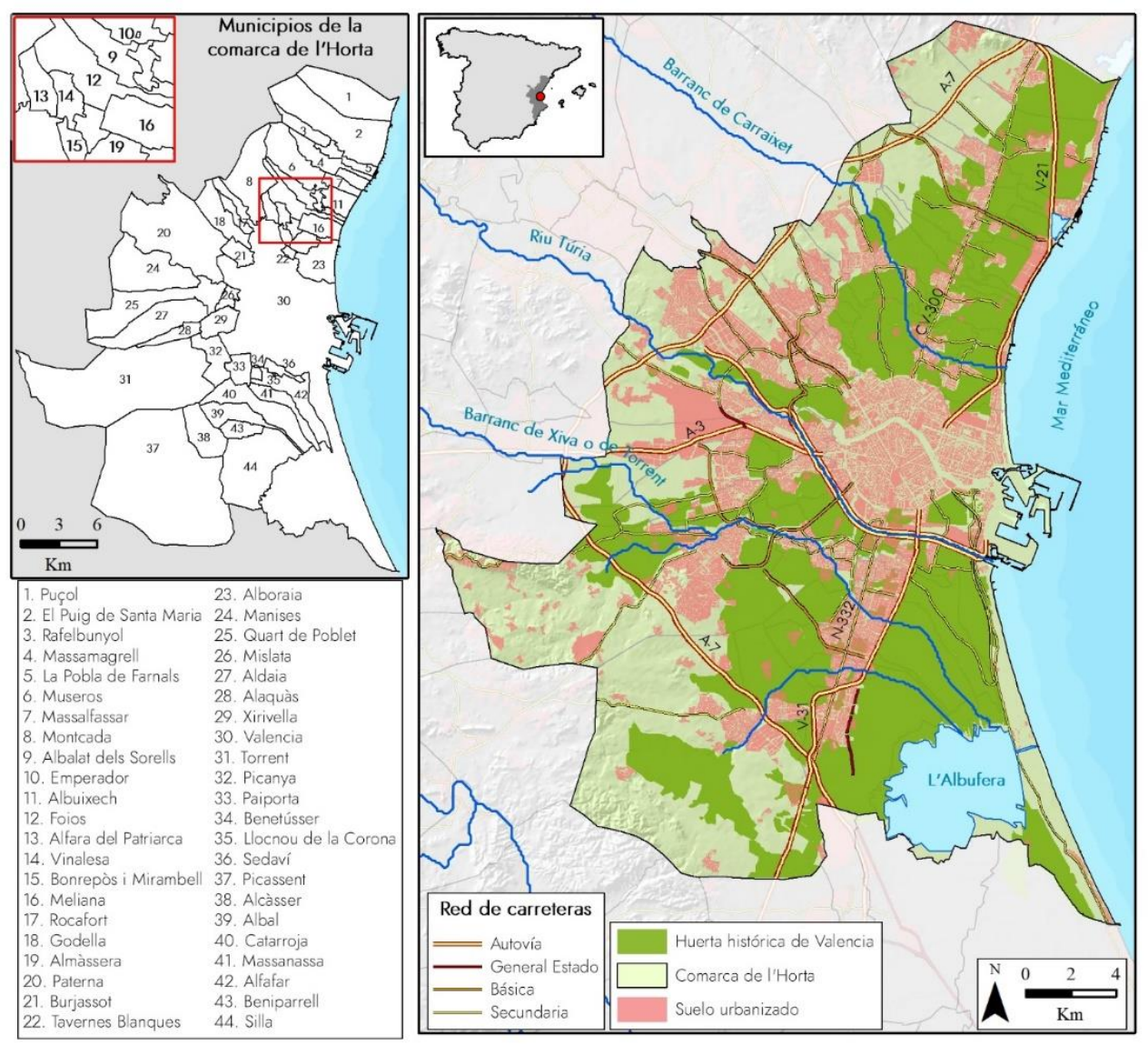

Fuente: elaboración propia

La Huerta de Valencia representa uno de los paisajes agrarios más relevantes del ámbito mediterráneo, y constituye una seña de identidad para la mayoría de sus habitantes. Las investigaciones sobre este espacio son cuantiosas, entre las que destacan aportaciones como las de 
Burriel (1971), Glick (1988), Hermosilla (2009) o Romero y Francés (2012). El regadío es el elemento vertebrador de este paisaje, cuyo origen, tal y como se concibe en la actualidad se sitúa en el periodo islámico medieval. Además de los elementos del agua y otros bienes materiales de índole rural, en la Huerta de Valencia son relevantes las manifestaciones inmateriales, como los saberes huertanos y la institución jurídica milenaria del Tribunal de las Aguas, inscrita en 2009 en la Lista Representativa del Patrimonio Cultural Inmaterial de la Humanidad de la UNESCO.

El paisaje de la Huerta de Valencia merece el calificativo de paisaje patrimonial, conformado por aquellos paisajes que merecen ser objeto de reconocimiento y tutela administrativa debido a sus singulares valores. La patrimonialidad de estos paisajes se sustenta en sus principales argumentos patrimoniales -denominados vectores de patrimonialización- y en la asignación institucional y social de valores - procesos de patrimonialización- (Silva, Fernández \& Mata, 2018). En el caso de la Huerta el reconocimiento patrimonial proviene tanto de la sociedad civil como de las instituciones, mediante la presencia de estudios académicos y normativas.

Las actividades y sistemas agrarios desarrollados a lo largo de la historia han generado un significativo acervo cultural inmueble (edificaciones, infraestructuras agrarias, sistemas hidráulicos...) y etnográfico (saberes, tradiciones, oficios...) generando a su vez paisajes de relevante valor patrimonial. Este valioso legado vinculado con las diferentes manifestaciones, materiales e inmateriales, originadas o aprovechadas por la agricultura constituye el patrimonio agrario (Castillo, 2014). No obstante, y a pesar de sus extraordinarios valores, el reconocimiento de este patrimonio como bien cultural es de reciente consideración. Como recoge Silva (2008), las razones que explican esta tradicional desconsideración son diversas: la visión dual dominante del patrimonio cultural y natural-, la primacía asignada a la función productiva de la agricultura, la asimilación desarrollista entre agricultura y degradación paisajística y cultural, la tradicional visión elitista y ligada a la antigüedad del patrimonio histórico, etc.

En la actualidad esta situación se ha modificado y existe una creciente reivindicación del valor patrimonial de la agricultura merced a diversos factores. En primer lugar, la ampliación del concepto de patrimonio es un proceso destacado, en el que inicialmente estaba asociado a obras monumentales y aisladas y posteriormente se ha extendido a bienes inmateriales y territorios complejos y paisajes. En segundo lugar, la agricultura se concibe actualmente como una actividad multifuncional y no únicamente productiva, donde además de aportar bienes y espacios de recreo a la población actúa en la preservación de la biodiversidad. En tercer lugar se observa un progresivo interés en la valoración de los paisajes agrarios y en sus significados, sus valores y las amenazas que poseen. Por último, el Convenio Europeo del Paisaje señala que la totalidad del territorio tiene interés como paisaje, lo que tiene una notable repercusión legal para los espacios agrarios (Silva, 2009; Molinero, Baraja \& Silva, 2013). 
El espacio de la Huerta de Valencia está conformado por un mosaico de usos, donde los campos de cultivo y las infraestructuras hidráulicas conviven con las áreas urbanas e industriales asociadas al área metropolitana de Valencia. La elevada presión urbanística se traduce en la reducción de la superficie agrícola y en una degradación ambiental y paisajística, por lo que es necesario establecer mecanismos para evitar su pérdida (Hermosilla, 2012).

Estos procesos de periurbanización y metropolización inciden en la degradación y desarticulación paisajística de otros espacios de regadío tradicional, como ocurre en la mayoría de las huertas valencianas y murcianas, en numerosas áreas menores irrigadas del litoral mediterráneo (Hernández, 2009), así como en varias vegas interiores próximas a aglomeraciones urbanas. Existen numerosos trabajos sobre esta temática. En el ámbito valenciano son relevantes los estudios de Marco, Mateu y Romero (1994), Mateu (1999), o Argyelan, Díez, Vallés y Galiana (2014); en la Huerta de Murcia destacan Morales (2001), Mata y Fernández (2004), y Martí y Moreno (2014); en el Valle de Córdoba es relevante el estudio de Torres (2013); o en la Vega granadina el trabajo de Menor (2000).

Con el propósito de detener los procesos de deterioro que sufre la Huerta y promover su preservación y revitalización, entró en vigor la Ley 5/2018, de 6 de marzo, de la Huerta de Valencia. Esta norma contempla la formulación del Plan de acción territorial de ordenación y dinamización de la Huerta de València (en adelante PAT), aprobado a finales de 2018. Constituye una herramienta de ordenación supramunicipal que regula los usos y actividades permitidos. Asimismo, la Ley propone la creación del Consejo de la Huerta de Valencia, una entidad adscrita a la Conselleria d'Agricultura, Medi Ambient, Canvi Climàtic i Desenvolupament Rural, de la Generalitat Valenciana, encargada de elaborar el Plan de desarrollo agrario. Su principal objetivo es garantizar la dinamización y pervivencia de las actividades agrarias en la Huerta.

El PAT dispone de un Catálogo de Protecciones de escala supramunicipal. Está constituido por aquellos bienes patrimoniales que muestran la riqueza de la cultura agraria de la Huerta y definen la complejidad de este espacio cultural, considerando las exigencias documentales derivadas de la legislación vigente. En su elaboración realiza una sistematización de los elementos en función de criterios unitarios y tipológicos. Este documento conforma una herramienta fundamental para la restauración del patrimonio existente y la integración paisajística de los bienes culturales de nueva planta.

En su propuesta de 2016 el Catálogo del PAT incluye 573 elementos patrimoniales y los agrupa en dos niveles: primer grado o estructurante, constituido por bienes esenciales en la identidad cultural de la Huerta que, por su naturaleza, implican su inclusión en un ámbito de protección; y segundo grado o no estructurante, conformado por el resto de edificios integrados en un paisaje al que caracterizan (Conselleria d'Habitatge, Obres Públiques i Vertebració del Territori, 2016). Los bienes 
de ambos niveles se clasifican, además, según su naturaleza hidráulica, arquitectónica, etnológica, arqueológica o de itinerarios históricos. En el presente estudio se realiza la implementación práctica del método de evaluación en 257 bienes seleccionados a partir de los 573 que identifica el Catálogo del PAT.

En este contexto, la hipótesis de esta investigación se basa en que la progresiva degradación y abandono del espacio agrario de la Huerta de Valencia conlleva el deterioro del valor cultural de un número relevante de sus bienes patrimoniales, ya sea desde el punto de vista técnico y/o según la percepción de los habitantes. En este sentido, se deduce que los elementos culturales que se evalúan en este trabajo presentan diferentes niveles de interés patrimonial, desde inmuebles que poseen extraordinarios valores y una destacada implicación de los actores territoriales, hasta bienes en situación de grave riesgo que requieren medidas urgentes de restitución y puesta en valor.

El estudio consta de dos objetivos. El primero consiste en la identificación de los elementos de mayor valor patrimonial mediante la aplicación del método de evaluación en los 257 bienes seleccionados. Esta tarea constituye una de las acciones necesarias para que se pudiera acometer en el futuro la creación de un Territorio Museo de la Huerta de Valencia, con bienes susceptibles de ser puestos en valor. Este espacio musealizado sería un producto cultural que trataría de promover la preservación del patrimonio e impulsar la dinamización del territorio. Los elementos culturales de mayor valor constituirían los hitos del Territorio Museo, es decir, bienes cuyo contenido e interpretación serían la base del relato. En segundo lugar, el método de evaluación pretende constituirse como un instrumento eficaz de gestión patrimonial y de toma de decisiones, aplicable en los procesos de evaluación, conservación y puesta en valor de los bienes culturales. La implementación del sistema metodológico permitirá la jerarquización de los inmuebles en función de su interés patrimonial. Esta información es fundamental para el diseño de medidas eficaces y adecuadas destinadas a la conservación y gestión de los elementos según el valor obtenido en la metodología. En ese sentido se señala como precedente el método de evaluación del patrimonio hidráulico de la unidad de investigación ESTEPA, aplicado en azudes de la demarcación territorial de la Confederación Hidrográfica del Júcar, a petición del propio organismo para la implementación de actuaciones coherentes de gestión patrimonial (Hermosilla, Antequera, Mayordomo \& Jiménez, 2018).

\section{Metodología}

\subsection{Sistema de evaluación patrimonial. Evaluación técnica y evaluación participativa}

La metodología de evaluación del patrimonio cultural inmueble está estructurada en tres categorías de valores: "valores intrínsecos", "valores patrimoniales" y "valores potenciales de viabilidad". Estos conjuntos son utilizados en diversos planes nacionales del Instituto del Patrimonio Cultural de 
España (Ministerio de Educación, Cultura y Deporte, 2015a \& 2015b), y han sido empleados como la base, con ciertas adaptaciones, en otros sistemas metodológicos de evaluación patrimonial (García-Cortés \& Carcavilla, 2013; Medina, 2015; Hermosilla \& Mayordomo, 2017a). En el presente método, estas categorías están compuestas por 15 criterios de valoración, basados en los principios que permiten definir y evaluar el patrimonio cultural. Cada uno de estos criterios se desglosa a su vez en 3 variables específicas, por lo que son 45 los atributos que constituyen el método de evaluación. En definitiva, el sistema posee una estructura de indicadores jerarquizada, que parte de lo general a lo particular, mediante el uso de tres niveles que posibilitan la evaluación técnica del elemento: categorías, criterios y variables. La metodología considera además la evaluación participativa del bien por parte de los agentes sociales a través del desarrollo de acciones complementarias. La estructura completa del sistema se muestra en la Tabla 1.

Tabla 1. Estructura del sistema de evaluación del patrimonio cultural inmueble

\begin{tabular}{|c|c|c|c|}
\hline Categorías & Criterios & & Variables \\
\hline \multirow{9}{*}{$\begin{array}{l}\text { Valores } \\
\text { Intrínsecos }\end{array}$} & \multirow{3}{*}{ 1. Representatividad } & 1.1. & Representatividad constructiva o tipológica \\
\hline & & 1.2 & $\begin{array}{l}\text { Representatividad por su asociación con funciones tradicionales } \\
\text { para la comunidad }\end{array}$ \\
\hline & & 1.3. & Representatividad por su vinculación con otros elementos anexos \\
\hline & \multirow{3}{*}{ 2. Autenticidad } & 2.1. & Morfología e imagen originaria \\
\hline & & 2.2 & $\begin{array}{l}\text { Procesos respetuosos con las características físicas y } \\
\text { morfológicas }\end{array}$ \\
\hline & & 2.3. & Ausencia de modificaciones del entorno o localización del bien \\
\hline & \multirow{3}{*}{ 3. Integridad } & 3.1. & Conservación óptima o satisfactoria \\
\hline & & 3.2. & Conservación de los atributos constitutivos \\
\hline & & 3.3. & Funcionalidad \\
\hline \multirow{18}{*}{$\begin{array}{l}\text { Valores } \\
\text { Patrimoniales }\end{array}$} & \multirow{3}{*}{ 4. Histórico } & 4.1. & $\begin{array}{l}\text { Vinculación a personajes, civilizaciones } 0 \text { instituciones de } \\
\text { carácter histórico }\end{array}$ \\
\hline & & 4.2. & Vestigios testimoniales de la historia y cultura de la comunidad \\
\hline & & 4.3. & Testimonio de un momento o lugar histórico \\
\hline & \multirow{3}{*}{ 5. Social } & 5.1. & Expresión de un patrimonio vivo, cohesionador y dinamizador \\
\hline & & 5.2. & Vinculación con modos y formas de habitar \\
\hline & & 5.3. & $\begin{array}{l}\text { Presencia de colectivos preocupados por la salvaguarda del } \\
\text { patrimonio cultural }\end{array}$ \\
\hline & \multirow{3}{*}{$\begin{array}{l}\text { 6. Simbólico / } \\
\text { Identitario }\end{array}$} & 6.1. & Identificación y conocimiento por las comunidades locales \\
\hline & & 6.2. & $\begin{array}{l}\text { Asociación del elemento con costumbres y tradiciones populares } \\
\text { o comunitarias }\end{array}$ \\
\hline & & 6.3. & $\begin{array}{l}\begin{array}{l}\text { Sentimiento de identidad y de pertenencia al grupo } 0 \\
\text { comunidad }\end{array} \\
\end{array}$ \\
\hline & \multirow{3}{*}{ 7. Artístico } & 7.1. & Autoría artística representativa del colectivo \\
\hline & & 7.2 . & Valores estéticos \\
\hline & & 7.3. & Capacidad de expresión \\
\hline & \multirow{3}{*}{ 8. Técnico } & 8.1. & Técnica empleada en la construcción del elemento \\
\hline & & 8.2. & Estructura técnica del bien \\
\hline & & 8.3. & Innovaciones y mejoras tecnológicas \\
\hline & \multirow{3}{*}{ 9. Territorial } & 9.1. & Interacción del bien con los usos tradicionales del territorio \\
\hline & & 9.2. & El bien como parte de un conjunto o sistema \\
\hline & & 9.3. & Accesibilidad al bien \\
\hline
\end{tabular}


Tabla 1. Continuación

\begin{tabular}{|c|c|c|c|}
\hline \multirow{6}{*}{$\begin{array}{c}\text { Valores } \\
\text { Patrimoniales }\end{array}$} & \multirow{3}{*}{ 10. Paisajístico } & 10.1. & $\begin{array}{l}\text { Entorno paisajístico de interés natural o medioambiental o con } \\
\text { protección oficial }\end{array}$ \\
\hline & & 10.2 & Grado de sostenibilidad medioambiental vinculada con el bien \\
\hline & & 10.3. & Visibilidad del bien \\
\hline & \multirow{3}{*}{$\begin{array}{l}\text { 11. Educativo / } \\
\text { Divulgativo / } \\
\text { Científico }\end{array}$} & 11.1. & Incorporación en inventarios o catálogos patrimoniales \\
\hline & & 11.2 & $\begin{array}{l}\text { Presencia en referencias bibliográficas y obras documentales, } \\
\text { artísticas o literarias }\end{array}$ \\
\hline & & 11.3. & Integración y transmisión en el ámbito educativo y formativo \\
\hline \multirow{12}{*}{$\begin{array}{c}\text { Valores } \\
\text { Potenciales y } \\
\text { de Viabilidad }\end{array}$} & \multirow{3}{*}{$\begin{array}{c}12 . \\
\text { Concienciación } \\
\text { de agentes } \\
\text { sociales }\end{array}$} & 12.1. & \begin{tabular}{|l}
$\begin{array}{l}\text { Inversiones y actuaciones de las administraciones } u \text { otros } \\
\text { colectivos }\end{array}$ \\
\end{tabular} \\
\hline & & 12.2. & Inclusión en rułas o programas culturales y turísticos sostenibles \\
\hline & & 12.3. & ia de soportes divulgativos \\
\hline & \multirow{3}{*}{$\begin{array}{c}\text { 13. Participación e } \\
\text { integración de las } \\
\text { comunidades } \\
\text { locales }\end{array}$} & 13.1. & Participación en la gestión del bien cultural \\
\hline & & 13.2 & $\begin{array}{l}\text { Participación en los procesos de documentación, investigación y } \\
\text { difusión }\end{array}$ \\
\hline & & 13.3. & ación como actor social del relato \\
\hline & \multirow{3}{*}{$\begin{array}{l}\text { 14. Rentabilidad } \\
\text { socioeconómica }\end{array}$} & 14.1. & actuación i \\
\hline & & 14.2. & beconómicos generados por el bien \\
\hline & & 14.3. & Situación jurídica del bien y del territorio en el que se emplaza \\
\hline & \multirow{3}{*}{ 15. Vulnerabilidad } & 15.1. & a de amenazas naturales \\
\hline & & 15.2 . & de amenazas antrópicas \\
\hline & & 15.3. & $\begin{array}{l}\text { Ausencia de vulnerabilidad intrínseca o de situación de } \\
\text { abandono }\end{array}$ \\
\hline \multicolumn{4}{|c|}{ Acciones complementarias: participación de los agentes sociales } \\
\hline \multicolumn{4}{|c|}{$\frac{\text { de expertos locales. Dos fases: 1- Aplicación del método de evaluación 2- Mesa redonda }}{\text { Encuestas a la población local }}$} \\
\hline
\end{tabular}

Fuente: elaboración propia

La categoría de los "valores intrínsecos" determina el valor inherente al propio elemento cultural, con independencia de su contexto. Considera la importancia del bien en relación con otros inmuebles de su tipología. Los 3 criterios que componen esta categoría coinciden en su nomenclatura con principios y conceptos utilizados por la UNESCO para la aceptación de nuevos bienes en la Lista del Patrimonio Mundial. Sin embargo, las definiciones propuestas no coinciden exactamente con las acepciones contempladas por parte de las cartas internacionales.

1. La Representatividad valora los aspectos que el elemento tiene en común con el resto de inmuebles análogos, en atributos como su construcción -diseño, materiales o técnica de factura-, su actividad como bien que mantiene funciones arraigadas para la comunidad, y su vinculación con otros materiales anexos.

2. La Autenticidad contempla la conservación y el mantenimiento de las características y valores originales de la obra y su entorno, aunque existan intervenciones posteriores. Las variables están referidas a la imagen, técnicas y morfología tradicionales del bien, y también consideran los procesos que afectan a sus cualidades físicas y a su emplazamiento primigenio.

3. La Integridad valora el estado de conservación del inmueble y de sus atributos constitutivos, así como su uso actual. 
La categoría de los "valores patrimoniales" está integrada por los atributos exógenos -culturales o ambientales- que influyen y mejoran las características inherentes del bien patrimonial. Dispone de los siguientes 8 criterios:

4. El criterio Histórico considera la propia historia del elemento y la de la comunidad testigo de su creación y evolución. Valora la vinculación del inmueble con personajes, civilizaciones o instituciones de carácter histórico, su capacidad de transmisión de la historia y cultura de los periodos y sociedades vividos, y su asociación con una fase, evento o lugar histórico.

5. El valor Social evalúa el bien como un elemento vivo y dinamizador del territorio y la comunidad, su vínculo con los modos y formas de habitar tradicionales de la población, así como la presencia de colectivos preocupados por la preservación del patrimonio cultural.

6. El indicador Simbólico o Identitario se basa en las percepciones y vínculos afectivos, emocionales o de identidad que poseen las comunidades locales hacia el bien. Considera el reconocimiento del elemento por la sociedad, su asociación con costumbres y tradiciones populares, y el sentimiento de identidad y de pertenencia que infunde al grupo o comunidad.

7. El criterio Artístico hace referencia a la calidad estética del bien y alude a sus cualidades plásticas. Las variables se relacionan con el carácter colectivo o de universalidad de la autoría de la obra, sus valores estéticos y de diseño, y su capacidad de transmisión del mundo material al conceptual.

8. El indicador Técnico contempla el valor tecnológico del bien como respuesta al desarrollo y evolución del arte de la construcción. Evalúa la complejidad o excepcionalidad de la técnica empleada en el diseño del elemento, su estructura técnica en términos de equilibrio y proporciones, y las innovaciones tecnológicas efectuadas destinadas a recuperar o mejorar su morfología y rendimiento.

9. El aspecto Territorial evalúa tres aspectos diferenciados. En primer lugar considera la interacción del elemento con la cultura o los usos tradicionales del territorio. La segunda variable está referida a la integración del bien en un conjunto o sistema patrimonial de relevancia. Finalmente se valora el acceso sencillo al inmueble. En los bienes afectados por un turismo masivo o los pertenecientes o reclamados por determinadas comunidades, este tercer atributo se evaluará de forma negativa si no existen herramientas de planificación en el acceso de visitantes.

10. El valor Paisajístico considera la combinación de la presencia física del bien con los elementos visibles que lo rodean y que caracterizan el entorno. Las variables contemplan el interés natural o medioambiental del enclave en el que se encuentra el inmueble, el grado de sostenibilidad vinculado con el elemento, y su visibilidad. 
11. El aspecto Educativo, Divulgativo o Científico está relacionado con las cualidades científicas que posee el bien y su potencial educativo y divulgativo. Se valora el registro del elemento en inventarios o catálogos patrimoniales, su presencia en referencias bibliográficas y publicaciones, y su integración en el ámbito educativo y formativo.

Los "valores potenciales y de viabilidad" contemplan las perspectivas del elemento en relación a su puesta en valor así como aspectos vinculados con su potencialidad. Están formados por 4 criterios:

12. La Concienciación de agentes sociales se vincula con las actuaciones y el compromiso de los actores del territorio para la salvaguarda del elemento cultural. Esta implicación se desarrolla mediante las inversiones dirigidas a la viabilidad del bien, su inserción en rutas o programas culturales y turísticos, o la presencia de soportes divulgativos relacionados con el elemento.

13. El criterio de Participación e integración de las comunidades locales valora la implicación activa de la población en los procesos de gestión del bien en las tareas de documentación, investigación y difusión, y en la construcción social del relato y la historia oral.

14. La Rentabilidad socioeconómica se relaciona con el aporte del bien al desarrollo local de las comunidades, así como los procesos y mecanismos existentes de revalorización y protección. Las variables consideran el grado de facilidad para la puesta en valor del inmueble, los beneficios socioeconómicos generados por el bien que contribuyen al desarrollo sostenible, y el marco jurídico del elemento y del territorio en el que se sitúa.

15. La Vulnerabilidad contempla la existencia de amenazas o riesgos naturales y antrópicos que pueden suponer impactos significativos en el mantenimiento del bien. También evalúa la vulnerabilidad o fragilidad que posee el propio elemento debido a sus características intrínsecas o a una situación de abandono.

La evaluación técnica de cada elemento patrimonial está basada en un sistema de puntuación binario sencillo, fundamentado en la existencia o no de cada una de las 45 variables que componen la metodología. De este modo, se asigna el valor "1" si la cualidad se cumple y, en caso contrario, el valor " $O$ ", sin ponderaciones. Este método de cuantificación ha mostrado su eficacia en sistemas como el de Serrano y González-Trueba (2005), Hermosilla e Iranzo (2014b) o el de Bravo (2018). El sumatorio de las calificaciones otorgadas a los 45 indicadores establece la puntuación global de cada bien, que se transforma a una escala de 0 a 10 puntos, y se clasifica en función de 6 niveles de valoración patrimonial: Muy Alto (8,6-10); Alto (7,2-8,5); Medio $(5,8-7,1)$; Bajo (4,4-5,7); Muy Bajo (3-4,3); y Sin Interés (0-2,9). Asimismo, cada categoría y criterio se evalúa de manera individual con la finalidad de analizar y comparar las particularidades existentes en los diferentes elementos. La evaluación de cada categoría se consigue a través del sumatorio de las calificaciones de sus criterios, mientras que la puntuación de cada criterio se obtiene mediante la suma de los valores de sus variables. 
El método posibilita el desarrollo de tareas adicionales fundamentadas en la participación de los actores territoriales, que permiten la obtención de la evaluación participativa de los bienes. El propósito de estas acciones es conocer las opiniones de la comunidad sobre su patrimonio. Están constituidas por dos procedimientos: la formación de paneles de expertos locales y la realización de encuestas a los habitantes del área de estudio. Ambos procesos están diseñados en función de los indicadores que constituyen la metodología, por lo que es posible el cálculo de las puntuaciones por categorías y criterios, y su comparación con las calificaciones obtenidas en la evaluación técnica.

Los paneles de expertos locales reúnen a especialistas sobre el patrimonio cultural de cada municipio o área considerada. Esta técnica se divide en dos partes. En la primera, cada uno de los expertos aplica el sistema de evaluación propuesto de la misma manera que se procede en la evaluación técnica. La segunda fase está constituida por una mesa redonda en la que los asistentes tratan aspectos vinculados con los bienes culturales del territorio.

Las encuestas a la población local están basadas en la implementación de un cuestionario conformado por 15 preguntas que hacen referencia a cada uno de los criterios que componen el método de evaluación. Las cuestiones son cerradas dicotómicas, donde las respuestas posibles son "sí", "no" y "no lo sabe". El encuestado contesta únicamente las preguntas para los bienes culturales que identifique, lo que posibilitará cuantificar la proporción de habitantes que conoce cada elemento. Las preguntas respondidas con "sí" suponen opiniones positivas. Las puntuaciones globales y de cada indicador se calculan a través de la relación entre el número de respuestas favorables y la totalidad de respuestas, sin considerar las respondidas como "no lo sabe". Las cifras obtenidas se transforman a un valor entre 0 y 10 puntos y se utilizan los 6 niveles de interés patrimonial establecidos.

\subsection{Plan de trabajo}

El plan de trabajo de la presente investigación consta de cinco fases, y se fundamenta en el proceso de aplicación del sistema de evaluación del patrimonio cultural inmueble. Esta propuesta metodológica de trabajo se ha inspirado en otros métodos empleados en estudios científicos de evaluación patrimonial, como los de Pereira y Pereira (2010) o Bouzekraoui, Barakat, Touhami, Mouaddine y El Youssi (2018).

La primera fase consiste en la selección de los bienes culturales de la Huerta de Valencia a los que se les aplicará posteriormente el método de evaluación patrimonial. Para ello, se efectúa una elección de elementos a partir de los 573 que recoge el Catálogo del PAT en su propuesta de 2016. Este catálogo distingue 220 inmuebles de primer grado-distribuidos en 205 bienes, 5 itinerarios, 8 acequias históricas y 2 barrancos- y 353 de segundo grado. El inventario que se 
propone en este estudio comprende la totalidad de los elementos de primer grado 2 del Catálogo del PAT (sin incluir los itinerarios ni barrancos), y una selección de 37 bienes de segundo grado, debido a su gran volumen. En este nivel se han excluido algunas tipologías arquitectónicas asociadas a la habitabilidad, como las casas, barracas o masías, aunque no los huertos. Están distribuidos en 124 elementos arquitectónicos, 73 hidráulicos (incluidas las acequias) y 60 etnológicos. La localización de los bienes en el área de estudio se observa en la Figura 2.

Figura 2. Localización de los bienes culturales seleccionados en el área de estudio

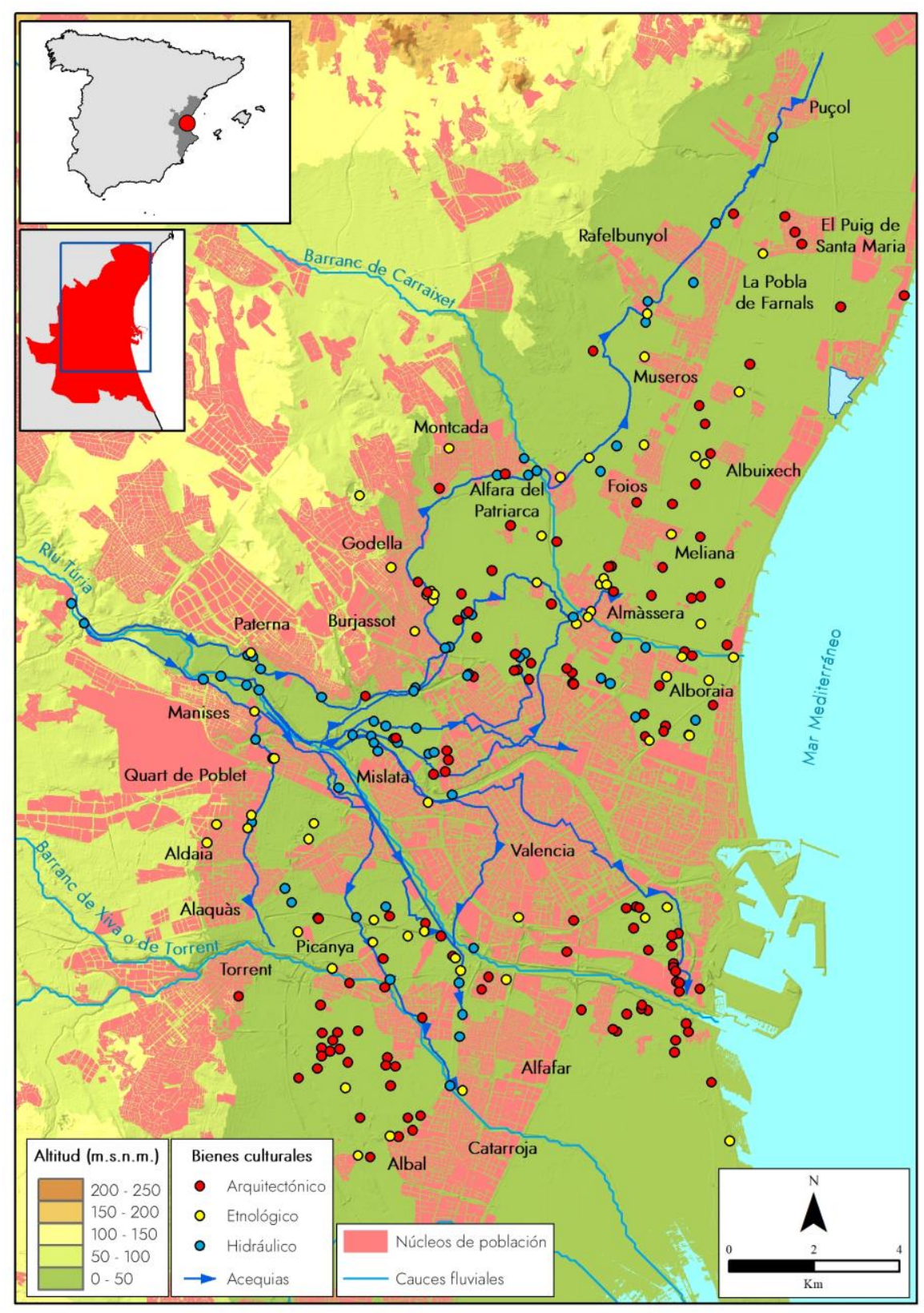

Fuente: elaboración propia

2 Algunos de los elementos de primer grado recogidos en el PAT están constituidos por varios bienes. Son los denominados "Cornisa sobre la huerta de la acequia de Montcada en Godella" y las "Chimeneas en Aldaia". En la selección efectuada estos conjuntos se han desglosado en 4 y 5 elementos respectivamente. 
La siguiente tarea del plan de trabajo consiste en la consulta de fuentes de información. Se realiza una búsqueda y análisis de documentación bibliográfica relacionada con los elementos culturales seleccionados. Esta tarea permite examinar las características y valores patrimoniales de los bienes, con el objeto de realizar su correcta puntuación y evaluación patrimonial. Entre las referencias bibliográficas consultadas para el estudio de los elementos arquitectónicos destacan las de Del Rey (1998, 2002, 2010), Besó (1999) y Pérez de los Cobos (2000). Las asociadas al patrimonio etnológico están constituidas por los estudios de Pepín (1996, 2003) y Soler (2007). Finalmente, las fuentes más significativas relacionadas con los elementos hidráulicos son las de Guinot et al. (1999), Guinot y Selma (2005) y Hermosilla (2007). Asimismo, el propio PAT incluye fichas individuales de cada bien de primer grado, con una descripción de su arquitectura, su situación actual o aspectos vinculados con su significado patrimonial.

La tercera etapa de la metodología se basa en el trabajo de campo. Consiste en la visita a los elementos culturales seleccionados para su evaluación. Esta labor es fundamental en el momento de hacer efectiva la aplicación del sistema metodológico, ya que diversas variables precisan de la observación directa de los bienes para la correcta asignación de valores. En esta fase se realizan además consultas a agricultores, regantes, residentes y usuarios o propietarios de los elementos, ya que aportan información valiosa y son los verdaderos conocedores del patrimonio. Se han podido visitar la totalidad de elementos inventariados, con excepción de dos alquerías que han sido derribadas en los últimos años, así como la barraca emplazada en la Zona de Actividades Logísticas del Puerto de Valencia, a la que no se ha tenido acceso.

De manera simultánea al periodo de trabajo de campo se desarrollan las acciones de participación mediante la realización de encuestas a los habitantes residentes en cada uno de los 33 municipios - o barrios y pedanías en el caso del término de Valencia- en los que se ubican los elementos patrimoniales. La técnica de recogida de información es la realización de encuestas personales asistidas mediante dispositivo móvil, efectuadas por una empresa externa especializada en la implementación de estas técnicas. Se consultaron a 11285 personas, de las 5630 pudieron contestar el cuestionario ya que identificaron al menos uno de los bienes de su municipio. El periodo de realización se extendió desde septiembre de 2018 a enero de 2019.

El universo de análisis está conformado por los habitantes con edad igual o superior a 18 años residentes en alguno de los 33 municipios o barrios del estudio y comprende aproximadamente 750000 personas. Se considera exclusivamente la población que habita en los núcleos urbanos principales, sin incluir áreas adyacentes, residenciales o diseminadas. El muestreo propuesto por la empresa es estratificado y por conglomerados, donde las unidades de primera etapa se basan en el tamaño del municipio o barrio, las de segunda en la selección del propio término, y las de tercera son seleccionadas de forma aleatoria por cuotas de sexo e intervalo de edad. La muestra se balancea, en la medida de lo posible, a los diferentes niveles sociodemográficos normalizados de 
la población. La propuesta de tamaño muestral se recoge en la Tabla 1 del Anexo l y está vinculada a una cuota de valoraciones para cada elemento considerado en cada municipio o barrio.

En esta investigación no se desarrollan las acciones complementarias relativas a los paneles de expertos, como consecuencia de la complejidad en su aplicación. El volumen de elementos y municipios considerados hubiera requerido la organización de más de una treintena de mesas redondas.

La última fase del plan de trabajo contempla labores de análisis e interpretación de los resultados. En este periodo se implementa el método de evaluación patrimonial a cada uno de los bienes culturales seleccionados con la finalidad de calcular su evaluación técnica. La asignación de puntuaciones se fundamenta en la información documental recopilada así como la adquirida en el trabajo de campo. Del mismo modo se realiza el tratamiento de las respuestas obtenidas en las encuestas para evaluar la percepción ciudadana sobre su patrimonio. La información tratada se incorpora a una base de datos geográfica y se elaboran las representaciones cartográficas. Finalmente se analizan los resultados obtenidos y se elaboran los informes de la investigación.

\section{Resultados}

La implementación del sistema metodológico se efectúa en los 257 bienes que se hallan distribuidos en 33 municipios del área de estudio. De la totalidad de elementos se han localizado 18 que están emplazados en más de un término -las 8 acequias, un tramo histórico de la acequia Mislata-Quart, 7 azudes, un partidor y unos mojones de límite-. La localidad que aglutina un mayor número de inmuebles es Valencia, con 112, lo que representa el 43 \% de los bienes seleccionados. Más de la mitad de los elementos de este municipio se sitúan en Faitanar (17), La Punta (17), Sant Pau (13) y Poble Nou (11). El siguiente término es Alboraia, con 17 inmuebles, seguido por Picanya, con 14, y Catarroja y Paterna, con 11 elementos cada uno. ${ }^{3}$

En los siguientes apartados se aborda la aplicación del método de evaluación patrimonial en los bienes culturales considerados. En primer lugar se detalla la evaluación técnica mediante un análisis de los resultados obtenidos. En segundo lugar se examinan los datos recopilados en las encuestas realizadas a los habitantes de las localidades de estudio. Para ambas modalidades se muestra la representación cartográfica de las valoraciones globales resultantes.

\subsection{Evaluación técnica}

La evaluación patrimonial efectuada en cada uno de los bienes culturales seleccionados en la Huerta de Valencia se observa en la Figura 1 del Anexo II. Esta matriz muestra las puntaciones

3 En el recuento del número de bienes que dispone cada municipio no se han contabilizado las 8 acequias seleccionadas, debido a que son elementos lineales que recorren numerosos términos. 
detalladas que han sido asignadas a las 45 variables que estructuran el método. Los inmuebles están organizados según su tipología patrimonial. Los elementos arquitectónicos comprenden los códigos del 1 al 124, los etnológicos del 125 al 184, y los hidráulicos del 185 al 257.

La calificación general del conjunto de bienes es de 6,5 puntos en una escala decimal, lo que representa un interés patrimonial medio según los 6 niveles propuestos. Las valoraciones globales ofrecen ciertas diferencias en función de la tipología de los elementos. El patrimonio arquitectónico ha obtenido una calificación media de 6,3 puntos; el etnológico cuenta con 7 puntos; mientras que el hidráulico posee 6,4 puntos. En general, los inmuebles etnológicos presentan un mejor estado de conservación y se mantienen funcionales.

El número de elementos agrupados en función de los niveles de valoración establecidos se observa en la Tabla 2. Se han identificado 79 inmuebles con calificaciones altas o muy altas. El grupo más cuantioso lo conforman los elementos con puntuaciones medias, con el 40,1\% de las edificaciones, mientras que las calificaciones bajas, muy bajas o sin interés aglutinan más del $29 \%$ de los bienes. Estas cifras muestran la presencia de un valioso patrimonio cultural en la Huerta de Valencia, aunque con una proporción relevante de elementos que poseen valoraciones escasas. Se ha constatado que numerosos bienes se encuentran actualmente abandonados y/o en un grave estado de degradación.

Tabla 2. Distribución de los bienes culturales en función de su tipología patrimonial y los niveles de valoración según la evaluación técnica

\begin{tabular}{|c|c|c|c|c|c|c|c|c|}
\hline \multirow{2}{*}{ Valoración } & \multicolumn{2}{|c|}{ Arquitectónicos } & \multicolumn{2}{|c|}{ Etnológicos } & \multicolumn{2}{c|}{ Hidráulicos } & \multicolumn{2}{c|}{ Total } \\
\cline { 2 - 9 } & $\mathrm{N}^{\circ}$ & $\%$ & $\mathrm{~N}^{\circ}$ & $\%$ & $\mathrm{~N}^{\circ}$ & $\%$ & $\mathrm{~N}^{\circ}$ & $\%$ \\
\hline Muy Alta $(8,6-10)$ & 8 & 6,5 & 16 & 26,7 & 2 & 2,7 & 26 & 10,1 \\
\hline Alta $(7,2-8,5)$ & 21 & 16,9 & 13 & 21,7 & 19 & 26 & 53 & 20,6 \\
\hline Media $(5,8-7,1)$ & 61 & 49,2 & 14 & 23,3 & 28 & 38,4 & 103 & 40,1 \\
\hline Baja $(4,4-5,7)$ & 22 & 17,7 & 12 & 20 & 20 & 27,4 & 54 & 21,0 \\
\hline Muy Baja (3-4,3) & 9 & 7,3 & 5 & 8,3 & 4 & 5,5 & 18 & 7,0 \\
\hline Sin Interés $(<3)$ & 3 & 2,4 & 0 & 0 & 0 & 0 & 3 & 1,2 \\
\hline Total & 124 & 100 & 60 & 100 & 73 & 100 & 257 & 100 \\
\hline
\end{tabular}

Fuente: elaboración propia

El análisis de la distribución de los inmuebles según su tipología y los niveles de valoración establecidos ofrecen aspectos de interés. En el patrimonio arquitectónico, la mitad de sus elementos 
han obtenido calificaciones medias. La mayoría de estas edificaciones están constituidas por alquerías y barracas en un aceptable estado de conservación, localizadas en un entorno paisajístico de interés. Las mejores puntuaciones de esta modalidad se encuentran en edificios religiosos de entidad, como la Cartuja Ara Christi en el Puig, así como en diversos huertos de naranjos situados en varios municipios de I'Horta Sud. Estos elementos proliferaron a finales del siglo XIX en la comarca, y están constituidos por una explotación agraria, rodeada generalmente por una valla, y presidida por una edificación. Se valora el conjunto formado por la edificación y los huertos que la rodean. Con puntuaciones bajas se han identificado 34 elementos arquitectónicos, relacionados generalmente con alquerías abandonadas y con evidentes signos de deterioro. En relación al patrimonio etnológico, una cuarta parte de los inmuebles de esta tipología presentan valoraciones muy elevadas, superiores a los 8,5 puntos. Se corresponden principalmente con ermitas de l'Horta Nord que poseen valores estéticos y simbólicos relevantes, y que reciben inversiones destinadas a su conservación. Los bienes etnológicos con las menores puntuaciones son en su mayoría antiguas chimeneas industriales localizadas en l'Horta Sud. Finalmente, el patrimonio hidráulico cuenta con un tercio de las obras con valoraciones inferiores a los 5,8 puntos, conformadas básicamente por molinos y partidores inactivos y deteriorados. Las mejores puntuaciones de esta modalidad son asignadas a molinos hidráulicos acondicionados para un nuevo uso. La representación cartográfica de la evaluación técnica global de cada uno de los bienes, clasificados según su naturaleza patrimonial y los niveles de valoración se refleja en las Figuras 3, 4 y 5 . Algunos de los elementos con mejores calificaciones técnicas son la Alquería del Magistre en Alboraia y el Molí de Benetússer o de Raga, con 9,3 puntos cada uno (Figuras 6 y 7 ). 
Figura 3. Evaluación técnica de los bienes arquitectónicos

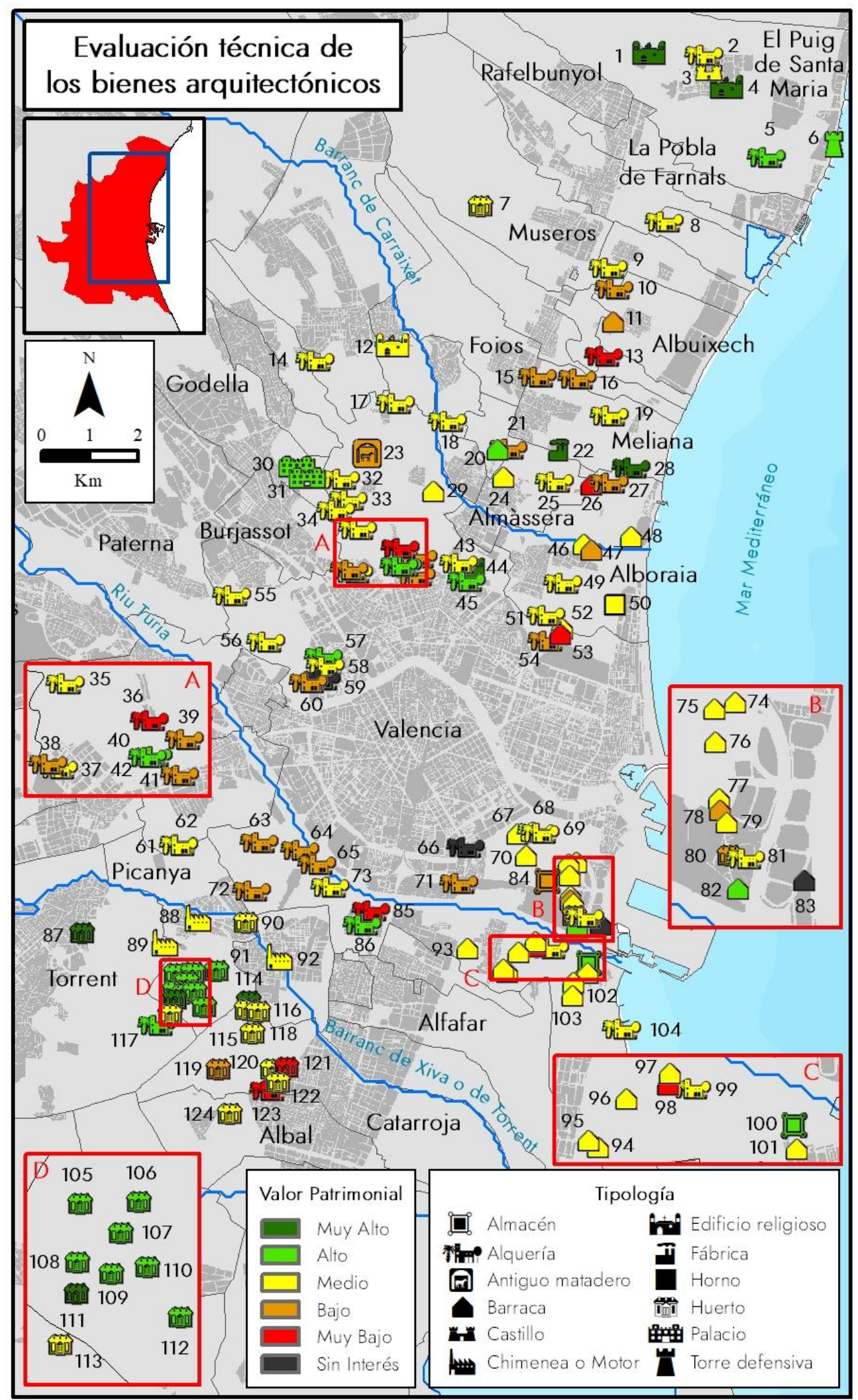

Nota: La denominación de cada bien puede observarse en los códigos utilizados en la Figura 1 del Anexo II Fuente: elaboración propia 
Figura 4. Evaluación técnica de los bienes etnológicos

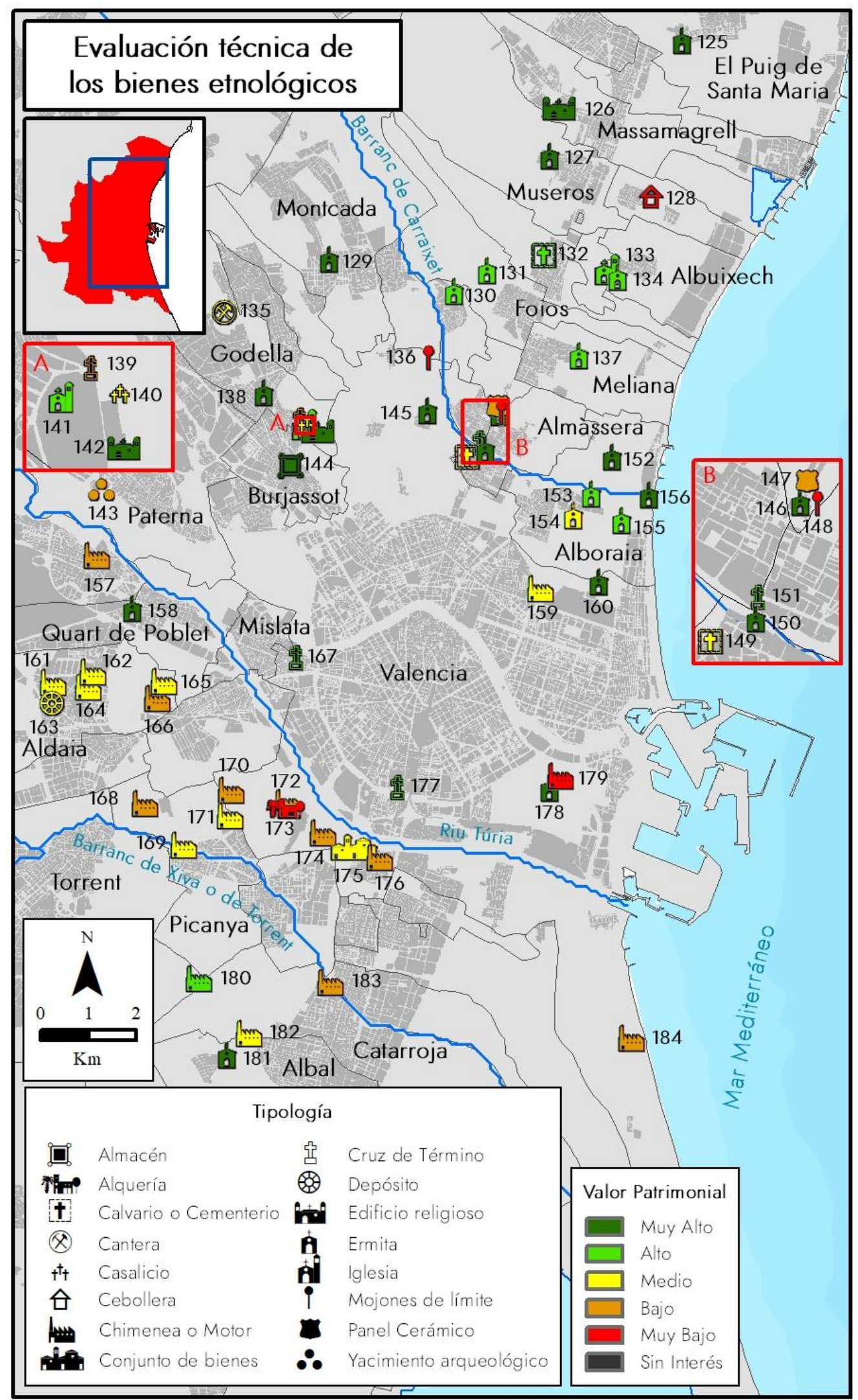

Nota: La denominación de cada bien puede observarse en los códigos utilizados en la Figura 1 del Anexo II Fuente: elaboración propia 
Figura 5. Evaluación técnica de los bienes hidráulicos

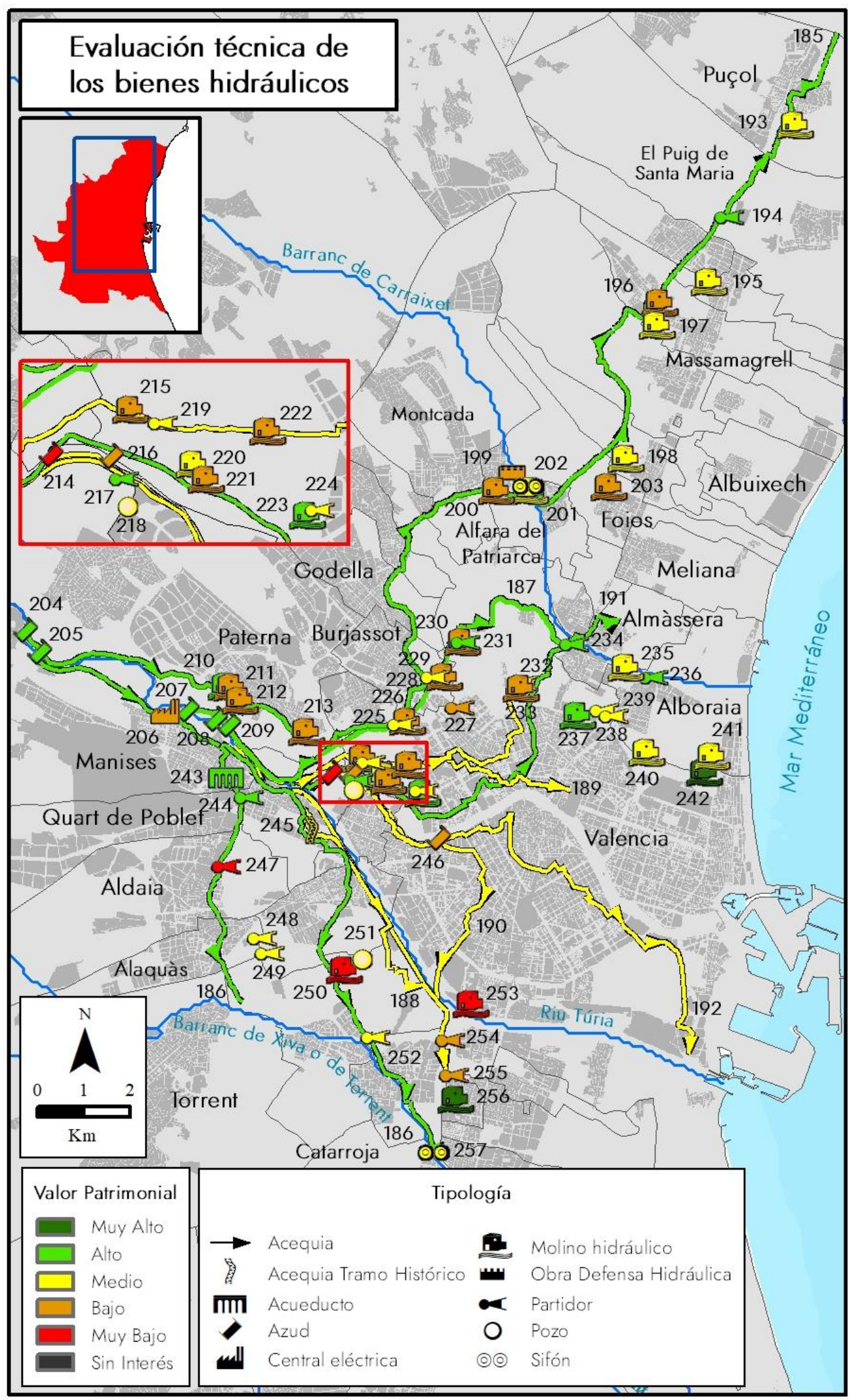

Nota: La denominación de cada bien puede observarse en los códigos utilizados en la Figura 1 del Anexo II Fuente: elaboración propia 
Figura 6. Alquería del Magistre (Alboraia)

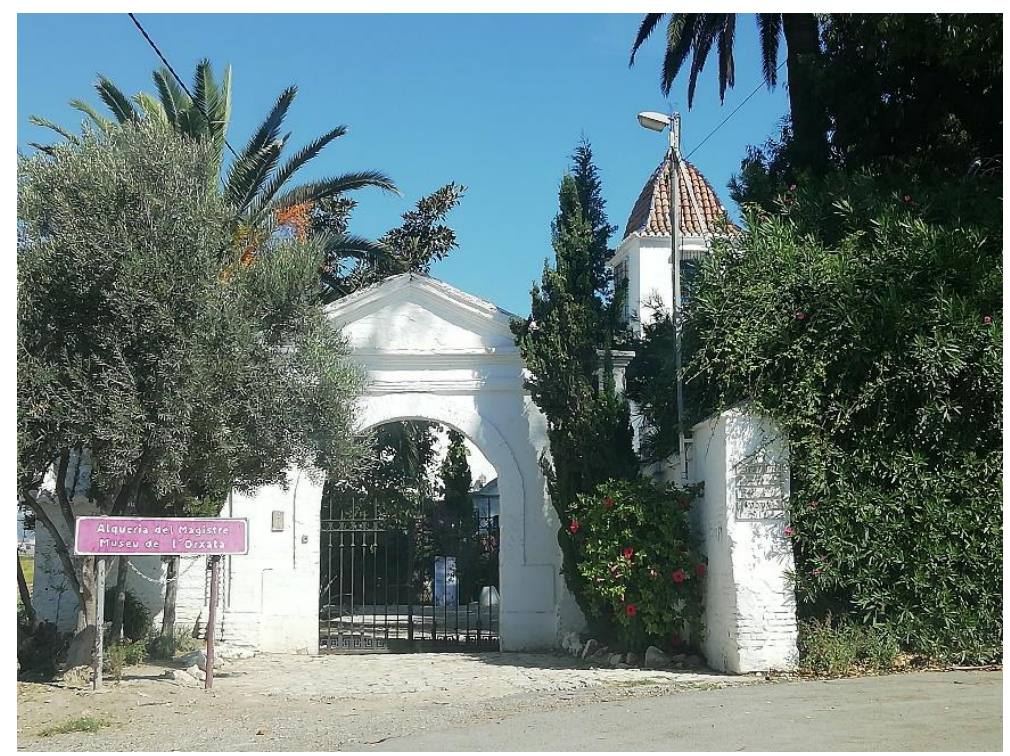

Fuente: elaboración propia

Figura 7. Molí de Benetússer o de Raga (Benetússer)

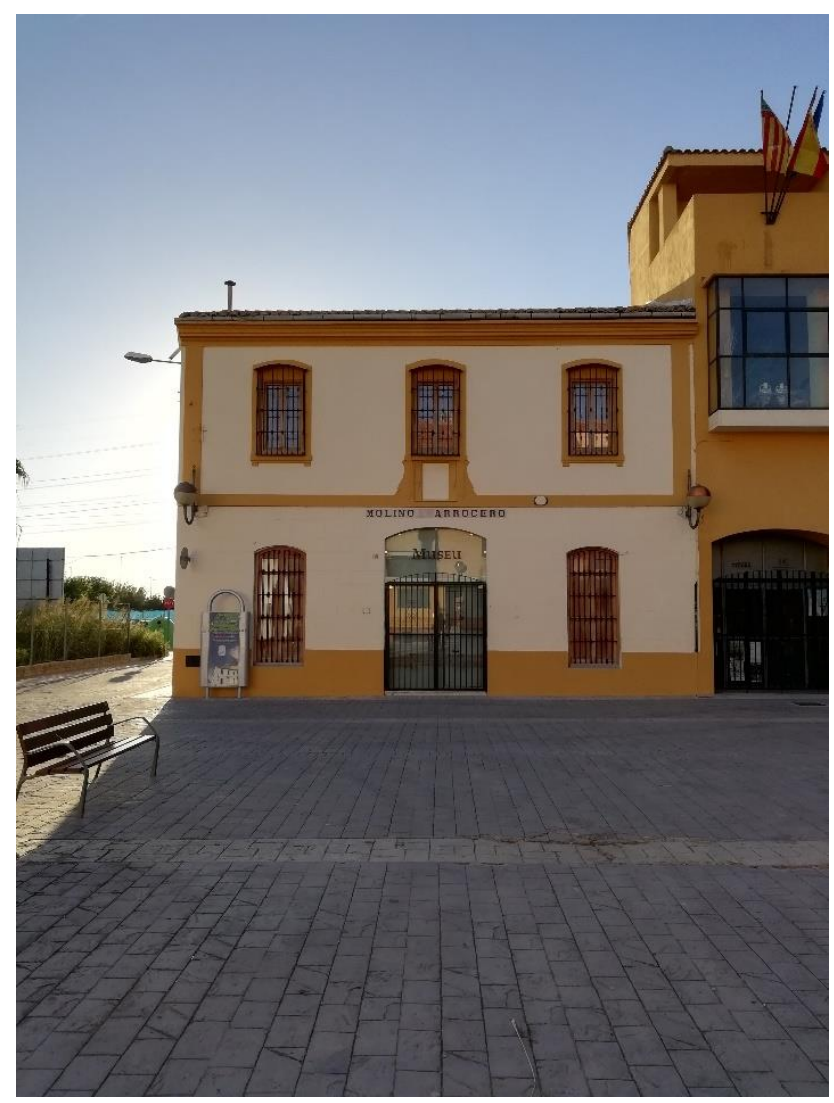

Fuente: elaboración propia

Las calificaciones de cada categoría y criterio para el conjunto de elementos seleccionados se muestra en la Tabla 3. Su estudio determina los valores más relevantes del patrimonio de la Huerta de Valencia, y posibilita la comparación y el análisis de sus atributos y peculiaridades. 
Tabla 3. Puntuaciones técnicas de las categorías y criterios para el conjunto de bienes

\begin{tabular}{|c|c|c|c|}
\hline Categorías & Criterios & \multicolumn{2}{|c|}{ Puntuaciones } \\
\hline \multirow{3}{*}{$\begin{array}{l}\text { Valores } \\
\text { intrínsecos }\end{array}$} & 1. Representatividad & 8,4 & \multirow{3}{*}{7,0} \\
\hline & 2. Autenticidad & 6,2 & \\
\hline & 3. Integridad & 6,5 & \\
\hline \multirow{8}{*}{$\begin{array}{c}\text { Valores } \\
\text { patrimoniales }\end{array}$} & 4. Histórico & 6,9 & \multirow{8}{*}{7,1} \\
\hline & 5. Social & 6,2 & \\
\hline & 6. Simbólico / Identitario & 2,8 & \\
\hline & 7. Artístico & 9,0 & \\
\hline & 8. Técnico & 7,1 & \\
\hline & 9. Territorial & 8,5 & \\
\hline & 10. Paisajístico & 8,5 & \\
\hline & 11. Educativo / Divulgativo / Científico & 7,5 & \\
\hline \multirow{4}{*}{$\begin{array}{l}\text { Valores } \\
\text { potenciales y de } \\
\text { viabilidad }\end{array}$} & 12. Concienciación de agentes sociales & 3,5 & \multirow{4}{*}{4,9} \\
\hline & 13. Participación e integración de las comunidades locales & 2,7 & \\
\hline & 14. Rentabilidad socioeconómica & 6,6 & \\
\hline & 15. Vulnerabilidad & 6,9 & \\
\hline \multicolumn{2}{|r|}{ Promedio } & \multicolumn{2}{|c|}{6,5} \\
\hline
\end{tabular}

Fuente: elaboración propia

Los valores intrínsecos y patrimoniales han obtenido puntuaciones técnicas relativamente elevadas, de 7 y 7,1 puntos respectivamente. Sin embargo, los valores potenciales y de viabilidad poseen una calificación baja, de 4,9 puntos. Si se atiende a las puntuaciones de los criterios se observan diferencias relevantes. El indicador con la mejor valoración es el Artístico, con 9 puntos. Las variables de este criterio referidas al carácter colectivo de la autoría del bien y su capacidad de expresión se cumplen en la práctica totalidad de los elementos, mientras que la relacionada con los valores estéticos cuenta con una calificación superior a los 7 puntos. En general, los inmuebles muestran rasgos artísticos relevantes en términos de diseño y calidad plástica, y tienen la capacidad de transmitir aspectos socioculturales de la época en la que fueron construidos. Los valores Territorial y Paisajístico poseen la segunda mayor calificación del sistema, con 8,5 puntos cada uno. El primero considera aspectos vinculados con el territorio y la identidad cultural. Las variables mejor 
puntuadas en este indicador valoran la accesibilidad a los elementos y su capacidad para ilustrar la cultura propia del lugar. El indicador Paisajístico posee calificaciones destacadas en sus tres variables.

El criterio con la menor puntuación es el de Participación e integración de las comunidades locales, con 2,7 puntos. Considera la participación de la comunidad en los propios procesos de toma de decisiones y en los vinculados con el elemento. Como indica Caraballo (2008), el patrimonio está definido por sus habitantes, por lo que la gestión de los bienes culturales debe tener una participación directa de la comunidad. Sin embargo, esto no siempre se produce. El segundo criterio con la menor calificación es el Simbólico o Identitario, con 2,8 puntos. Numerosos inmuebles no son identificados por los habitantes $y$, en general, no infunden un sentimiento de pertenencia. El criterio de Concienciación de agentes sociales tiene la tercera peor calificación, con 3,5 puntos. La implicación y sensibilización que poseen los agentes sociales hacia la protección y puesta en valor de los inmuebles es mejorable. Es necesario el incremento de las inversiones y actuaciones por parte de las administraciones dirigidas a la viabilidad de los bienes, así como a la mejora de su promoción turística y divulgativa.

Como se observa en la Figura 8, los criterios muestran puntuaciones diferentes según la tipología patrimonial de los elementos. Los edificios hidráulicos poseen un valor Histórico y Técnico superior al resto de bienes. Se trata de inmuebles vinculados con la institución milenaria del Tribunal de las Aguas que suelen poseer varios siglos de antigüedad. Además, el diseño de estos elementos requiere el dominio de complejas técnicas para su correcto funcionamiento. No obstante, el criterio de Autenticidad obtiene una puntuación menor en esta tipología patrimonial, ya que diversos bienes no conservan sus características y valores debido al desarrollo de intervenciones irrespetuosas y otros procesos perjudiciales. En relación al patrimonio etnológico se registran puntuaciones más elevadas en los indicadores Simbólico, Concienciación de agentes sociales y Participación e integración de las comunidades locales. Diversos elementos de esta tipología están asociados a tradiciones populares de índole religiosa y generan sentimientos identitarios. Asimismo, la comunidad muestra una mayor implicación en los procesos destinados a su gestión y difusión, y los agentes sociales realizan inversiones para su conservación. Finalmente, el patrimonio Arquitectónico muestra una puntuación destacada en el criterio Social. Su vínculo con los modos tradicionales de habitar el territorio propicia una calificación elevada. 
Figura 8. Puntuaciones técnicas de los criterios según la tipología patrimonial de los bienes

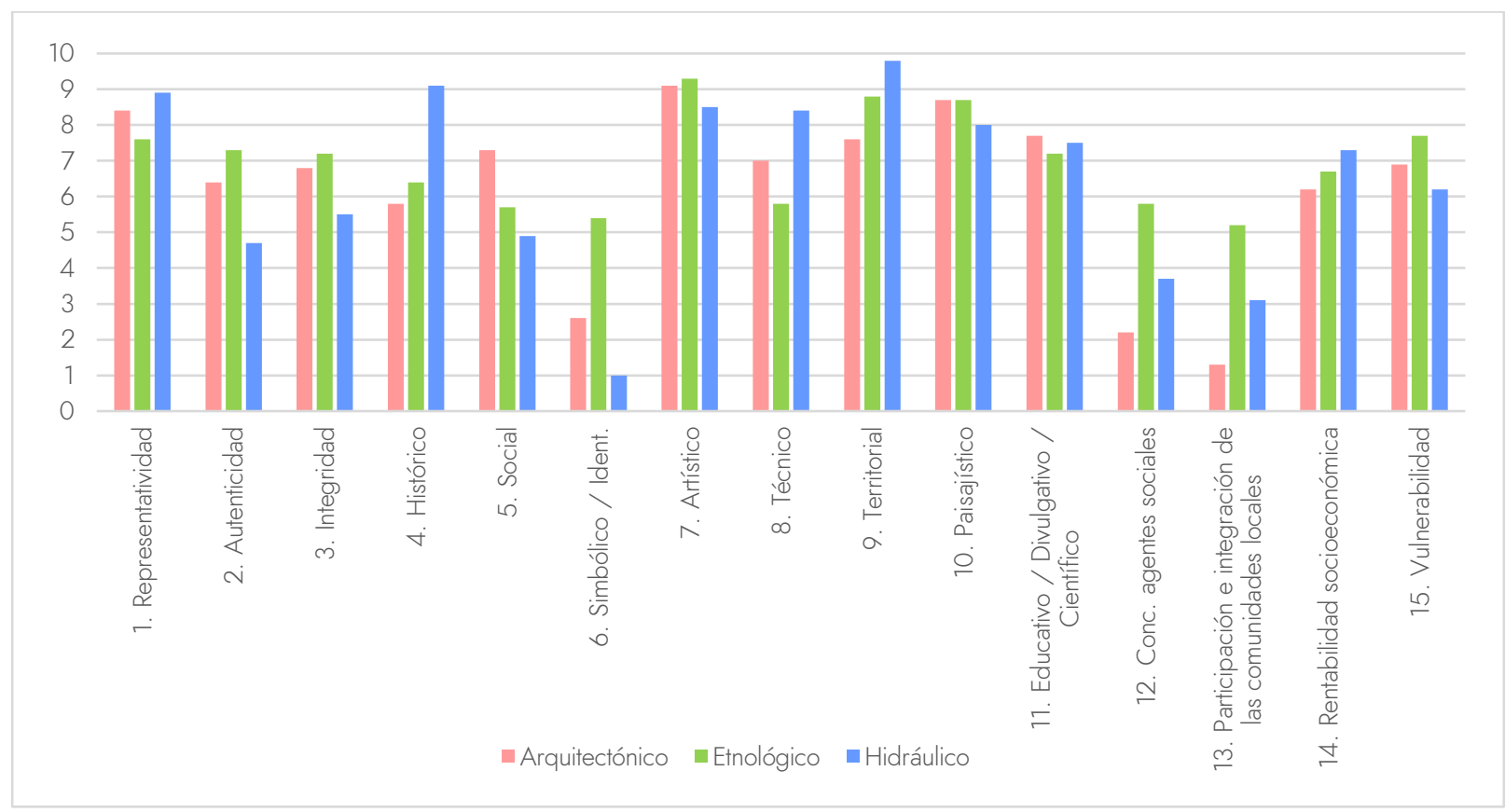

Fuente: elaboración propia

\subsection{Evaluación participativa}

La evaluación participativa se fundamenta en el desarrollo de encuestas a los habitantes mayores de edad residentes en los municipios y barrios de la Huerta de Valencia. En el trabajo de campo se consultó a 11285 personas, pero únicamente $5630^{4}$ pudieron contestar el cuestionario, ya que identificaron uno o más elementos de los catalogados en su localidad. La población restante (5655) no cumplimentó la encuesta porque no conocía ninguno de los bienes propuestos (2810) o porque no residía en ninguna de las poblaciones señaladas (2845). La Figura 1 del Anexo III recoge la población de los municipios o barrios considerados y el número de personas consultadas residentes en cada uno de ellos, con el objeto de constatar la representatividad de las encuestas. Los bienes evaluados se clasifican según la localidad en la que se emplazan, y para cada uno se diferencian las personas que han contestado la encuesta de aquellas que no la han respondido porque no identificaron ninguno de los elementos de su municipio o barrio.

Los principales resultados de la evaluación participativa se muestran en la Figura 2 del Anexo III. Para cada bien se indica su puntuación global, el número de cuestionarios respondidos según sexo, así como el grado de conocimiento de los habitantes, calculado mediante la relación entre las personas que han contestado la encuesta y el total de los residentes consultados. Los elementos culturales están ordenados según los códigos utilizados en la evaluación técnica. Las ocho acequias (códigos del 185 al 192) no han sido propuestas para su evaluación por la población, debido a la

4 Es conveniente señalar que hay habitantes que contestaron a más de un elemento de su localidad. 
complejidad que suponía su inclusión para la confección de la muestra, ya que estos canales recorren numerosos municipios y barrios. Asimismo, el elemento denominado Llengües d'Estadella (código 254) no dispone de datos ya que no se ha localizado ningún habitante que lo identificara. En consecuencia, el número de inmuebles culturales evaluados por los habitantes es de 248.

El grado de conocimiento de los bienes por la población ha obtenido un promedio para el conjunto de inmuebles del 26,9\%. En función de la naturaleza de los elementos, los hidráulicos y arquitectónicos muestran porcentajes reducidos, del $21,1 \%$ y 22,8 \% respectivamente, mientras que los etnológicos alcanzan una cifra superior, del 41,5\%. En general, estos elementos infunden un mayor valor sentimental. En la Tabla 4 se recoge la distribución de los inmuebles según la proporción de habitantes que los identifican. Como se observa, únicamente una quinta parte de los bienes son reconocidos por más de la mitad de los residentes a los que se les ha consultado, y solo 13 edificios superan el 75 \%. En este sentido, los elementos culturales de la Huerta de Valencia son escasamente reconocidos y valorados por sus habitantes, ya que más del 81 \% de los bienes (201 obras) obtienen porcentajes de identificación inferiores al $50 \%$.

Tabla 4. Distribución de los bienes culturales según el grado de conocimiento de los habitantes encuestados

\begin{tabular}{|c|c|c|}
\hline \multirow{2}{*}{$\begin{array}{c}\text { Grado de } \\
\text { conocimiento (\%) }\end{array}$} & \multicolumn{2}{|c|}{ Bienes culturales } \\
\cline { 2 - 3 } & $\mathrm{N}^{\circ}$ & $\%$ \\
\hline $75-100$ & 13 & 5,2 \\
\hline $50-74,9$ & 34 & 13,7 \\
\hline $25-49,9$ & 57 & 23,0 \\
\hline $0-24,9$ & 144 & 58,1 \\
\hline Total & 248 & 100 \\
\hline
\end{tabular}

Fuente: elaboración propia

La calificación patrimonial participativa para el conjunto de bienes es de 6 puntos, cifra que supone una valoración media. El patrimonio etnológico posee la puntuación más elevada, con 6,3 puntos. La población considera en estos bienes aspectos vinculados principalmente con su autenticidad, su integración en el paisaje tradicional y sus valores artísticos. A continuación se sitúa el patrimonio arquitectónico, con 6 puntos, mientras que el hidráulico ha obtenido la peor evaluación participativa, con 5,8 puntos. No obstante, no existen destacadas diferencias entre las tres tipologías. 
La Tabla 5 recoge la distribución de los bienes culturales según su tipología patrimonial y los niveles de valoración propuestos. Las calificaciones altas y muy altas representan una quinta parte de los inmuebles inventariados, con puntuaciones comprendidas entre 7,2 y 10 puntos. Resulta significativo que únicamente un elemento, el Real Monasterio de Santa María en el Puig, posea una puntuación superior a los 8,5 puntos. El conjunto más numeroso está constituido por valoraciones medias, con el 40,7\% de los bienes. Finalmente, alrededor de un centenar de elementos ha obtenido puntuaciones bajas, muy bajas o de sin interés, lo que representa el 39,1\% del patrimonio evaluado. Se advierte que las puntuaciones de algunos elementos se han calculado a partir de un número reducido de encuestas, debido al elevado grado de desconocimiento, por lo que podrían no ser representativas.

Tabla 5. Distribución de los bienes culturales en función de su tipología patrimonial y los niveles de valoración según la evaluación participativa

\begin{tabular}{|c|c|c|c|c|c|c|c|c|}
\hline \multirow{2}{*}{ Valoración } & \multicolumn{2}{|c|}{ Arquitectónicos } & \multicolumn{2}{|c|}{ Etnológicos } & \multicolumn{2}{c|}{ Hidráulicos } & \multicolumn{2}{c|}{ Total } \\
\cline { 2 - 9 } & $\mathrm{N}^{\circ}$ & $\%$ & $\mathrm{~N}^{\circ}$ & $\%$ & $\mathrm{~N}^{\circ}$ & $\%$ & $\mathrm{~N}^{\circ}$ & $\%$ \\
\hline Muy Alta $(8,6-10)$ & 1 & 0,8 & 0 & 0 & 0 & 0 & 1 & 0,4 \\
\hline Alta $(7,2-8,5)$ & 20 & 16,1 & 22 & 36,7 & 7 & 10,9 & 49 & 19,8 \\
\hline Media $(5,8-7,1)$ & 52 & 41,9 & 20 & 33,3 & 29 & 45,3 & 101 & 40,7 \\
\hline Baja $(4,4-5,7)$ & 38 & 30,6 & 13 & 21,7 & 22 & 34,4 & 73 & 29,4 \\
\hline Muy Baja $(3-4,3)$ & 13 & 10,5 & 3 & 5,0 & 5 & 7,8 & 21 & 8,5 \\
\hline Sin Interés $(<3)$ & 0 & 0 & 2 & 3,3 & 1 & 1,6 & 3 & 1,2 \\
\hline Total & 124 & 100 & 60 & 100 & 64 & 100 & 248 & 100 \\
\hline
\end{tabular}

Fuente: elaboración propia

La clasificación de los bienes según su tipología y los niveles de valoración ofrece datos relevantes. El patrimonio etnológico posee 22 bienes con puntuaciones altas. Están constituidos fundamentalmente por ermitas que conservan sus atributos originales y con un valor identitario para los habitantes. Las puntuaciones más bajas de esta modalidad se corresponden con antiguas chimeneas y otras tipologías menos representativas en la selección efectuada, como los mojones de término, las cebolleras y las canteras. En cuanto al patrimonio arquitectónico, el $42 \%$ de los bienes cuentan con puntuaciones medias, mientras que las calificaciones bajas o muy bajas agrupan al $41,1 \%$ de los inmuebles. Este conjunto está conformado principalmente por barracas y alquerías que según la población se caracterizan por una sencilla técnica constructiva y una escasa 
contribución socioeconómica. Los bienes mejor puntuados comprenden edificios solemnes, así como los huertos de naranjos situados en l'Horta Sud. Por último, el patrimonio hidráulico también aglutina una proporción relevante de bienes con puntuaciones inferiores a los 5,8 puntos, con más del $39 \%$. En general se trata de molinos abandonados y otros elementos del patrimonio del agua deteriorados. Las puntuaciones medias suponen el 40,7\% de estos edificios, mientras que el restante $20 \%$ ha obtenido puntuaciones altas, donde destacan varios partidores y molinos en buen estado de conservación. Las Figuras 9, 10 y 11 muestran la representación cartográfica de la evaluación global participativa de cada inmueble, clasificados según su naturaleza patrimonial y los niveles de valoración. Las Figuras 12 y 13 se corresponden con el Real Monasterio de Santa María en el Puig y la Ermita de Santa Ana de Albal, con unas calificaciones participativas de 9,8 y 8,0 puntos respectivamente. 
Figura 9. Evaluación participativa de los bienes arquitectónicos

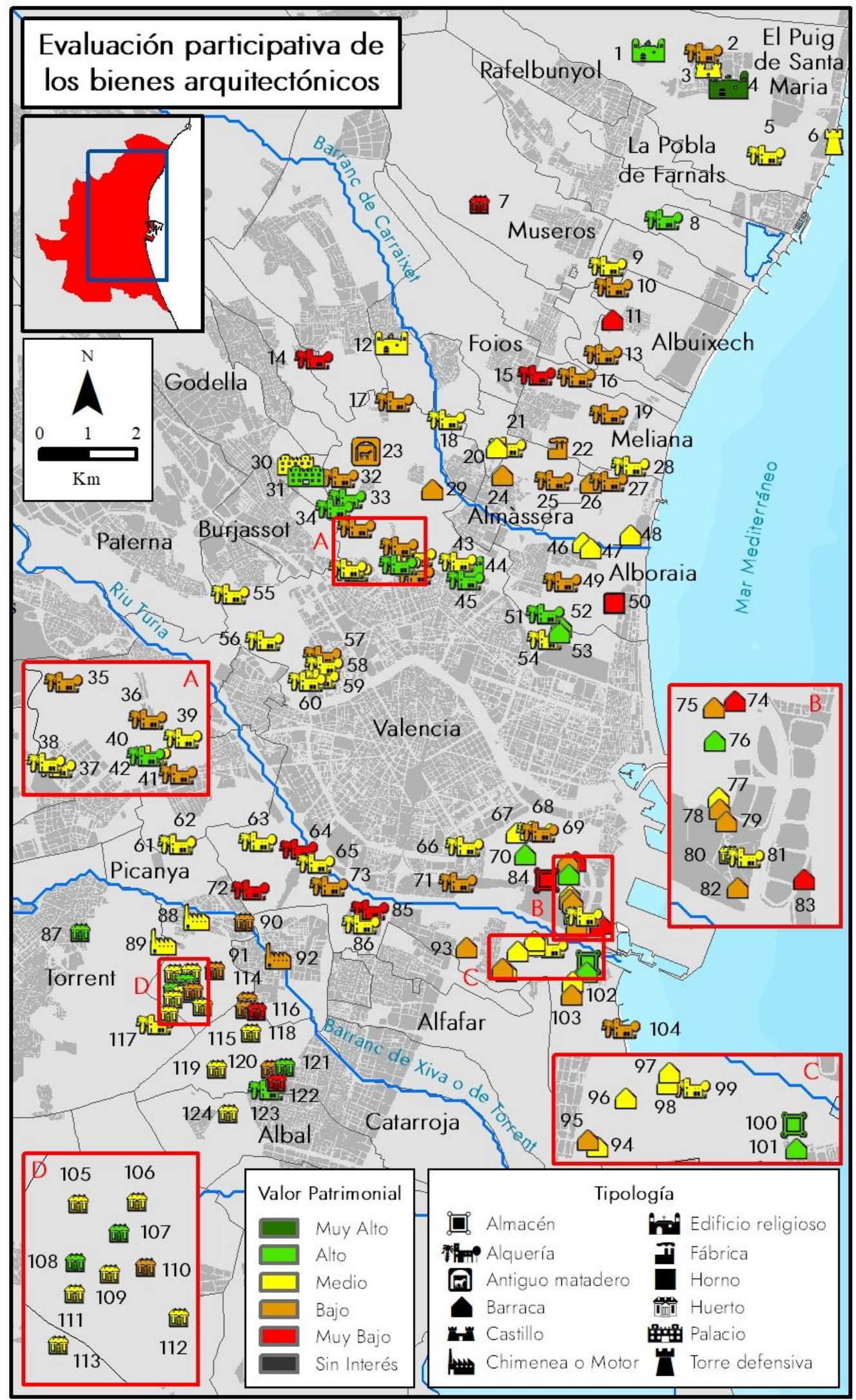

Nota: La denominación de cada bien puede observarse en los códigos utilizados en la Figura 2 del Anexo III Fuente: elaboración propia 
Figura 10. Evaluación técnica de los bienes etnológicos

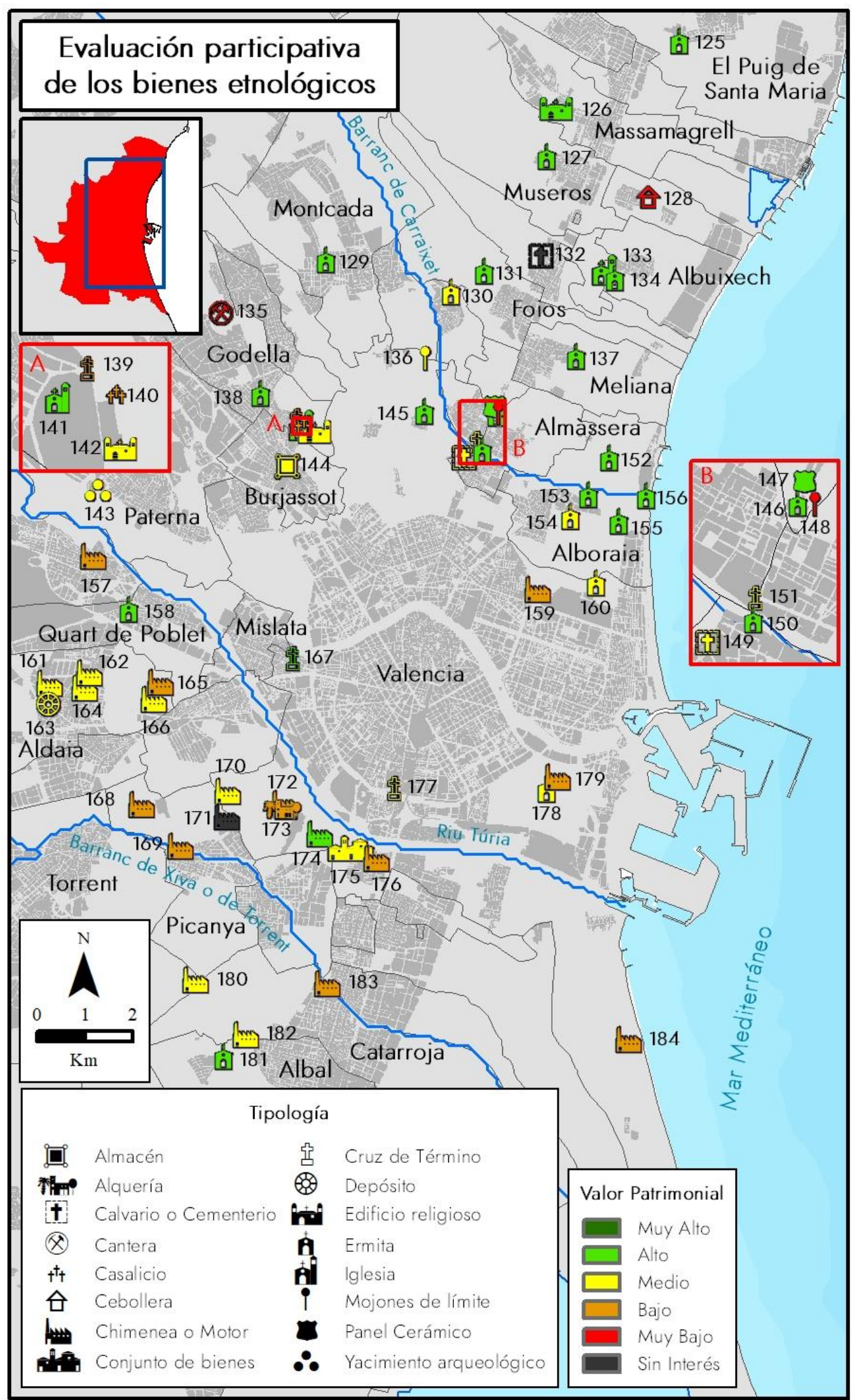

Nota: La denominación de cada bien puede observarse en los códigos utilizados en la Figura 2 del Anexo III Fuente: elaboración propia 
Figura 11. Evaluación participativa de los bienes hidráulicos

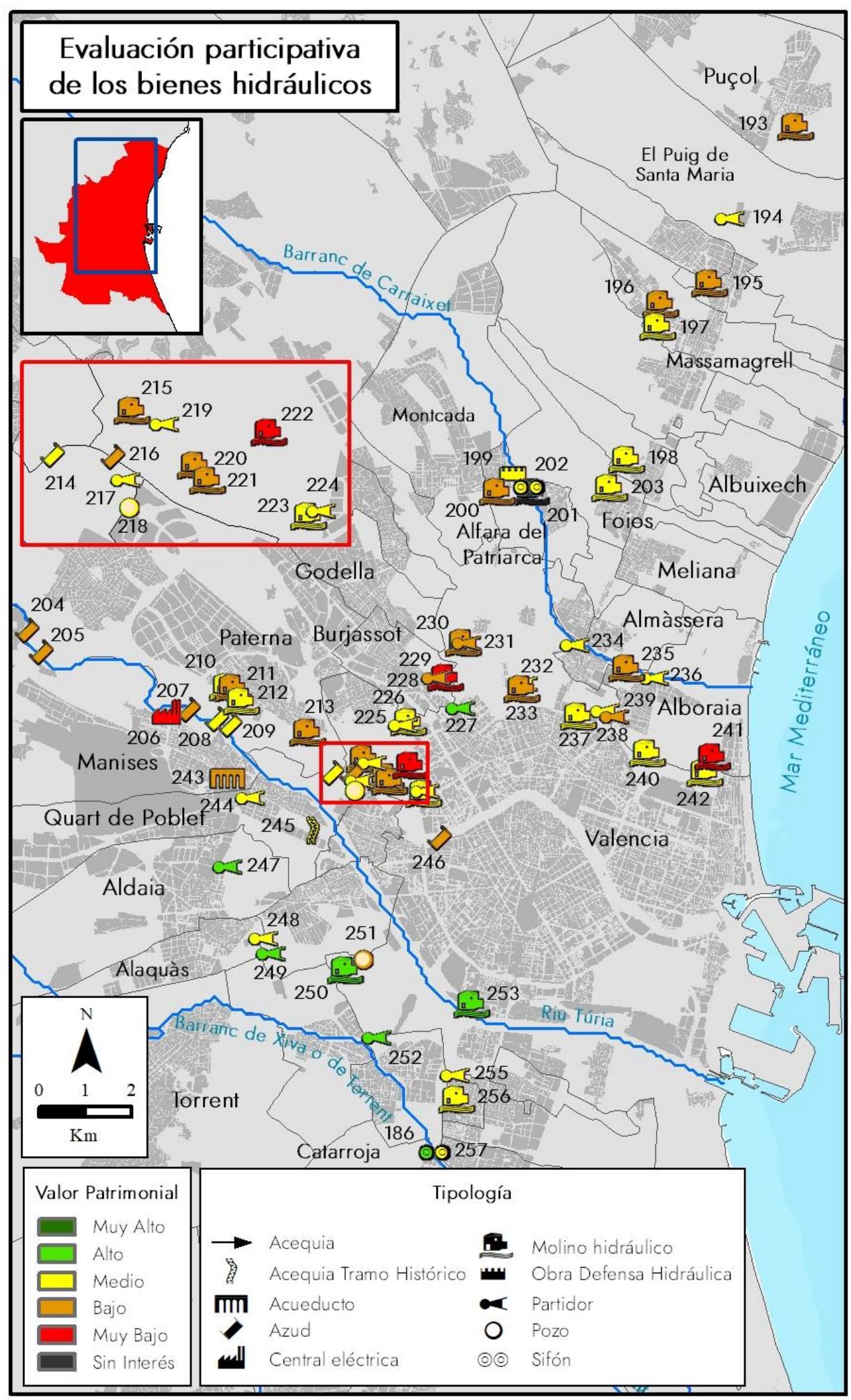

La denominación de cada bien puede observarse en los códigos utilizados en la Figura 2 del Anexo III Fuente: elaboración propia 


\section{Figura 12. Real Monasterio de Santa María (El Puig)}

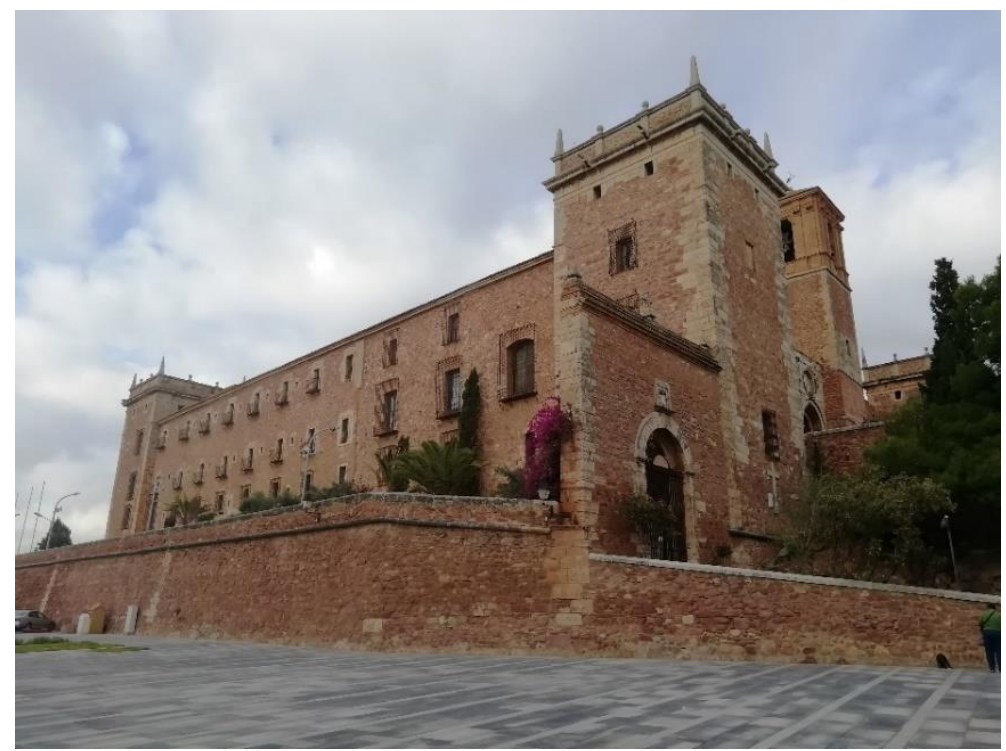

Fuente: elaboración propia

\section{Figura 13. Ermita de Santa Ana (Albal)}

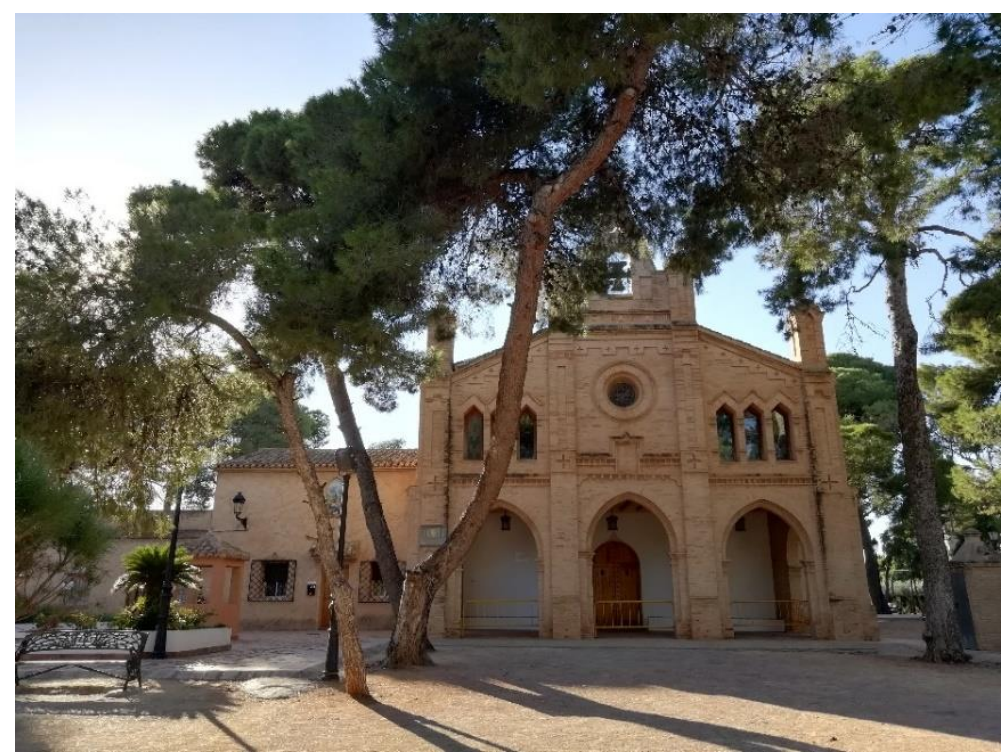

Fuente: elaboración propia

La evaluación participativa de cada categoría y criterio para el conjunto de bienes se observa en la Tabla 6. Los valores intrínsecos cuentan con las puntuaciones más elevadas de las tres categorías, con 6,8 puntos. A continuación se sitúan los valores patrimoniales, con 6,2 puntos, y por último se encuentran los valores potenciales y de viabilidad, con 5 puntos. Respecto a las puntuaciones de los criterios existen diferencias relevantes. Los indicadores Territorial y de Autenticidad han obtenido las puntuaciones más elevadas del sistema, con 8 puntos cada uno. En el primero, los habitantes valoran la interacción y la integración de los inmuebles en su paisaje tradicional, vinculado con la cultura territorial de la Huerta de Valencia. En el criterio de Autenticidad se puntúa el grado de 
fidelidad que mantienen los elementos con su imagen y valores originales. En tercera posición se sitúa el indicador Paisajístico, con 7,8 puntos.

Tabla 6. Puntuaciones participativas de las categorías y criterios para el conjunto de bienes

\begin{tabular}{|c|c|c|c|}
\hline Categorías & Criterios & \multicolumn{2}{|c|}{ Puntuaciones } \\
\hline \multirow{3}{*}{$\begin{array}{l}\text { Valores } \\
\text { intrínsecos }\end{array}$} & 1. Representatividad & 5,5 & \multirow{3}{*}{6,8} \\
\hline & 2. Autenticidad & 8,0 & \\
\hline & 3. Integridad & 7,1 & \\
\hline \multirow{8}{*}{$\begin{array}{c}\text { Valores } \\
\text { patrimoniales }\end{array}$} & 4. Histórico & 5,4 & \multirow{8}{*}{6,2} \\
\hline & 5. Social & 5,1 & \\
\hline & 6. Simbólico / Identitario & 7,2 & \\
\hline & 7. Artístico & 5,8 & \\
\hline & 8. Técnico & 4,4 & \\
\hline & 9. Territorial & 8,0 & \\
\hline & 10. Paisajístico & 7,8 & \\
\hline & 11. Educativo / Divulgativo / Científico & 6,2 & \\
\hline \multirow{4}{*}{$\begin{array}{c}\text { Valores } \\
\text { potenciales y de } \\
\text { viabilidad }\end{array}$} & 12. Concienciación de agentes sociales & 5,1 & \multirow{4}{*}{5,0} \\
\hline & 13. Participación e integración de las comunidades locales & 4,8 & \\
\hline & 14. Rentabilidad socioeconómica & 4,2 & \\
\hline & 15. Vulnerabilidad & 6,1 & \\
\hline & Promedio & \multicolumn{2}{|c|}{6,0} \\
\hline
\end{tabular}

Fuente: elaboración propia

El criterio con la peor evaluación participativa es el de Rentabilidad socioeconómica, con 4,2 puntos. La población local considera que la mayoría de los elementos no contribuyen al desarrollo sostenible del territorio. El criterio Técnico posee la segunda menor puntuación del método, con 4,4 puntos. Numerosos encuestados señalan que la técnica con la que se han diseñado y construido los inmuebles fue sencilla. Finalmente, el indicador con la tercera calificación más baja es el de Participación e integración de las comunidades locales, que ha obtenido 4,8 puntos. Valora la implicación de la comunidad en la gestión del bien y en otras tareas asociadas. Es conveniente fortalecer la presencia activa de las poblaciones en estos aspectos. 
La Figura 14 representa las calificaciones de los criterios según la naturaleza patrimonial de los elementos. Las tres tipologías muestran puntuaciones similares para cada indicador, por lo que no suele destacar ninguna modalidad sobre las demás. No obstante se observan algunas particularidades. El patrimonio etnológico obtiene valoraciones ligeramente superiores en 11 de los 15 criterios, con diferencias más destacadas en los valores Simbólico e Histórico. Los habitantes mantienen un mayor vínculo afectivo con estos inmuebles y los relacionan con personajes, acontecimientos o instituciones históricas significativas. Sin embargo, la población considera que esta tipología patrimonial genera un menor crecimiento socioeconómico que el resto. En cuanto a los edificios arquitectónicos, las puntuaciones de los criterios Artístico e Integridad son mayores a las demás tipologías. Para la población encuestada, estos bienes poseen relevantes valores estéticos y muestran un mejor estado de conservación. Por último, el patrimonio hidráulico tiene puntuaciones superiores en los indicadores Técnico y de Rentabilidad Socioeconómica. Los habitantes han considerado la complejidad tecnológica que requiere el diseño y materialización de este tipo de elementos. Además valoran su contribución al desarrollo sostenible del territorio, como consecuencia de la importancia otorgada a la producción agraria y al regadío tradicional.

Figura 14. Puntuaciones participativas de los criterios según la tipología patrimonial de los bienes

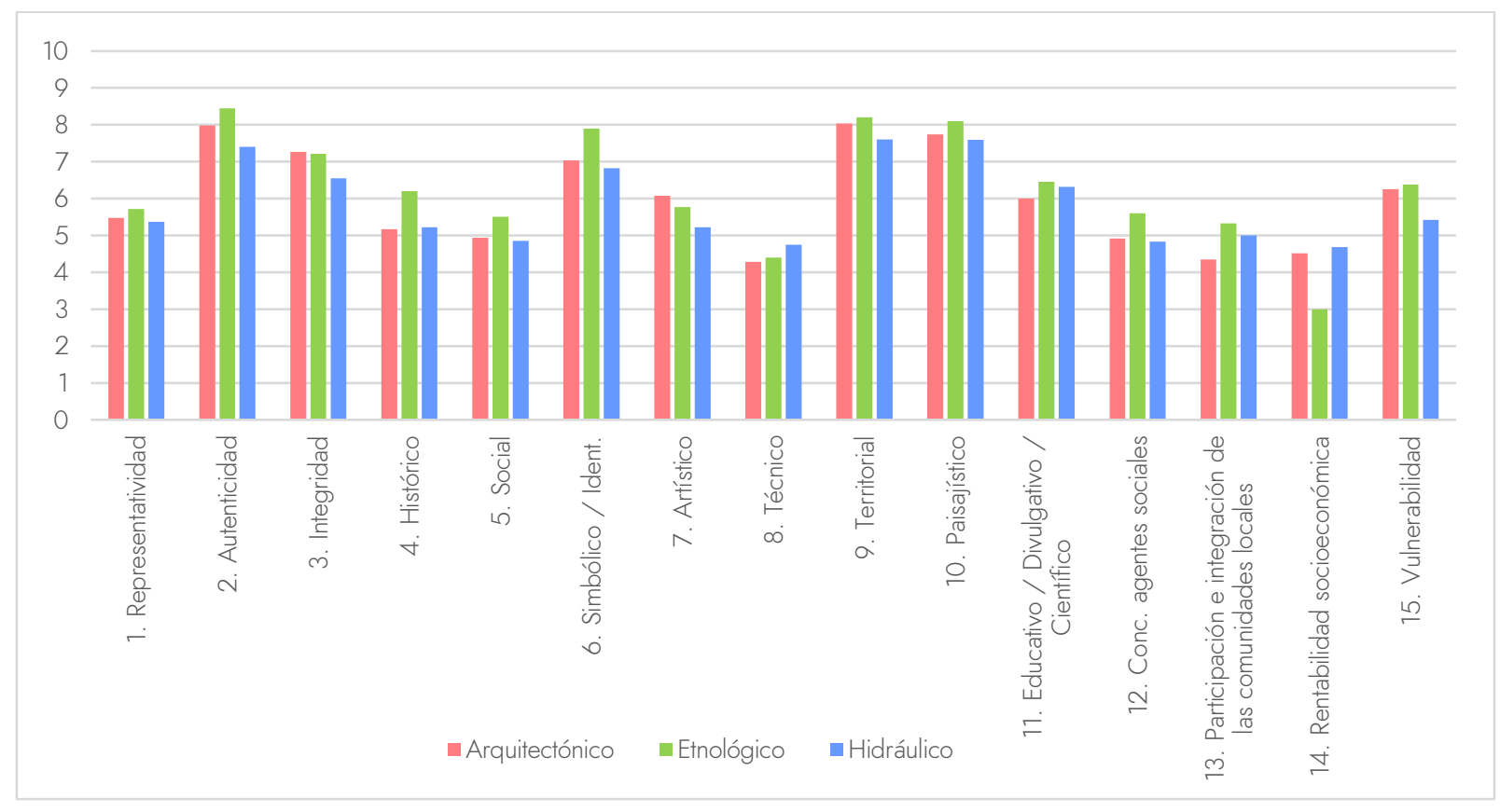

Fuente: elaboración propia

\subsection{Comparativa entre la evaluación técnica y la participativa}

La aplicación del método de evaluación patrimonial desarrollado ha permitido el cálculo de dos modalidades de evaluación para los bienes culturales inventariados: la evaluación técnica y la evaluación participativa. El análisis de los resultados obtenidos en ambos procedimientos aporta información relevante sobre el valor del patrimonio de la Huerta de Valencia y posibilita la 
comparación de las calificaciones de cada tipología de evaluación. Estos procesos están estructurados en función de los mismos criterios y categorías. Sin embargo, las puntuaciones no han de equipararse de manera estricta, ya que son resultado de procesos diferentes y adaptados a cada colectivo. La evaluación técnica se fundamenta en el cumplimiento o no de 45 variables a través de un sistema de puntuación binario, mientras que la calificación participativa se obtiene mediante las respuestas de la población a un cuestionario constituido por 15 preguntas de respuestas dicotómicas.

La Tabla 7 muestra las valoraciones globales técnicas y participativas para el conjunto de bienes culturales según su tipología patrimonial. Como se observa, las puntuaciones totales medias en ambos procedimientos son moderadas, de 6,5 puntos en la evaluación de los técnicos, y 6 puntos en la establecida por los habitantes. Esta menor calificación asignada por la población local se registra también en otros estudios de evaluación patrimonial cuantitativa, como el de Hermosilla y Mayordomo (2017b). Si se examinan los valores para cada tipología del patrimonio se observa que las puntuaciones globales participativas son también inferiores a las técnicas. Las causas pueden ser diversas. En general, los habitantes han conocido los elementos culturales en periodos de mayor esplendor. En la actualidad, debido a los procesos de degradación existentes, la población posee una valoración más negativa y crítica. Asimismo, otro factor que puede influir es la falta de una mayor conciencia social de los habitantes hacia los valores del patrimonio de su entorno.

\section{Tabla 7. Valoraciones globales técnicas y participativas para el conjunto de bienes según su tipología patrimonial}

\begin{tabular}{|c|c|c|}
\hline \multirow{2}{*}{$\begin{array}{c}\text { Tipología } \\
\text { patrimonial }\end{array}$} & \multicolumn{2}{|c|}{ Evaluación } \\
\cline { 2 - 3 } & Técnica & Participativa \\
\hline Arquitectónico & 6,3 & 6,0 \\
\hline Etnológico & 7,0 & 6,3 \\
\hline Hidráulico & 6,4 & 5,8 \\
\hline Media global & 6,5 & 6,0 \\
\hline
\end{tabular}

Fuente: elaboración propia

Las calificaciones de los criterios según las dos tipologías de evaluación se observan en la Figura 15. La evaluación técnica obtiene puntuaciones superiores en 10 de los 15 indicadores. Destacan aspectos vinculados con la calidad estética de los bienes, la complejidad de las técnicas utilizadas en la construcción de los elementos, y su contribución al desarrollo socioeconómico. Por su parte, la evaluación participativa obtiene mejores calificaciones en los criterios de Autenticidad, Integridad, Simbólico, Concienciación de agentes sociales y Participación e integración de las comunidades 
locales. Los habitantes valoran en mayor medida los vínculos emocionales y de identidad que infunden los bienes, así como su estado de conservación. Resultan llamativas las mayores puntuaciones registradas en los indicadores de implicación de los actores territoriales y de participación comunitaria. En general, la población suele mostrarse crítica con las escasas inversiones público-privadas dirigidas a la puesta en valor de los bienes, y con los limitados mecanismos de participación ciudadana existentes relacionados con la gestión patrimonial.

\section{Figura 15. Puntuaciones globales de los criterios según la evaluación técnica y participativa}

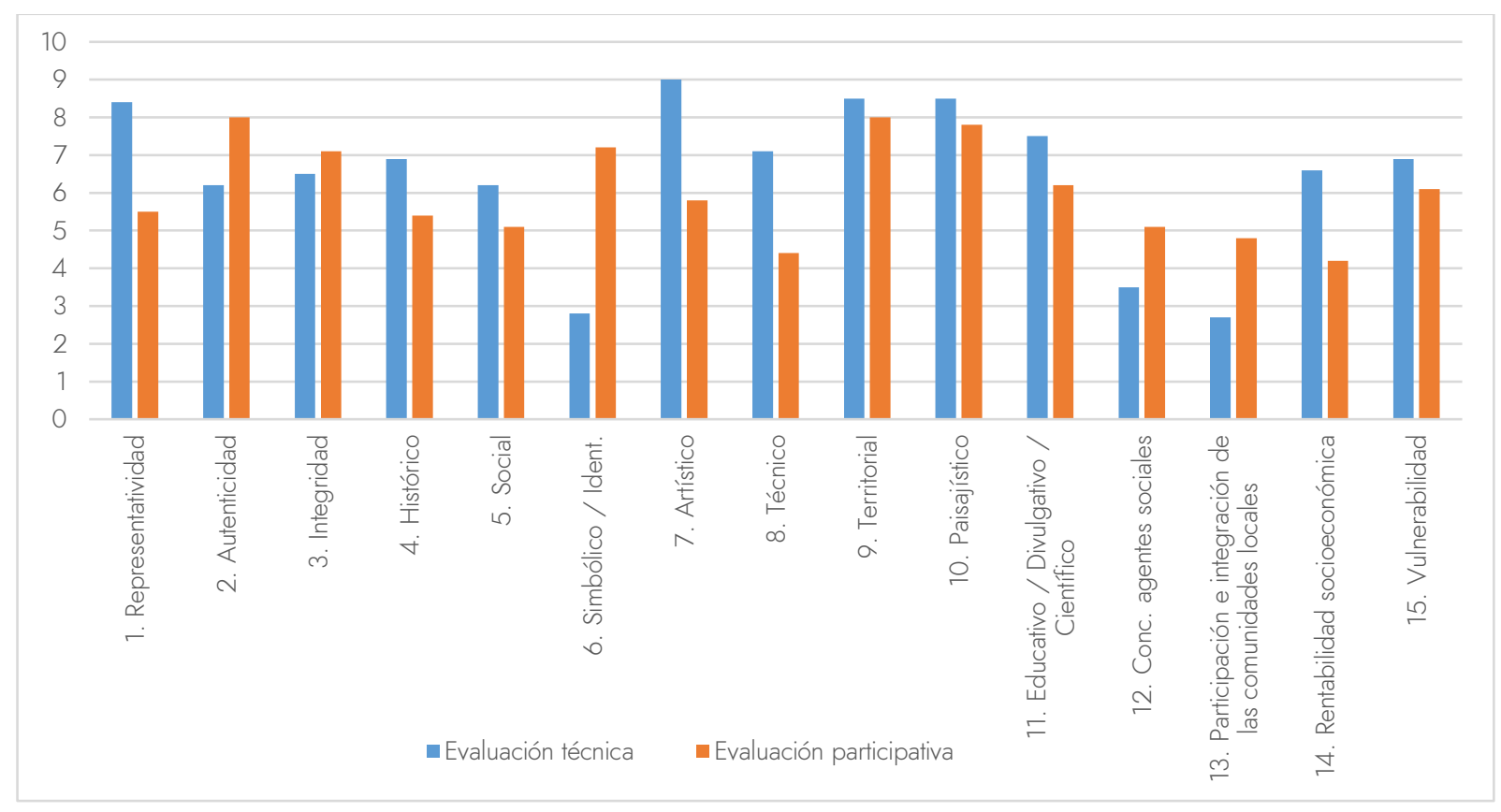

Fuente: elaboración propia

\section{Discusión de resultados}

La aplicación del método desarrollado ha permitido evaluar un patrimonio cultural de innegable valor. La naturaleza de los indicadores empleados reconoce el carácter multidisciplinar que requieren las tipologías patrimoniales analizadas. La integración de los diferentes valores patrimoniales supone una complejidad en la nomenclatura de valores estándar. Aun así, el sistema es práctico y sencillo de aplicar, por lo que se trata de un método útil y con un elevado grado de implementación. El uso de una puntuación binaria y equitativa para los distintos indicadores consigue una operatividad destacada.

La evaluación técnica del método ofrece resultados válidos sin necesidad de efectuar las acciones complementarias de participación. Sin embargo, la implicación activa de la población y otros actores en la valoración de sus bienes patrimoniales constituye una actuación necesaria. La aplicación de estas acciones ha conllevado una serie de dificultades. En relación a las encuestas a la población, el elevado grado de desconocimiento existente ha supuesto una inversión temporal y 
económica mayor que la prevista inicialmente. En el estudio se ha desestimado la realización del panel de expertos, lo que ha supuesto la ausencia de la valoración de los especialistas. En consecuencia, debido a las complicaciones reseñadas, las acciones de participación representan el aspecto más frágil del método. Con el propósito de reducir la complejidad de estas acciones, se contempla la futura incorporación de otras técnicas de menor dificultad, como la organización de talleres u otras experiencias colectivas.

Las encuestas implementadas han puesto de manifiesto el elevado grado de desconocimiento de los bienes patrimoniales de la Huerta de Valencia por sus habitantes. En las últimas décadas se han acentuado los procesos que conllevan la desvalorización de los paisajes de regadío y de su patrimonio asociado. Diversos estudios constatan este desconocimiento. En la Huerta de Valencia se encuentran investigaciones como las de Sanchis (2004) o Mangue (2016). En la Huerta de Alicante y sus torres de defensa destaca el trabajo de Morote y Medina (2015), en la Huerta de Orihuela el estudio de Canales y López (2015), mientras que en la Vega de Granada sobresale la investigación de Torres, Matarán y Bejarano (2016).

La escasa valoración y grado de conocimiento que la población local tiene sobre el patrimonio de la Huerta está motivado por la incidencia de varios factores. Unos motivos se relacionan con la crisis general del sector agrario y con las recientes dinámicas socioeconómicas desarrolladas especialmente en las áreas metropolitanas españolas; otros son específicos de la Huerta de Valencia y de su carácter periurbano.

La crisis que afecta a la actividad agraria se manifiesta en procesos como el envejecimiento, la falta de relevo generacional, la sustitución de cultivos tradicionales por otros comerciales, la escasa rentabilidad, o la transformación de los sistemas históricos por otros más modernos. Estos factores contribuyen a una depreciación de los espacios agrarios y el deterioro del patrimonio asociado, que se materializa en la proliferación del barbecho social en espacios periurbanos (Hermosilla \& Iranzo, 2014a).

En la actualidad el espacio de la Huerta de Valencia se encuentra social y culturalmente ajeno a la ciudad. La progresiva desarticulación entre la actividad urbana y el área agrícola adyacente se acentuó a partir de años sesenta del siglo XX, como consecuencia del desarrollo urbano industrial y la expansión de la ciudad (Sanchis \& Díez, 2012). La progresiva urbanización, la terciarización de la economía, y la expansión de las actividades e infraestructuras en detrimento del espacio agrario ha conllevado la creciente fragmentación y reducción de las áreas de huerta. Estas transformaciones socioeconómicas, unidas a la permisividad política y la descoordinación de las administraciones, han supuesto un progresivo alejamiento entre la huerta y la cultura urbana en los últimos años. Asimismo, el mensaje que se transmite del espacio agrario en múltiples centros educativos es simple y taxonómico, y se limita a su función productivista. En definitiva, la conjunción de estos factores 
económicos, sociales y didácticos contribuyen a la desvinculación social entre la ciudadanía y su entorno agrícola. Numerosos habitantes de la ciudad de Valencia consideran a la Huerta un territorio desconocido e inaccesible, y poseen una imagen de la misma ligada al pasado que facilita su olvido (Ruiz, 2017).

Las iniciativas y actuaciones dirigidas a la mejora del conocimiento del patrimonio incrementan la cultural territorial de los habitantes, así como su sensibilización hacia el paisaje en el que residen o visitan. Es imprescindible el diseño y la aplicación de acciones de diversa índole dirigidas a la revalorización del territorio por la ciudadanía.

La puesta en valor de los paisajes como recursos de utilización turística favorece su preservación y promoción. En este sentido resulta fundamental el desarrollo de rutas culturales y de productos turísticos sostenibles. Por ejemplo, la apertura de la vía verde de l'Horta Nord, conocida como Vía Xurra, ha conllevado la aproximación de la población urbana a la huerta, así como la proliferación de negocios agrícolas en el entorno. Asimismo, son numerosas las propuestas relacionadas con la creación de itinerarios y productos en otros paisajes de regadío, como las planteadas por Mata y Fernández (2010) en la Huerta de Murcia, o por Olcina y Hernández (2017) en la Huerta de Alicante.

La educación es un instrumento fundamental para la conservación y valoración de la Huerta de Valencia, ya que mejora el conocimiento y la sensibilización del educando sobre este espacio agrario (García, 2007). Es posible el diseño de itinerarios didácticos para enseñar los valores culturales, patrimoniales y agrícolas, el uso de zonas de huerta para su cultivo por escolares o el aumento de los módulos de formación profesional de agricultura (García \& García, 2014). En los últimos años han mejorado los contenidos educativos y han proliferado los materiales dedicados a la difusión del paisaje y el significado de la Huerta.

Es necesario un mayor grado de concienciación y de información a la ciudadanía mediante la implementación de acciones de difusión como seminarios, exposiciones, talleres o jornadas vinculadas con el valor de los paisajes agrarios. Además, la labor divulgativa de los museos facilita el conocimiento de la población sobre estos espacios, como la realizada por el Museo de la Ermita de Vera (Valencia) o el Museu de l'Horta (Almàssera). Otras acciones interesantes son la implementación de campañas para fomentar el consumo de los productos de la Huerta o los huertos de autoconsumo.

La progresiva concienciación de la población sobre el valor de sus paisajes ha propiciado el aumento de asociaciones y otros grupos sociales relacionados con la protección paisajística y patrimonial. En la Huerta de Valencia una de las plataformas ciudadanas más conocidas es Per I'Horta, constituida en el año 2001. 
La implicación y coordinación de las diversas escalas de la administración pública y el diseño de políticas sostenibles deben contribuir a la preservación paisajística y, en consecuencia, a minimizar la distancia entre la población urbana y la huerta. Por ello es preciso el impulso de planes territoriales metropolitanos que consideren la importancia de la actividad agraria así como medidas legales eficaces y coherentes (Romero \& Melo, 2016). En este sentido, son relevantes el PAT o el Plan de desarrollo agrario, con la presencia de estrategias y acciones dirigidas a la dinamización y preservación de la agricultura y sus elementos culturales, paisajísticos y ambientales. La recuperación de la figura del agricultor y la revitalización del sector agrario son acciones necesarias para la revalorización de estos paisajes.

\section{Conclusiones}

La gestión y el tratamiento del patrimonio cultural constituyen tareas complejas como consecuencia de las circunstancias y desafíos existentes. Aspectos como las desigualdades socioeconómicas, la masificación turística, la globalización, o las aglomeraciones urbanísticas conllevan la necesidad de diseñar actuaciones que consideren el beneficio de las comunidades, y que garanticen el desarrollo endógeno del territorio.

La identificación, caracterización y evaluación de los bienes culturales son acciones necesarias para llevar a cabo su preservación y puesta en valor. En el presente artículo se propone un método de evaluación que permite conocer el valor patrimonial de los bienes culturales en beneficio de la comunidad, los tomadores de decisiones y/o cualquier usuario interesado.

La metodología de evaluación es cuantitativa y está conformada por múltiples indicadores jerarquizados de tipo estructural y funcional que posibilitan la comprensión de los bienes desde diferentes dimensiones. Se fundamentan en parámetros objetivos, aunque con un cierto grado de subjetividad. En este sentido, y con el propósito de reducir la subjetividad inherente a cualquier metodología de evaluación se han procurado diversos aspectos, como la incorporación de un número considerable de variables, el diseño de definiciones precisas y el uso de un sistema de puntuación binario. El método considera además el desarrollo de acciones adicionales de participación, con el objeto de conocer el valor del patrimonio por parte de la comunidad. Estas técnicas son fundamentales para la gestión de los bienes y contribuyen a la mejora de la gobernanza participativa.

La aplicación práctica del sistema metodológico en la Huerta de Valencia ha permitido la jerarquización de una selección de 257 elementos culturales según su valor patrimonial. Se han obtenido dos tipos de puntuaciones: la técnica, mediante el sumatorio de las variables que estructuran el método; y la participativa, calculada a partir de la realización de encuestas a la población local. La clasificación patrimonial de los elementos inventariados posibilita la 
implementación de posibles estrategias coherentes de preservación, restitución y planificación por parte de las administraciones y los tomadores de decisiones.

Uno de los principales valores de la investigación ha consistido en poner en práctica la aplicabilidad del método de evaluación en numerosos bienes de variada tipología. La evaluación técnica ha otorgado calificaciones muy altas a 26 inmuebles. Se trata de bienes de significativo valor que conforman un referente del patrimonio cultural valenciano. La identificación de estos elementos de mayor calificación constituye una tarea imprescindible en el futuro diseño de un Territorio Museo de la Huerta de Valencia. Este espacio consistiría en un museo al aire libre abierto y habilitado, compuesto por itinerarios señalizados, centros de interpretación y elementos patrimoniales relevantes, que tiene como objetivo la puesta en valor de los recursos del territorio.

Se observa como una proporción relevante de los inmuebles seleccionados posee calificaciones bajas, tanto en la evaluación efectuada por el personal técnico como la realizada por los residentes en el territorio. Se trata generalmente de bienes deteriorados y en desuso que requieren de actuaciones destinadas a su rehabilitación y puesta en valor. El patrimonio de la Huerta de Valencia se asocia a su condición de territorio vivo, por lo que en la medida que este espacio agrario se deteriora y descuida, igualmente se degrada el valor cultural de sus recursos y elementos patrimoniales. De hecho, dos alquerías catalogadas han sido derribadas recientemente como consecuencia de la presión urbanística existente.

Los habitantes han asignado calificaciones medias inferiores a las técnicas, debido a su visión más crítica y a la necesidad de una mayor sensibilización hacia sus valores. La implementación de cuestionarios ha permitido el cálculo del grado de conocimiento de los bienes por los habitantes, situado en el 26,9\% para el conjunto de inmuebles. El $80 \%$ de las obras son identificadas por menos de la mitad de los habitantes consultados, lo que advierte que el patrimonio cultural de la Huerta de Valencia es mínimamente conocido y reconocido socialmente. Es conveniente la puesta en valor de estos bienes y la difusión de su importancia y significado.

La metodología de evaluación propuesta ha permitido la evaluación de múltiples y variados bienes culturales de manera práctica. Los criterios utilizados son sencillos de comprender y aplicar, aunque algunas variables pueden ser cuestionables y discutibles. El método desarrollado se configura como una herramienta válida y efectiva para el diseño de actuaciones de gestión patrimonial. Es un sistema universal que posibilita obtener resultados reproducibles y transparentes para las distintas modalidades de elementos inmuebles y para cualquier área geográfica. Las administraciones y otras instituciones pueden reconocerlo, asumirlo y aplicarlo como un instrumento útil para la toma de decisiones y la planificación de los recursos territoriales.

En base a la investigación realizada es posible la definición de diversas líneas de trabajo a desarrollar en el futuro. En primer lugar, el método de evaluación es un sistema abierto, actualizable 
en función de las aplicaciones y susceptible de ser revisado y mejorado. Por ejemplo se pueden proponer o modificar indicadores, así como diseñar nuevas acciones complementarias de participación, a través de talleres de opinión o de otras experiencias comunitarias. En segundo lugar sería interesante la evaluación del impacto real que supone la aplicación del método en el territorio. En este sentido, en aquellos ámbitos en los que se desarrolle el sistema es conveniente realizar un seguimiento de las actuaciones desarrolladas en base a los resultados de evaluación obtenidos. En tercer lugar sería necesario el diseño de diferentes mecanismos para que las empresas, técnicos y otros potenciales actores beneficiarios puedan adoptar y utilizar esta metodología, diseñada desde el ámbito académico. Finalmente es necesaria la implementación del sistema de evaluación en diferentes áreas de estudio, lo que permitiría comprobar la eficacia del método en otros ámbitos geográficos y tipologías del patrimonio cultural.

Agradecimientos: Este artículo es resultado de la investigación realizada en el marco del proyecto europeo "Museums and Community: Concepts, Experiences, and Sustainability in Europe, Latin America and the Caribbean (EU-LAC-MUSEUMS)" (Museos y Comunidad: Conceptos, Experiencias y Sostenibilidad en Europa, América Latina y Caribe). Este proyecto ha recibido financiación del programa de investigación e innovación Horizonte 2020 de la Unión Europea en virtud del acuerdo de subvención $N^{\circ} 693669$.

Declaración responsable: Las/os autoras/es declaran que no existe ningún conflicto de interés en relación con la publicación de este artículo. Para su elaboración, Sandra Mayordomo Maya, como autora principal, ha participado en el diseño del sistema de evaluación del patrimonio cultural, que parte de la metodología aplicada a bienes hidráulicos elaborada por el grupo de investigación ESTEPA, dirigido por el profesor Jorge Hermosilla Pla, del Departamento de Geografía de la Universitat de València. La autora realizó además la consulta y el análisis de las fuentes de información, el trabajo de campo con la visita a los bienes culturales seleccionados, la aplicación del método de evaluación, la elaboración de la cartografía, y el análisis y tratamiento de los resultados y estadísticas. El Dr. Jorge Hermosilla Pla decidió el objeto de estudio, planteó el establecimiento del enfoque de la investigación y de su estructura, la realización de correcciones en el texto y la aportación de sugerencias a su contenido y a las conclusiones. 


\section{Bibliografía}

Argyelan, T., Díez, I., Vallés, M., \& Galiana, F. (2014). Land use change in Huerta de Valencia (2008-2013). Resilience and cultural landscapes. In C. Sanchis-lbor, G. Palau-Salvador, I. MangueAlférez \& L. P. Martínez-Sanmartín (Eds.), Irrigation, Society, Landscape. Tribute to Thomas F. Glick (pp. 910-923). Valencia: Universitat Politècnica de València. http://dx.doi.org/10.4995/ISL2014.2014.201

Australia Internacional Council on Monuments and Sites (ICOMOS) (1979). The Australia ICOMOS Guidelines for the Conservation of Places of Cultural Significance ("Burra Charter"). Retrieved from https://australia.icomos.org/wp-content/uploads/Burra-Charter_1979.pdf

Besó, A. (1999). Els horts de tarongers de Picanya: arquitectura i paisatge. Picanya: Ajuntament de Picanya.

Bouzekraoui, H., Barakat, A., Touhami, F., Mouaddine, A., \& El Youssi, M. (2018). Inventory and assessment of geomorphosites for geotourism development: A case study of Aït Bou Oulli valley (Central High-Atlas, Morocco). Area, 50, 331-343. http://dx.doi.org/10.1111/area.12380

Bravo, J. M. (2018). Paisaje Rural y Patrimonio Hidráulico, referentes señeros presentes en la cultura rural del valle de Ricote (España) y de la Zona Central de Chile (Unpublished doctoral dissertation). Murcia: Universidad de Murcia.

Brunetta, G., Monaco, R., Salizzoni, E., \& Salvarani, F. (2018). Integrating in regional development: A multidisciplinary approach to evaluation in Trentino planning policies, Italy. Land Use Policy, 77, 613-626. http://dx.doi.org/10.1016/j.landusepol.2018.05.024

Burriel, E. L. (1971). La huerta de Valencia, zona sur: estudio de geografía agraria. Valencia: Institució Alfons el Magnànim, Institut de Geografia.

Canales, G., \& López, A. (2015). Riesgos naturales en la huerta de Orihuela. In T. Ferrández \& E. Diz (Coor.), Historia natural de la Huerta de Orihuela (pp. 251-282). Orihuela: Ayuntamiento de Orihuela. Retrieved from: http://rua.ua.es/dspace/handle/10045/47065

Caraballo, C. (2008). El patrimonio cultural y los nuevos criterios de intervención. La participación de los actores sociales. Palapa. Revista de Investigación Científica en Arquitectura, 3(1), 41-49. Retrieved from https://www.redalyc.org/pdf/948/94811212006.pdf

Castillo, J. (2014). Cultivando el agua. Valoración y protección de los sistemas históricos de riego: el caso de la Vega de Granada. In M. M. Lozano \& V. Méndez (Coord.), Patrimonio cultural vinculado con el agua: paisaje, urbanismo, arte, ingeniería y turismo (pp. 301-320). Mérida: Editora Regional de Extremadura, Universidad de Extremadura \& Ministerio de Economía, Industria y Competitividad. Retrieved from https://dialnet.unirioja.es/servlet/articulo?codigo=4856774 
Conselleria d'Habitatge, Obres Públiques i Vertebració del Territori (2016). Catálogo de protecciones. Plan de Acción Territorial de Ordenación y Dinamización de la Huerta de Valencia. Propuesta de Plan. Valencia: Generalitat Valenciana. Retrieved from http://www.habitatge.gva.es/es/web/planificacion-territorial-e-infraestructura-verde/participacionpublica-pat-huerta

Del Rey, M. (1998). Arquitectura rural valenciana: tipos de casas dispersas y análisis de su arquitectura. Valencia: Direcció General de Patrimoni Artístic.

Del Rey, M. (2002). Alqueries: paisatge i arquitectura en l'horta. Valencia: Consell Valencià de Cultura.

Del Rey, M. (2010). Arquitectura rural valenciana. Valencia: Museu Valencià d'Etnologia.

Fitri, I., Ahmad, Y., \& Ahmad, F. (2015). Conservation of Tangible Cultural Heritage in Indonesia: A Review Current National Criteria for Assessing Heritage Value. Procedia-Social and Behavioral Sciences, 184, 71-78. http://dx.doi.org/10.1016/j.sbspro.2015.05.055

García, I. (2007). Los espacios periurbanos como recurso didáctico: el caso de la Huerta de Valencia. Didáctica de las ciencias experimentales y sociales, 21, 197-210. Retrieved from http://roderic.uv.es/handle/10550/20919

García, M. P. (2012). El patrimonio cultural. Conceptos básicos. Zaragoza: Prensas Universitarias de Zaragoza.

García, I., \& García, J. (2014). La educación en la gestión del territorio: el caso de la Huerta de Valencia. In Unitat de Suport del Vicerectorat de Participació i Projecció Territorial, Medi Ambient $i$ Desenvolupament Territorial. Segon Congrés Universitat de València-Institut d'Estudis Comarcals. Valencia: Universitat de València.

García, M. V., Soto, V., \& Martínez, J. (2017). El estudio del patrimonio cultural. Madrid: Editorial Universitaria Ramón Areces D.L.

García-Cortés, Á., \& Carcavilla, L. (2013). Documento metodológico para la elaboración del inventario español de Lugares de Interés Geológico (IELIG). Madrid: Instituto Geológico y Minero de España. Retrieved from

hHp://www.igme.es/patrimonio/novedades/METODOLOGIA\%2OIELIG\%20web.pdf

Glick, T. F. (1988). Regadío y sociedad en la Valencia medieval. Valencia: Del Cènia al Segura.

González-Varas, I. (2015). Patrimonio cultural: conceptos, debates y problemas. Madrid: Cátedra.

Guinot, E., Ferri, M., Mangue, I., Martí, J., Martínez, A., Sales, V., \& Selma, S. (1999). La Real Acequia de Moncada. Valencia: Conselleria d'Agricultura, Pesca i Alimentació. 
Guinot, E., \& Selma, S. (2005). Les séquies de l'Horta Nord de València: Mestalla, Rascanya i Tormos. Valencia: Conselleria d'Agricultura, Pesca i Alimentació.

Hermosilla, J. (Dir.) (2007). El patrimonio hidráulico del Bajo Turia: L'Horta de València. Valencia: Dirección General de Patrimonio Cultural Valenciano \& Departament de Geografia, Universitat de València.

Hermosilla, J. (Dir.) (2009). Catálogo de los paisajes de l'Horta Sud. Valencia: Publicacions de la Universitat de València.

Hermosilla, J. (2012). La Huerta de Valencia. Un modelo de espacio agrícola, social, económico y cultural en crisis. In J. Romero \& M. Francés (Eds.), La huerta de Valencia: un paisaje cultural con futuro incierto (pp. 99-112). Valencia: Publicacions de la Universitat de València.

Hermosilla, J., Antequera, M., Mayordomo, S., \& Jiménez, S. M. (2018). Evaluación patrimonial de azudes en la Demarcación Hidrográfica del Júcar. Valencia: Tirant Humanidades.

Hermosilla, J., \& Iranzo, E. (2014a). Claves geográficas para la interpretación del patrimonio hidráulico mediterráneo. A propósito de los regadíos históricos valencianos. Boletín de la Asociación de Geógrafos Españoles, 66, 49-66. http://dx.doi.org/10.21138/bage. 1779

Hermosilla, J., \& Iranzo, E. (2014b). The crisis facing Tunisian drainage tunnels: identification, analysis and evaluation of water heritage in the Mediterranean region. Water Science and Technology: Water Supply, 14(5), 829-840. http://dx.doi.org/10.2166/ws.2014.042

Hermosilla, J., \& Mayordomo, S. (2017a). A methodological system for hydraulic heritage assessment: a management tool. Water Science and Technology: Water Supply, 17(3), 879-888. http://dx.doi.org/10.2166/ws.2016.186

Hermosilla, J., \& Mayordomo, S. (2017b). Sistema metodológico de evaluación del patrimonio hidráulico. Valencia: Tirant Humanidades.

Hernández, M. (2009). El paisaje como seña de identidad territorial: valorización social y factor de desarrollo, ¿utopía o realidad? Boletín de la Asociación de Geógrafos Españoles, 49, 169-183. Retrieved from https://www.age-geografia.es/ojs/index.php/bage/article/view/780/0

Ibáñez, G. P., Ahumada, A. L., Toledo, M. A., \& Páez, S. V. (2018). Cuantificación del patrimonio geológico de una potencial georuta interpretativa en la sierra de Santa Victoria, Salta, Argentina. Pasos. Revista de Turismo y Patrimonio Cultural, 16(3), 583-598. http://dx.doi.org/10.25145/j.pasos.2018.16.043 
Instituto Nacional de Estadística (2017). Nomenclátor: Población del Padrón Continuo por unidad poblacional. In Instituto Nacional de Estadística. Retrieved from http://www.ine.es/dyngs/INEbase/es/operacion.htm?c=Estadistica_C\&cid=1254736177010\& $\underline{\text { menu }=\text { resultados\&id } p=1254734710990}$

Iranzo, E. (2009). El paisaje como patrimonio rural. Propuesta de una sistemática integrada para el análisis de los paisajes valencianos (Doctoral dissertation, Universidad de Valencia, Spain). Retrieved from http://roderic.uv.es/handle/10550/15883

Iranzo, E. (2014). La Huerta de Valencia. Incertidumbre para un paisaje cultural ancestral. In F. Molinero (Coord.), Atlas de los paisajes agrarios de España (pp. 512-532). Madrid: Ministerio de Agricultura, Alimentación y Medio Ambiente. Retrieved from http://www.upv.es/contenidos/CAMUNISO/info/U0691607.pdf

Labadi, S. (2007). Representations of the nation and cultural diversity in discourses on world heritage. Journal of Social Archaeology, 7(2), 147-170. http://dx.doi.org/10.1177/1469605307077466

LEY 5/2018, de 6 de marzo, de la Generalitat, de la Huerta de València. Retrieved from http://www.dogv.gva.es/datos/2018/03/12/pdf/docv_8252.pdf

Llull, J. (2005). Evolución del concepto y de la significación social del patrimonio cultural. Arte, Individuo y Sociedad, 17, 175-204. Retrieved from http://revistas.ucm.es/index.php/ARIS/article/view/6656

Mangue, I. (2016). Els patrimonis inmaterials de l'aigua i la terra a l'Horta de València. Entre el desconeixement, la urbanalització i la multiculturalitat. In V. M. Algarra \& C. Cárcel (Coord.), València, quan la ciutat aplega a l'horta (pp. 71-78). Valencia: Ajuntament de València.

Marco, J., Mateu, J., \& Romero, J. (1994). Regadíos históricos valencianos. Propuestas de rehabilitación. Valencia: Generalitat Valenciana. Conselleria d’Agricultura, Pesca i Alimentació.

Martí, P., \& Moreno, E. (2014). La transformación urbana y territorial de la ciudad de Murcia y su entorno (1977-2010). Estudios Geográficos, LXXV(276), 261-309.

http://dx.doi.org/10.3989/estgeogr.201407

Mata, R., \& Fernández, S. (2004). La Huerta de Murcia: landscape guidelines for a peri-urban territory. Landscape Research, 29(4), 385-397.

http://dx.doi.org/10.1080/0142639042000289028

Mata, R., \& Fernández, S. (2010). Paisajes y patrimonios culturales del agua. La salvaguarda del valor patrimonial de los regadíos tradicionales. Scripta Nova. Revista Electrónica de Geografía y Ciencias Sociales. XIV(337). Retrieved from http://www.ub.es/geocrit/sn/sn-337.htm 
Mateu, J. (1999). Una aproximació a les hortes valencianes. Mètode, 22, 14-15. Retrieved from https://metode.cat/wp-

content/uploads/2012/01/22ca_Una_aproximacio_a_les_hortes_valencianes.pdf

Mayordomo, S., Antequera, M., \& Hermosilla, J. (2018). Application of a method to assess hydraulic heritage as regards diversion dams in the Júcar River Basin. A decision-making tool. European Journal of Geography, 9(3), 62-79. Retrieved from http://www.eurogeographyjournal.eu/articles/07. Entire\%20manuscript_APPLICATION\%200F\% 20A\%20METHOD\%20TO\%20ASSESS\%2OHYDRAULIC\%2OHERITAGE\%20AS\%2OREGARDS\%20 DIVERSION\%2ODAMS\%2OIN\%2OTHE\%20J\%C3\%9ACAR\%2ORIVER\%2OBASIN.\%20A\%2ODECISI ON-MAKING\%2OTOOL_OK.pdf

Medina, W. (2015). Importancia de la Geodiversidad. Método para el inventario y valoración del Patrimonio Geológico. Serie correlación geológica, 31(1). Retrieved from http://www.scielo.org.ar/scielo.php?script=sci_abstract\&pid=S1666-94792015000100004

Menor, J. (2000). La Vega de Granada. Transformaciones agrarias recientes en un espacio periurbano. Granada: Instituto de Desarrollo Regional, Universidad de Granada.

Ministerio de Educación, Cultura y Deporte (2015a). Plan Nacional de Paisaje Cultural. Madrid: Secretaría General Técnica. Subdirección General de Documentación y Publicaciones. http://dx.doi.org/10.4438/030-16-422-7

Ministerio de Educación, Cultura y Deporte (2015b). Plan Nacional de Patrimonio Industrial. Madrid: Secretaría General Técnica. Subdirección General de Documentación y Publicaciones. http://dx.doi.org/10.4438/030-423-2

Molinero, F., Baraja, E., \& Silva, R. (2013). La tipificación de los paisajes agrarios de España: categorías y clases. Una clasificación escalar. In Molinero, F., Atlas de los Paisajes Agrarios de España (pp. 8-24). Madrid: Ministerio de Agricultura, Alimentación y Medio Ambiente. Retrieved from http://www.upv.es/contenidos/CAMUNISO/info/U0691606.pdf

Morales, A. (2001). Agua y Territorio en la Región de Murcia. Murcia: Fundación Centro de Estudios Históricos \& Investigaciones Locales Región de Murcia.

Morey, B. (2018). Cataloguing, Characterization, Valuation and Management of the Palaeontological Heritage: a Perspective from Majorca (Spain). Geoheritage, 10, 483-498. http://dx.doi.org/10.1007/s12371-017-0278-4

Morote, A. F., \& Medina, R. E. (2015). La Huerta de Alicante y sus torres de defensa: propuesta de una ruta turística. Cuadernos de Turismo, 35, 287-309. http://dx.doi.org/10.6018/turismo.35.221621 
Mydland, L., \& Grahn, W. (2012). Identifying heritage values in local communities. International Journal of Heritage Studies, 18, 564-587. http://dx.doi.org/10.1080/13527258.2011.619554

Olcina, J., \& Hernández, M. (2017). Alicante y su Huerta. In Hermosilla, J. (Dir.), Paisajes Turísticos Valencianos: paisajes valiosos, paisajes valorados (pp. 208-216). Valencia: Generalitat Valencia \& Universitat de València. Retrieved from http://paisajesturisticosvalencianos.com/category/publicaciones

Pepín, M. (1996). Ermitas de la Comunidad Valenciana. Valencia: Carena.

Pepín, M. (2003). Santuarios valencianos. Valencia: Consell Valencià de Cultura.

Pereira, P., \& Pereira, D. (2010). Methodological guidelines for geomorphosite assessment. Géomorphologie: relief, processus, environnement, 16(2), 215-222. http://dx.doi.org/10.4000/geomorphologie.7492

Pérez de los Cobos, F. J. (2000). Alquerías, masías y heredades valencianas. Valencia: Federico Domenech.

Riegl, N. (1903). Der moderne Denkmalkultus. Sein Wesen und seine Entstehung. Wien \& Leipzig: Braumüller.

Romero, J., \& Francés, M. (Eds.) (2012). La huerta de Valencia: un paisaje cultural con futuro incierto. Valencia: Publicacions de la Universitat de València.

Romero, J., \& Melo, C. (2016). La ordenación y gestión de las huertas mediterráneas españolas. El tiempo de la(s) política(s). In Vera, J. F., Olcina, J., \& Hernández, M. (Eds.), Paisaje, cultura territorial y vivencia de la Geografía. Libro homenaje al profesor Alfredo Morales Gil (pp. 361380). San Vicente del Raspeig: Publicaciones de la Universidad de Alicante. Retrieved from: https://rua.ua.es/dspace/bitstream/10045/58766/1/Homenaje-Alfredo-Morales_18.pdf

Ruiz, J. (2017). Ensenyant horta, aprenent paisatge. Anàlisi dels discursos educatius sobre el paisatge de l'Horta i propostes de millora. GeoGraphos. Revista digital para estudiantes de $\begin{array}{llll}\text { geografía } y & \text { ciencias } & \text { 8(100), }\end{array}$

http://dx.doi.org/10.14198/geogra2017.8.100

Sanchis, C. (2004). Crònica de la recent reducció superficial del regadiu històric. Afers: fulls de recerca i pensament, 19(47), 111-128.

Sanchis, C., \& Díez, I. (2012). Huerta y ciudad: contigüidad geográfica y distancia cultural. In Romero, J., \& Francés, M. (Eds.), La Huerta de Valencia. Un paisaje cultural con futuro incierto (pp. 77-98). Valencia: Publicacions de la Universitat de València. 
Serrano, E., \& González-Trueba, J. J. (2005). Assessment of geomorphosites in natural protected areas: the Picos de Europa National Park (Spain). Géomorphologie: relief, processus, environnement, 3, 197-208. http://dx.doi.org/10.4000/geomorphologie.364

Siguencia, M. E., \& Rey, J. (2016). Heritage values protection, from the monument to the urban dimension. Case study: the historic centre of Santa Ana de los Ríos de Cuenca, Ecuador. The Historic Environment: Policy \& Practice, 7(2-3), 164-176. http://dx.doi.org/10.1080/17567505.2016.1172785

Silva, R. (2008). Hacia una valoración patrimonial de la agricultura. Scripta Nova. Revista Electrónica de Geografía y Ciencias Sociales, XII(275). Retrieved from http://www.ub.edu/geocrit/sn/sn-275.htm

Silva, R. (2009). Agricultura, paisaje y patrimonio territorial. Los paisajes de la agricultura vistos como patrimonio. Boletín de la Asociación de Geógrafos Españoles, 49, 309-334. Retrieved from https://www.age-geografia.es/ojs/index.php/bage/article/view/786/709

Silva, R., Fernández, V., \& Mata, R. (2018). Concepto, ámbito y significado de los paisajes patrimoniales. In F. Molinero \& J. Tort (Coord.), Paisajes Patrimoniales de España (pp. 13-38). Madrid: Ministerio de Agricultura, Pesca y Alimentación \& UAM Ediciones.

Sirovica, F., \& Kudelić, J. (2019). Protecting the Value of Archaeological Heritage: Frame of Reference in Value Assessments. In R. Aguilar, D. Torrealva, S. Moreira, M. A. Pando, L. F. Ramos (Eds.), Structural Analysis of Historical Constructions (pp. 1816-1829). Cham: Springer. http://dx.doi.org/10.1007/978-3-319-99441-3_195

Soler, J. (2007). Las ermitas de Valencia. Valencia: Ayuntamiento de Valencia.

Stanners, D., \& Bourdeau, P. (Eds.) (1995). Europe's Environment: The Dobris Assessment. Copenhagen: European Environmental Agency. Retrieved from https://www.eea.europa.eu/publications/92-826-5409-5

Torres, A. J., Matarán, A., \& Bejarano, J. F. (2016). Narrativas de la Vega de Granada como mito en peligro de desaparición: semántica del conflicto local-global. Encrucijadas. Revista Crítica de Ciencias Sociales, 11. Retrieved from

http://www.encrucijadas.org/index.php/ojs/article/view/198

Torres, M. (2013). Paisajes del Valle medio del Guadalquivir cordobés: funcionalidad y cambios. Revista de estudios regionales, 96, 135-180. Retrieved from http://www.revistaestudiosregionales.com/documentos/articulos/pdf1207.pdf

Zhang, J., \& Wang, S. (2017). Method for evaluating the value of architectural heritage. Journal of Harbin Engineering University, 38(10), 1661-1668.http://dx.doi.org/10.11990/jheu.201612075 


\section{Anexo I. Tamaño muestral de las encuestas}

Tabla 1. Propuesta de tamaño muestral

\begin{tabular}{|c|c|c|c|}
\hline \multicolumn{4}{|c|}{ Tamaño muestral para los municipios } \\
\hline Habitantes & $\begin{array}{l}\mathrm{N}^{\circ} \\
\text { municipios }\end{array}$ & $\begin{array}{l}\text { Tamaño muestral } \\
\text { por municipio }\end{array}$ & $\begin{array}{l}\text { Error muestral con un nivel de confianza } \\
\text { del } 95,5 \%(p=q=50 \%)\end{array}$ \\
\hline \multirow{2}{*}{ Hasta 5000} & \multirow{2}{*}{6} & \multirow{2}{*}{50} & Por municipio: $\pm 13,7 \%$ \\
\hline & & & Para el conjunto del estrato: $\pm 5,6 \%$ \\
\hline \multirow{2}{*}{ De 5000 a 10000} & \multirow{2}{*}{8} & \multirow{2}{*}{100} & Por municipio: $\pm 9,7 \%$ \\
\hline & & & Para el conjunto del estrato: $\pm 3,4 \%$ \\
\hline \multirow{2}{*}{ Más de 10000} & \multirow{2}{*}{18} & \multirow{2}{*}{150} & Por municipio: $\pm 7,97 \%$ \\
\hline & & & Para el conjunto del estrato: $\pm 1,9 \%$ \\
\hline Total & 32 & 3800 & $\pm 1,59 \%$ \\
\hline
\end{tabular}

\begin{tabular}{|c|c|c|c|}
\hline \multicolumn{3}{|c|}{ Tamaño muestral para los barrios de Valencia } \\
\hline Habitantes & No barrios & $\begin{array}{c}\text { Tamaño muestral } \\
\text { por barrio }\end{array}$ & $\begin{array}{r}\text { Error muestral con un nivel de confianza } \\
\text { del } 95,5 \%(p=q=50 \%)\end{array}$ \\
\hline Hasta 2000 & 7 & 50 & Por barrio: $\pm 13,5 \%$ \\
\cline { 3 - 4 } De 2000 a 10 000 & 8 & 100 & Para el conjunto del estrato: $\pm 5,0 \%$ \\
\hline \multirow{2}{*}{ Más de 10000} & 7 & 150 & Para el conjunto del estrato: $\pm 3,0 \%$ \\
\hline Total & 24 & 2400 & Para el conjunto del estrato: $\pm 3,0 \%$ \\
\hline
\end{tabular}

Fuente: elaboración propia 


\section{Anexo II. Evaluación técnica}

Figura 1. Evaluación técnica de cada uno de los bienes seleccionados

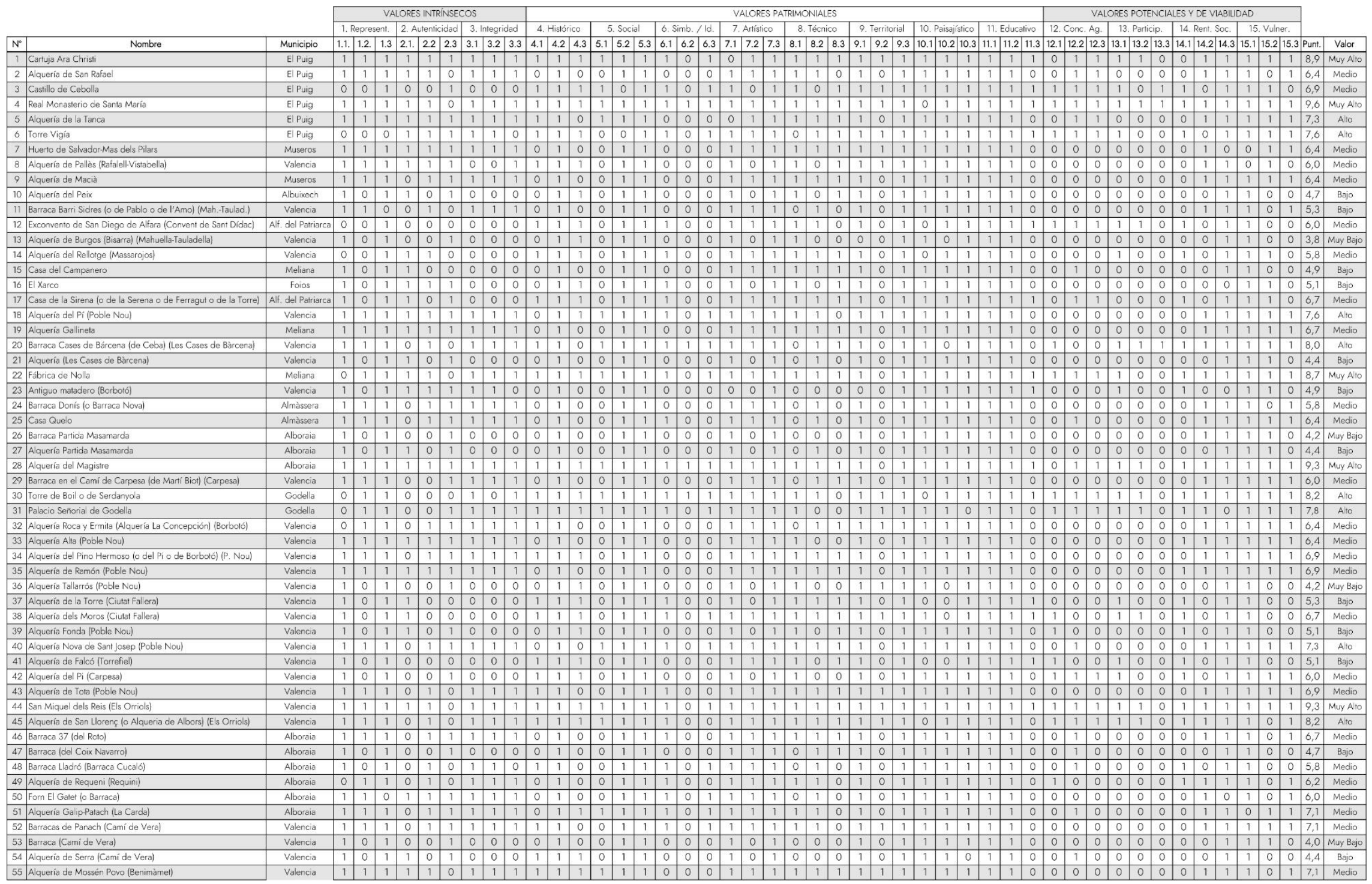

Boletín de la Asociación de Geógrafos Españoles, 82, 2790, 1-57 


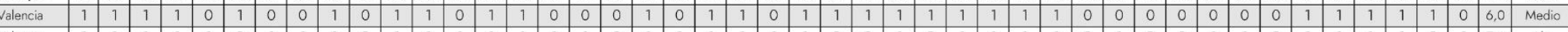
\begin{tabular}{llllllllllllllllllllllllllllllllllllllllllllllllllllll} 
Valencia & 1 & 0 & 1 & 1 & 1 & 0 & 1 & 1 & 1 & 0 & 1 & 1 & 1 & 1 & 1 & 1 & 1 & 0 & 1 & 1 & 1 & 1 & 1 & 1 & 0 & 0 & 1 & 0 & 1 & 1 & 1 & 1 & 0 & 1 & 0 & 0 & 1 & 1 & 0 & 1 & 1 & 1 & 1 & 0 & 1 & 7,6 & Ali \\
\hline
\end{tabular}

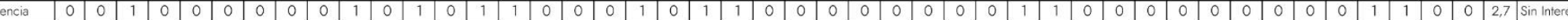

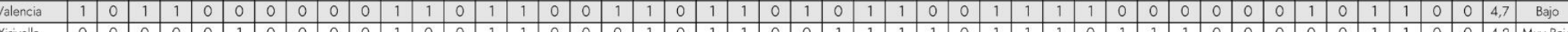

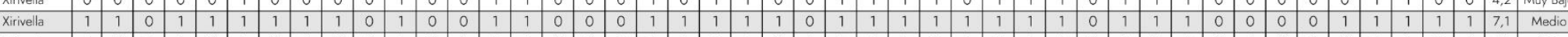

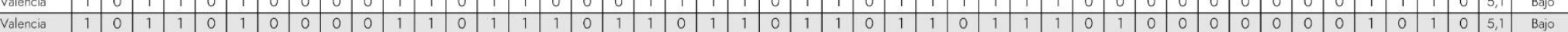

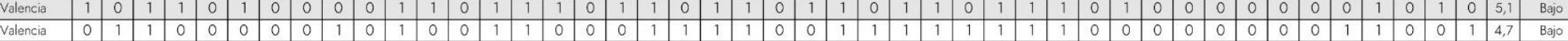

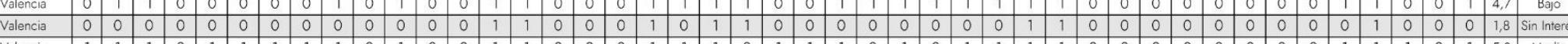

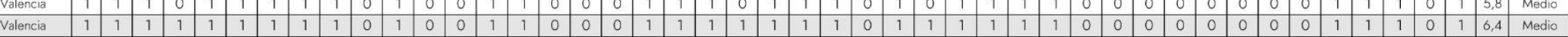

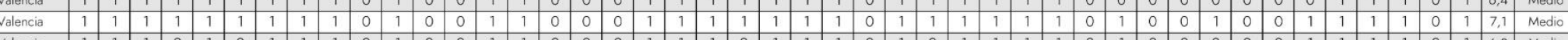

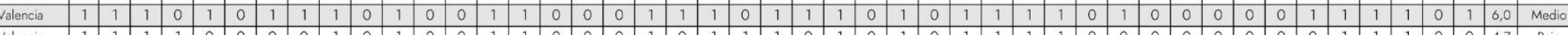

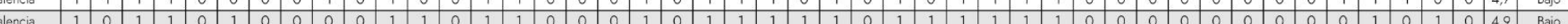
\begin{tabular}{lllllllllllllllllllllllllllllllllllllllllllllllllllllllllll} 
Valencia & 1 & 1 & 1 & 1 & 1 & 0 & 1 & 1 & 1 & 0 & 1 & 0 & 0 & 1 & 1 & 0 & 0 & 0 & 1 & 1 & 1 & 1 & 1 & 1 & 1 & 0 & 1 & 1 & 1 & 1 & 1 & 1 & 0 & 0 & 0 & 0 & 0 & 0 & 0 & 0 & 1 & 1 & 0 & 0 & 1 & 6,0 & Medio \\
\hline
\end{tabular} \begin{tabular}{lllllllllllllllllllllllllllllllllllllllllllllllllllllllllllll} 
Valencia & 1 & 1 & 1 & 0 & 1 & 1 & 1 & 1 & 1 & 0 & 1 & 0 & 0 & 1 & 1 & 0 & 0 & 0 & 1 & 1 & 1 & 0 & 1 & 1 & 1 & 0 & 1 & 1 & 1 & 1 & 1 & 1 & 0 & 0 & 0 & 0 & 0 & 0 & 0 & 0 & 1 & 1 & 1 & 0 & 1 & 6,0 & Medio \\
\hline
\end{tabular} \begin{tabular}{|l|l|l|l|l|l|l|l|l|l|l|l|l|l|l|l|l|l|l|l|l|l|llllllllllllllllllllllllll} 
Valencia & 1 & 1 & 1 & 0 & 1 & 1 & 1 & 1 & 1 & 0 & 1 & 0 & 0 & 1 & 1 & 0 & 0 & 0 & 1 & 1 & 1 & 0 & 1 & 1 & 1 & 0 & 1 & 1 & 1 & 1 & 1 & 1 & 0 & 0 & 0 & 0 & 0 & 0 & 0 & 0 & 1 & 1 & 1 & 0 & 1 & 6,0 & Medio \\
\hline
\end{tabular} \begin{tabular}{lllllllllllllllllllllllllllllllllllllllllllllllllllllll} 
Valencia & 1 & 1 & 1 & 0 & 1 & 1 & 1 & 1 & 0 & 0 & 1 & 0 & 0 & 1 & 1 & 0 & 0 & 0 & 1 & 1 & 1 & 0 & 1 & 1 & 1 & 0 & 1 & 1 & 1 & 1 & 1 & 1 & 0 & 0 & 0 & 0 & 0 & 0 & 0 & 0 & 1 & 1 & 1 & 0 & 1 & 5,8 & Medio \\
\hline
\end{tabular}

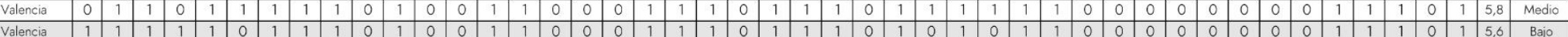

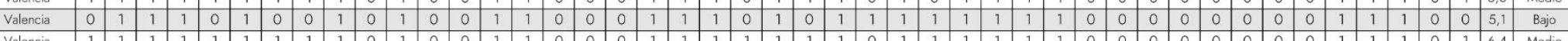

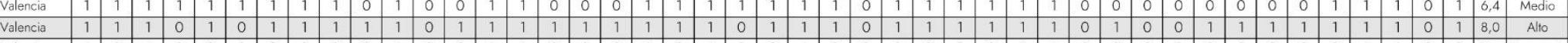

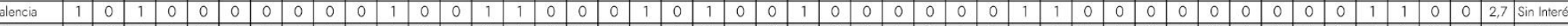

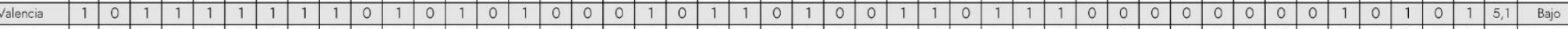
\begin{tabular}{|l} 
Valencla \\
\hline
\end{tabular}

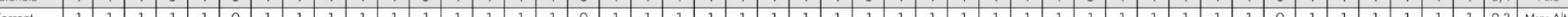

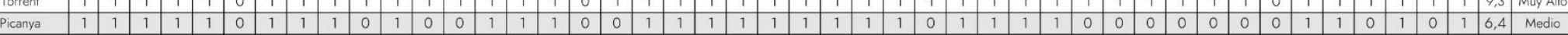
\begin{tabular}{llllllllllllllllllllllllllllllllllllllllllllllllllll}
\hline Torrent & 1 & 1 & 1 & 1 & 1 & 1 & 0 & 0 & 1 & 0 & 1 & 0 & 0 & 1 & 1 & 0 & 0 & 0 & 1 & 0 & 1 & 1 & 1 & 1 & 1 & 1 & 1 & 1 & 1 & 1 & 1 & 1 & 0 & 0 & 0 & 0 & 1 & 0 & 0 & 1 & 1 & 0 & 1 & 1 & 0 & 6 & Media \\
\hline
\end{tabular}

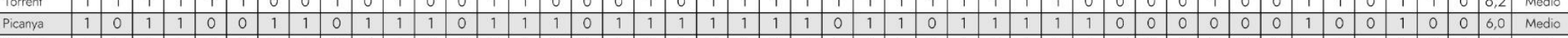

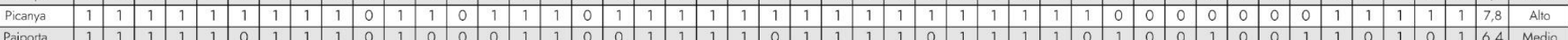

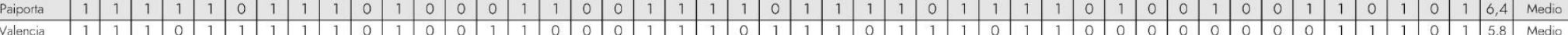
\begin{tabular}{lllllllllllllllllllllllllllllllllllllllllllllllllll} 
Valencia & 1 & 1 & 1 & 1 & 1 & 1 & 1 & 1 & 1 & 0 & 1 & 0 & 0 & 1 & 1 & 0 & 0 & 0 & 1 & 1 & 1 & 0 & 1 & 1 & 1 & 1 & 1 & 1 & 1 & 0 & 1 & 1 & 0 & 0 & 0 & 0 & 0 & 0 & 0 & 0 & 1 & 1 & 1 & 0 & 1 & 6,2 & Media \\
\hline
\end{tabular}

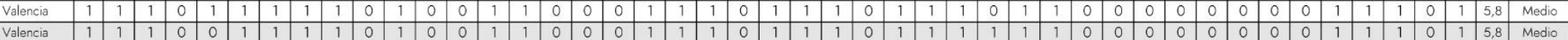

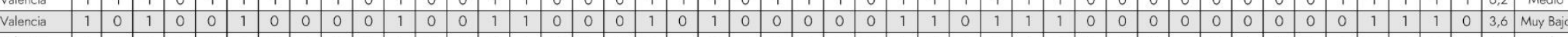

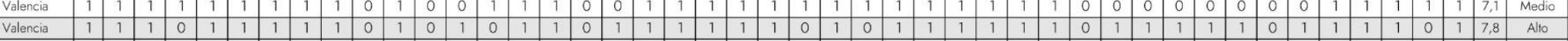

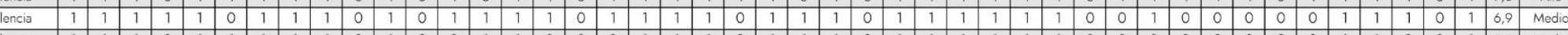

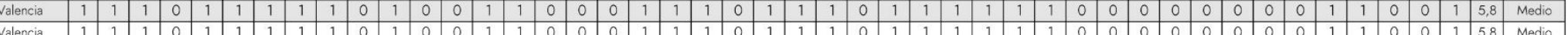

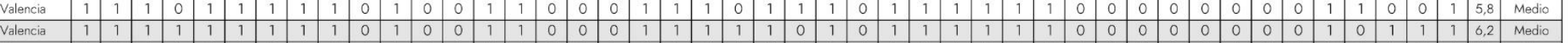

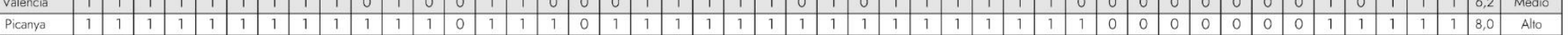

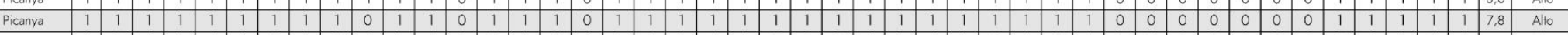
\begin{tabular}{lllllllllllllllllllllllllllllllllllllllllllllllllll}
\hline Picanya & 1 & 1 & 1 & 1 & 1 & 1 & 1 & 1 & 1 & 0 & 1 & 1 & 0 & 1 & 1 & 1 & 0 & 1 & 1 & 1 & 1 & 1 & 1 & 1 & 1 & 1 & 1 & 1 & 1 & 1 & 1 & 1 & 1 & 0 & 0 & 0 & 0 & 0 & 0 & 0 & 1 & 1 & 1 & 1 & 1 & 7,8 & Alio \\
\hline
\end{tabular} \begin{tabular}{lllllllllllllllllllllllllllllllllllllllllllllllllllllll} 
Picanya & 1 & 1 & 1 & 1 & 1 & 1 & 1 & 1 & 1 & 1 & 1 & 1 & 0 & 1 & 1 & 1 & 0 & 1 & 0 & 1 & 1 & 1 & 1 & 1 & 1 & 1 & 1 & 1 & 1 & 1 & 1 & 1 & 1 & 0 & 0 & 0 & 0 & 0 & 0 & 0 & 1 & 1 & 1 & 1 & 1 & 7,8 & Alto \\
\hline Picanya & 1 & 1 & 1 & 1 & 1 & 1 & 1 & 1 & 1 & 1 & 1 & 1 & 1 & 1 & 1 & & & &
\end{tabular}

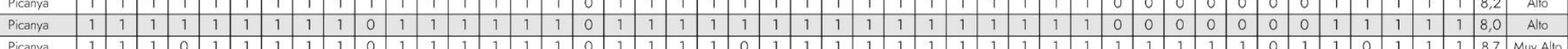

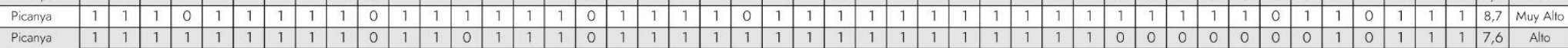




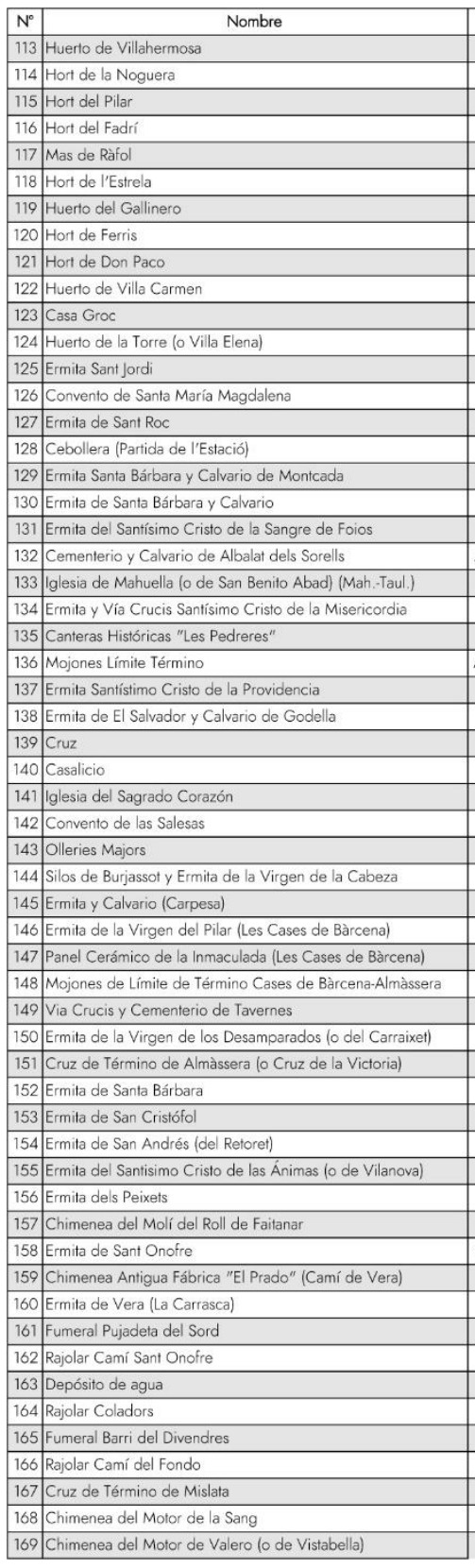

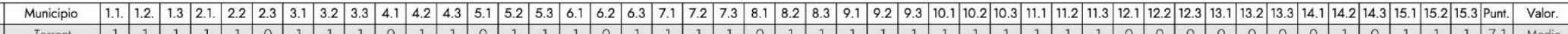

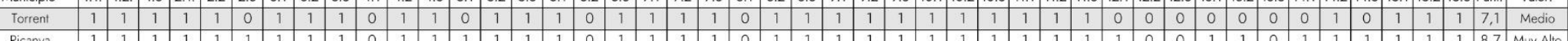

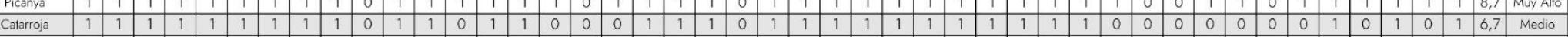

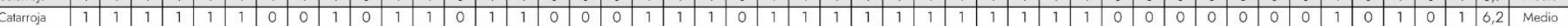

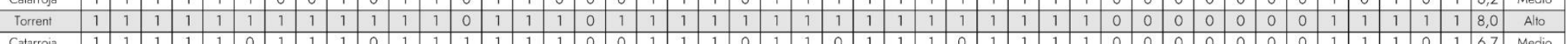

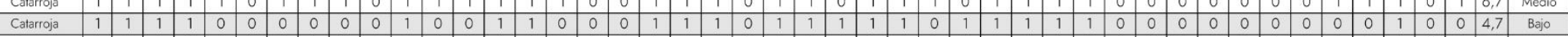

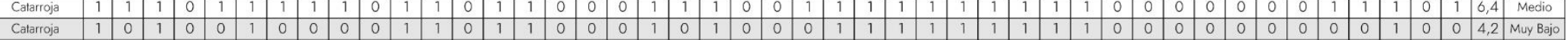

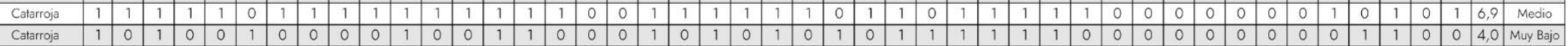

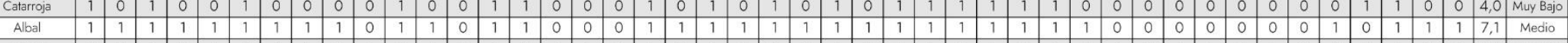

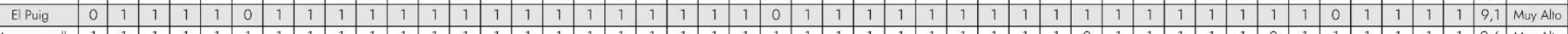

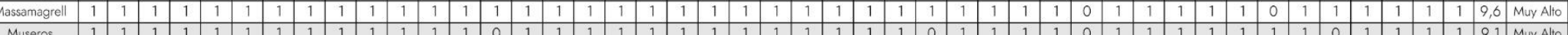

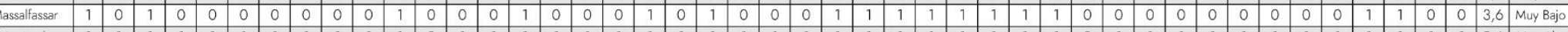

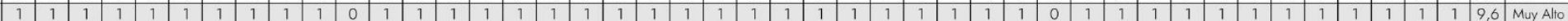
\begin{tabular}{lllllllllllllllllll|llllllllll}
1 & 1 & 1 & 1 & 0 & 1 & 1 & 1 & 1 & 0 & 1 & 0 & 1 & 1 & 1 & 1 & 8,0 & Alio \\
\hline
\end{tabular}

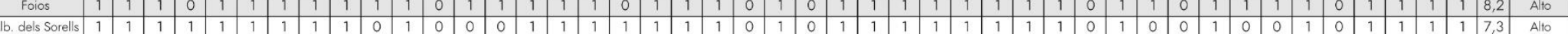

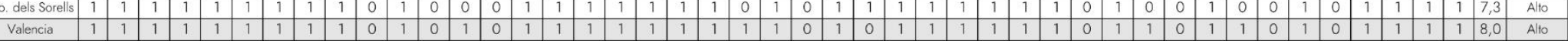
\begin{tabular}{|lllllllllllllllllllllllllllllllllllllllllllllllllllll} 
Albuixech & 1 & 1 & 1 & 1 & 1 & 1 & 1 & 1 & 1 & 0 & 1 & 0 & 1 & 0 & 1 & 1 & 1 & 1 & 1 & 1 & 1 & 0 & 1 & 0 & 1 & 1 & 1 & 1 & 1 & 1 & 1 & 1 & 0 & 1 & 1 & 1 & 1 & 1 & 0 & 1 & 0 & 1 & 1 & 1 & 1 & 8,2 & Alto \\
\hline
\end{tabular} \begin{tabular}{llllllllllllllllllllllllllllllllllllllllll|llll}
8 & A.
\end{tabular}

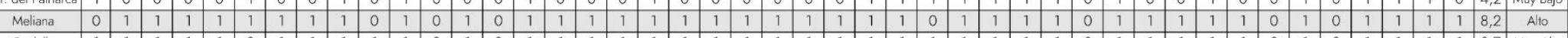

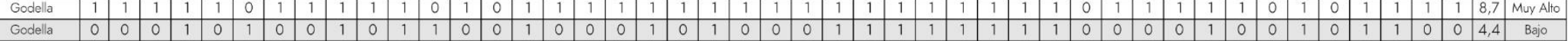

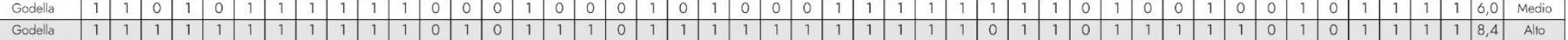
\begin{tabular}{lllllllllllllllllllllllllllllllllllllllllllllllllllllllllll} 
Godella & 1 & 1 & 1 & 1 & 1 & 1 & 1 & 1 & 1 & 1 & 1 & 0 & 1 & 1 & 1 & 1 & 1 & 1 & 1 & 1 & 1 & 1 & 1 & 0 & 1 & 1 & 1 & 1 & 1 & 1 & 1 & 1 & 0 & 1 & 1 & 1 & 1 & 0 & 0 & 1 & 1 & 1 & 1 & 1 & 1 & 8,9 & Muy Alto \\
\hline
\end{tabular}

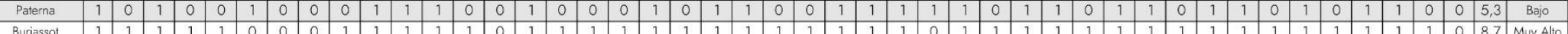
\begin{tabular}{|lllllllllllllllllllllllllllllllllllllllllllllllllllllllll}
\hline Valencia & 1 & 1 & 1 & 1 & 1 & 1 & 1 & 1 & 1 & 1 & 1 & 1 & 1 & 0 & 1 & 1 & 1 & 1 & 1 & 1 & 1 & 0 & 1 & 0 & 1 & 1 & 1 & 1 & 1 & 1 & 1 & 1 & 0 & 1 & 1 & 1 & 1 & 1 & 0 & 1 & 0 & 1 & 1 & 1 & 1 & 8.7 & Muy Alto \\
\hline
\end{tabular}

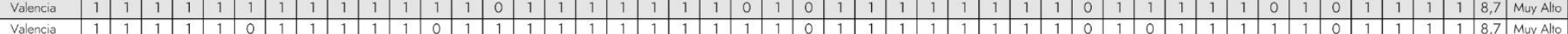

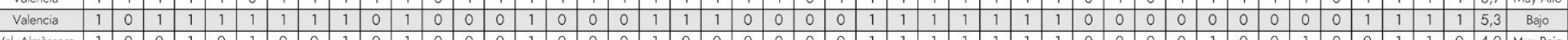

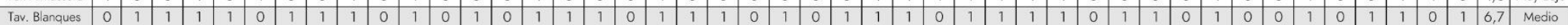

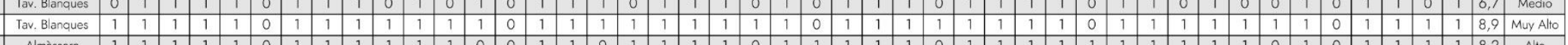

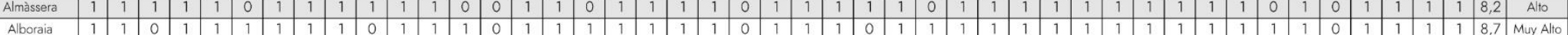

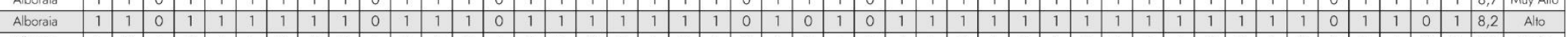
\begin{tabular}{lllllllllllllllllllllllllllllllllllllllllllllllllllllllll} 
Alboraia & 1 & 0 & 1 & 1 & 1 & 1 & 0 & 0 & 0 & 1 & 1 & 0 & 0 & 1 & 1 & 0 & 0 & 0 & 1 & 1 & 1 & 0 & 1 & 0 & 1 & 1 & 1 & 1 & 1 & 1 & 1 & 1 & 0 & 0 & 1 & 1 & 0 & 0 & 1 & 0 & 0 & 1 & 1 & 0 & 0 & 5,8 & Medio \\
\hline
\end{tabular}

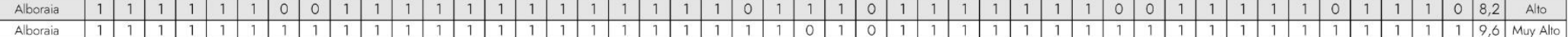
\begin{tabular}{llllllllllllllllllllllllllllllllllllllllllllllllllll} 
Manises & 1 & 0 & 0 & 1 & 1 & 0 & 1 & 1 & 0 & 0 & 1 & 0 & 0 & 0 & 1 & 1 & 0 & 0 & 1 & 1 & 1 & 1 & 1 & 0 & 1 & 0 & 1 & 0 & 1 & 1 & 1 & 1 & 0 & 0 & 0 & 0 & 1 & 0 & 0 & 1 & 0 & 1 & 0 & 0 & 1 & 5,1 & Bajo \\
\hline
\end{tabular}

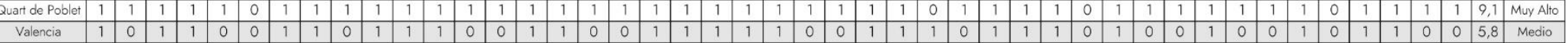

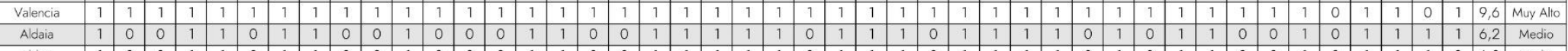

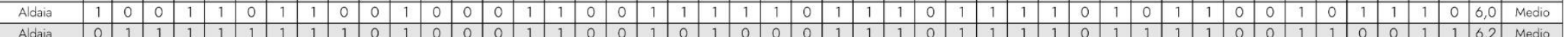

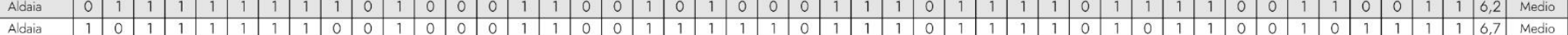

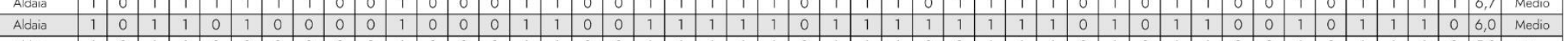

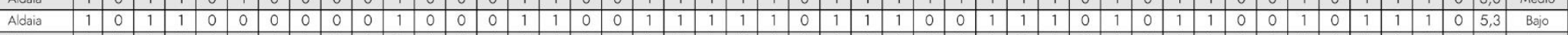

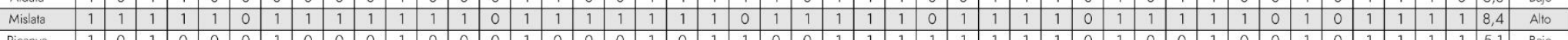

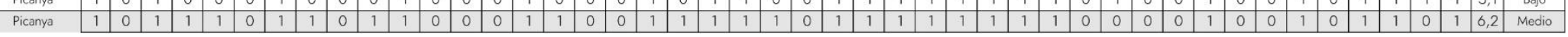




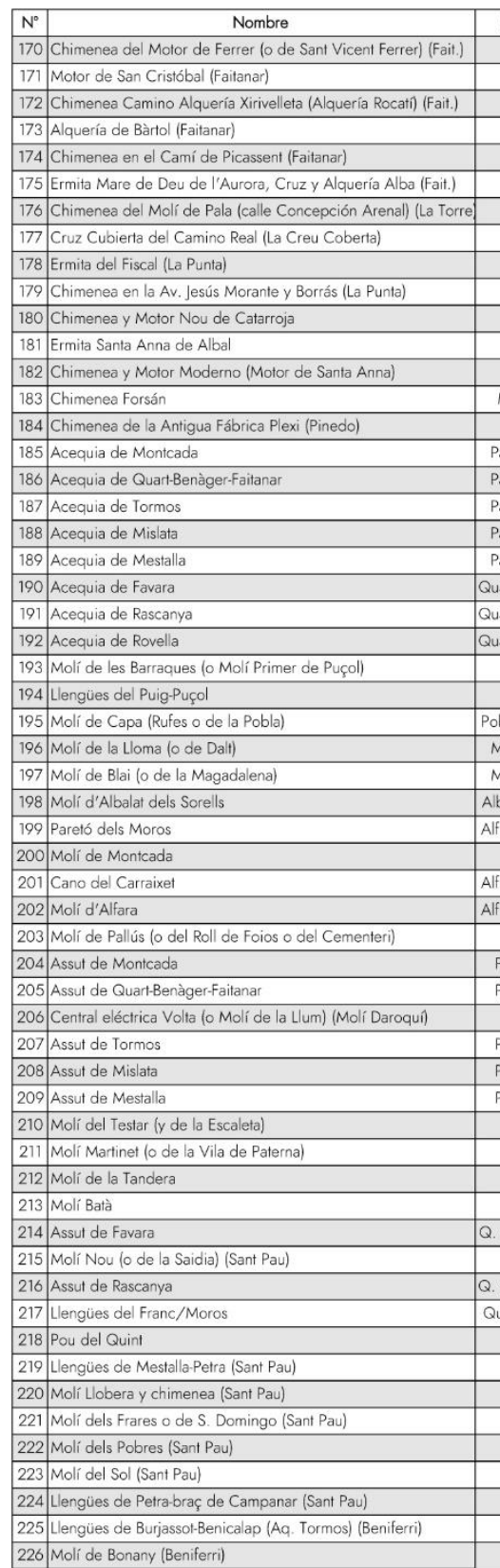

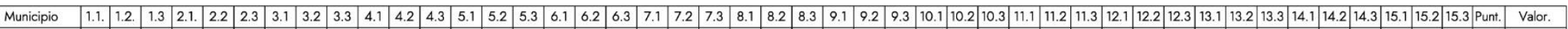

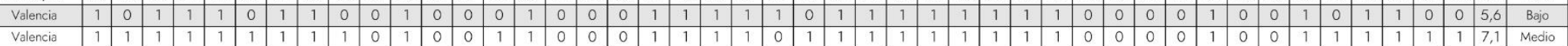

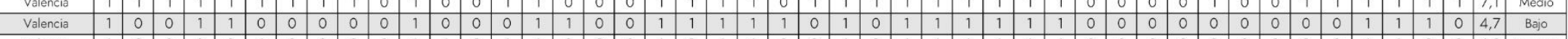

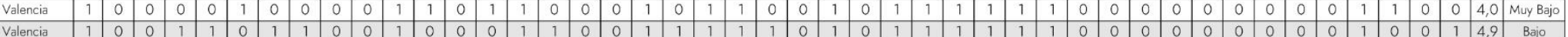

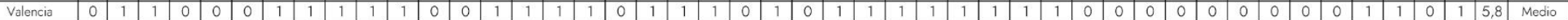

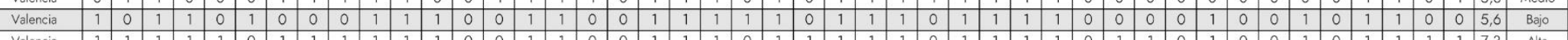

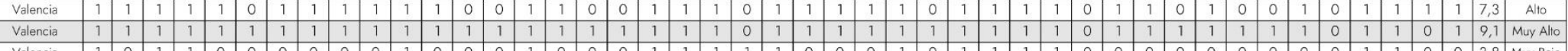

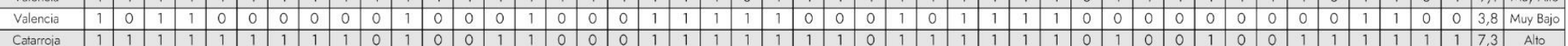

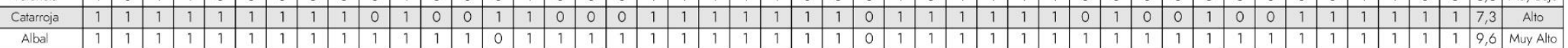

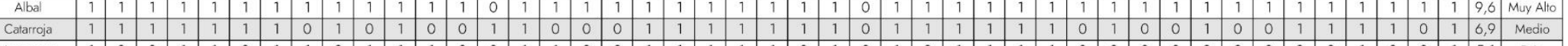

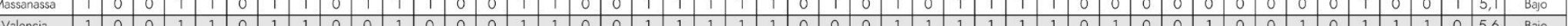

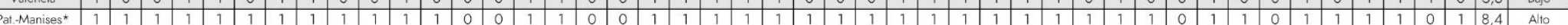

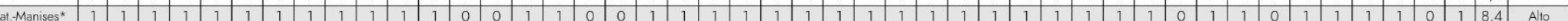

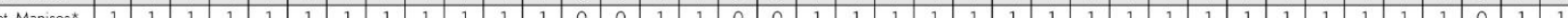

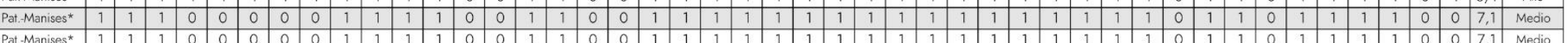

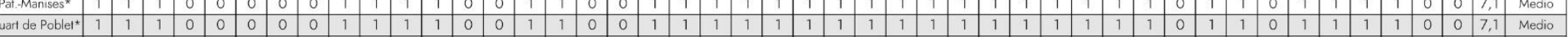

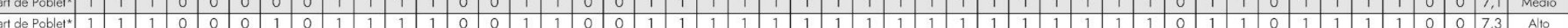

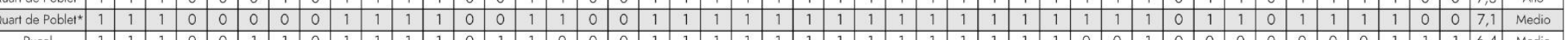

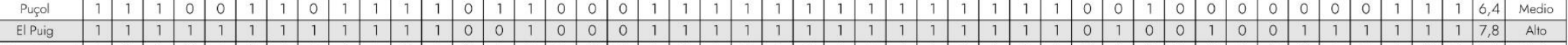

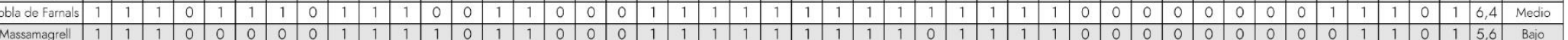

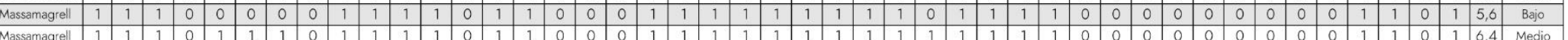

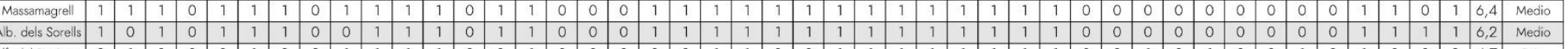

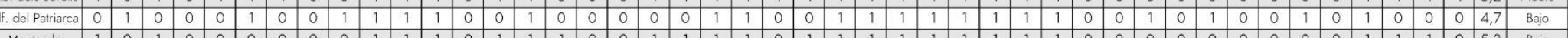

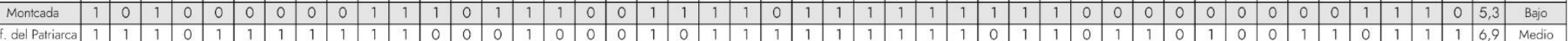

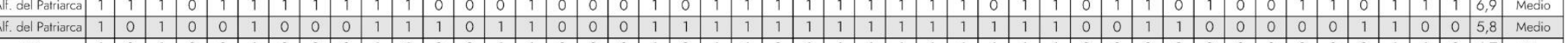

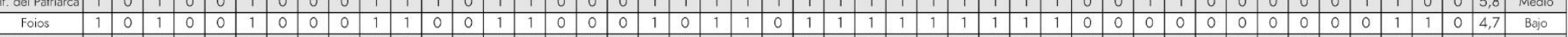

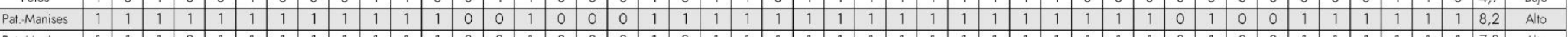

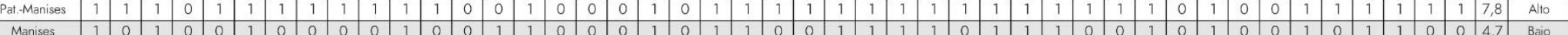

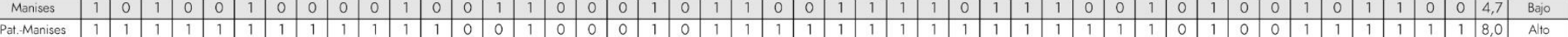

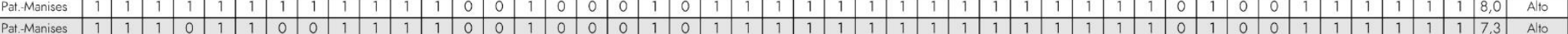

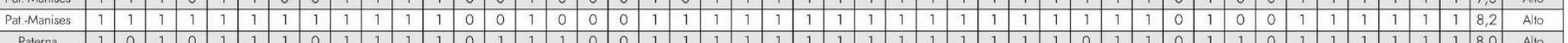

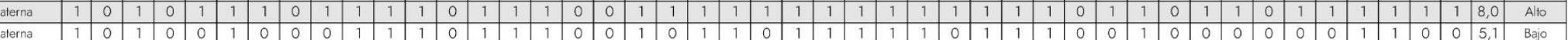

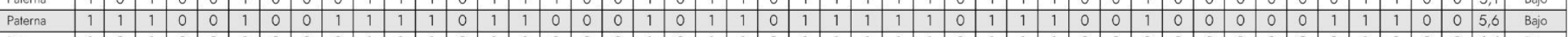

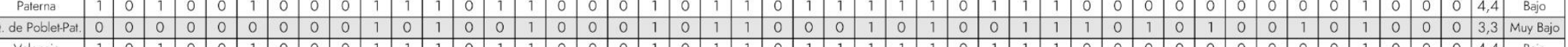

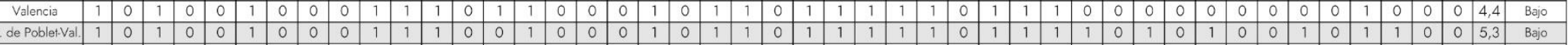

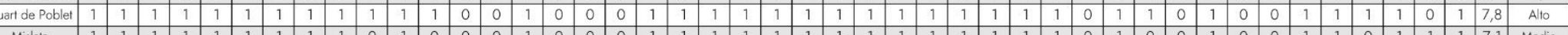

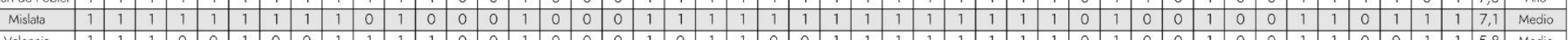

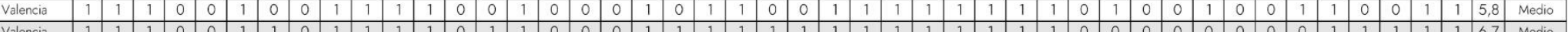

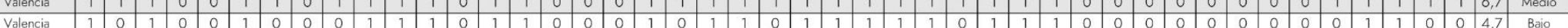

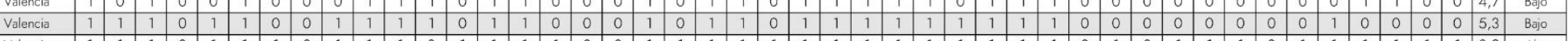

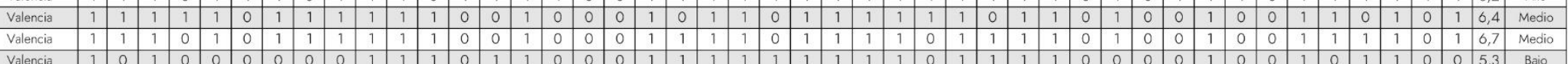

225 Llengües de Bujajassot:Benicalap (Aq. Tormos) (Benifent)

Boletín de la Asociación de Geógrafos Españoles, 82, 2790, 1-57 


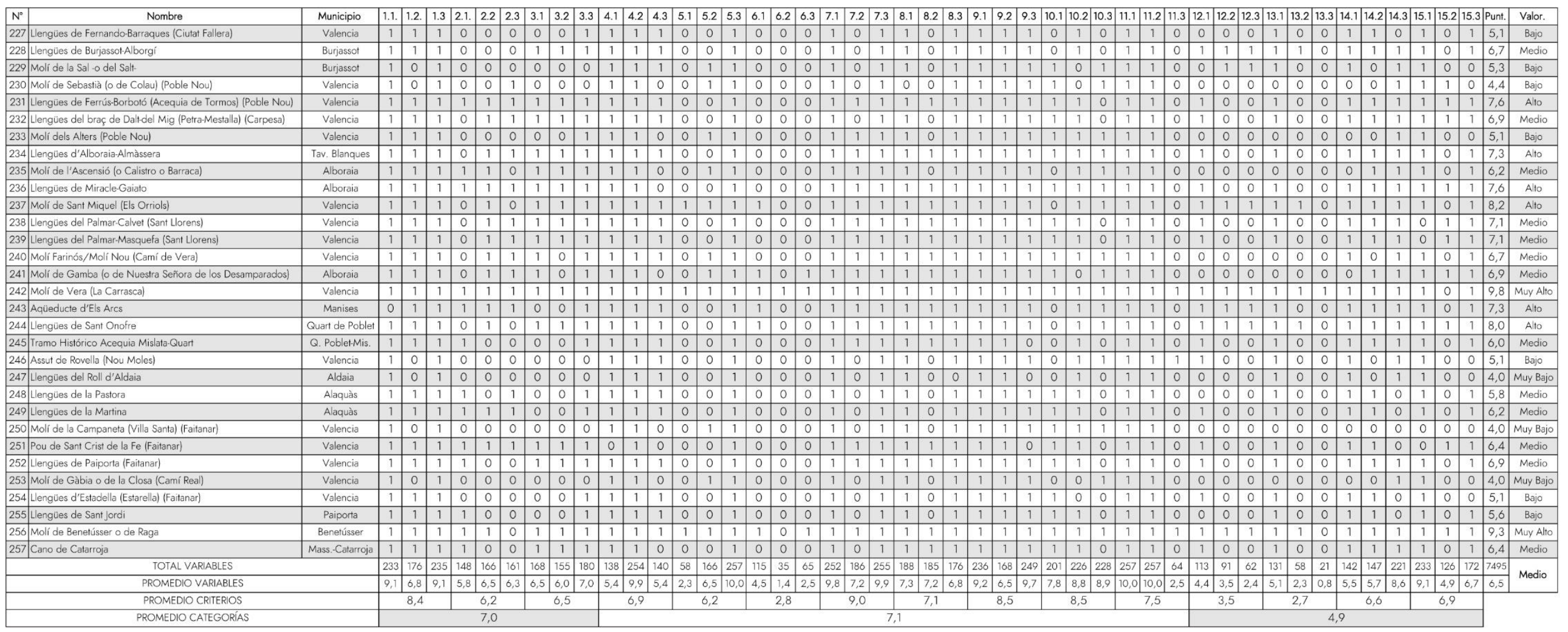

Leyenda: *Indica municipios de origen.

Fuente: elaboración propia 


\section{Anexo III. Evaluación participativa}

Figura 1. Universo de análisis y número de personas consultadas en las encuestas
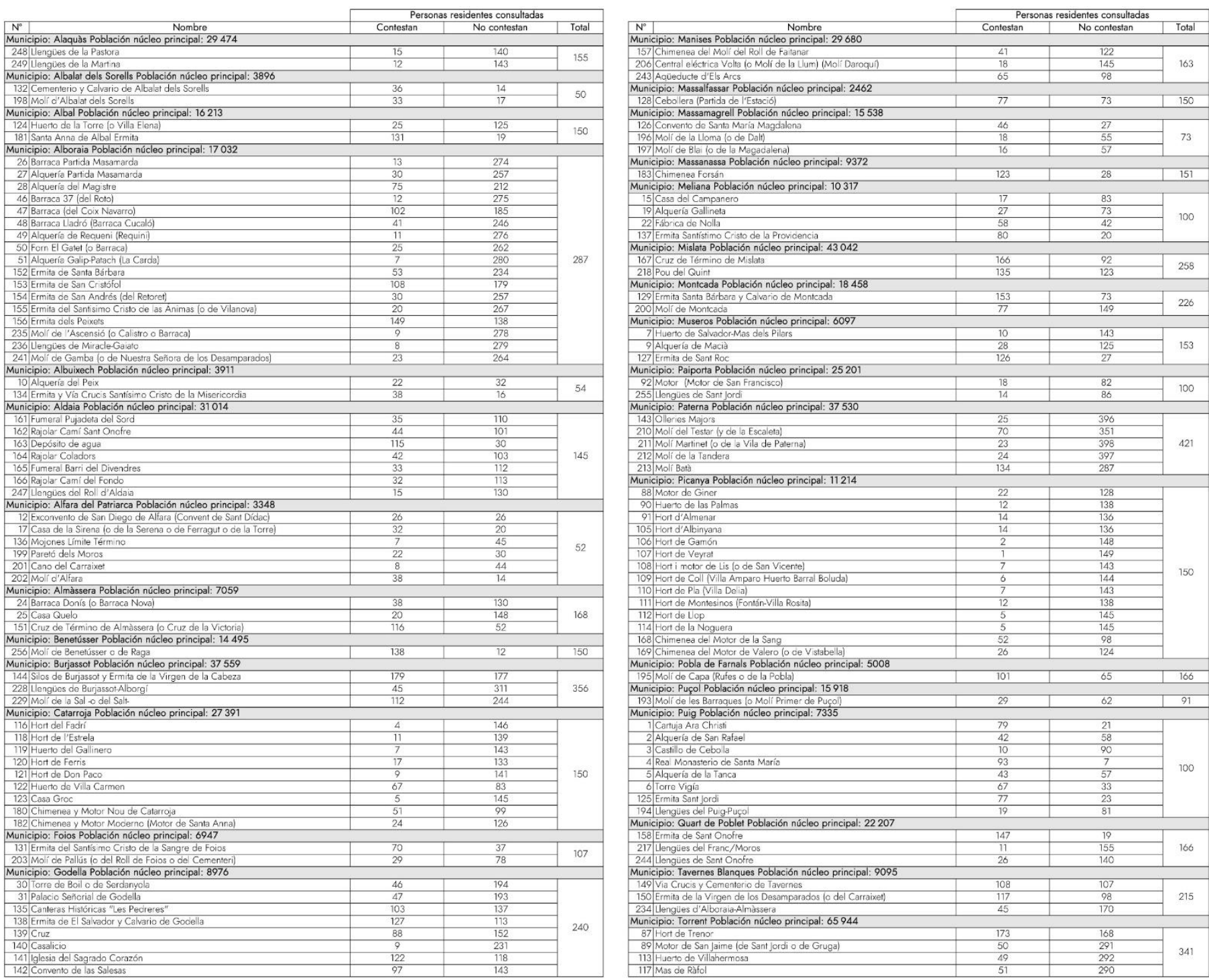

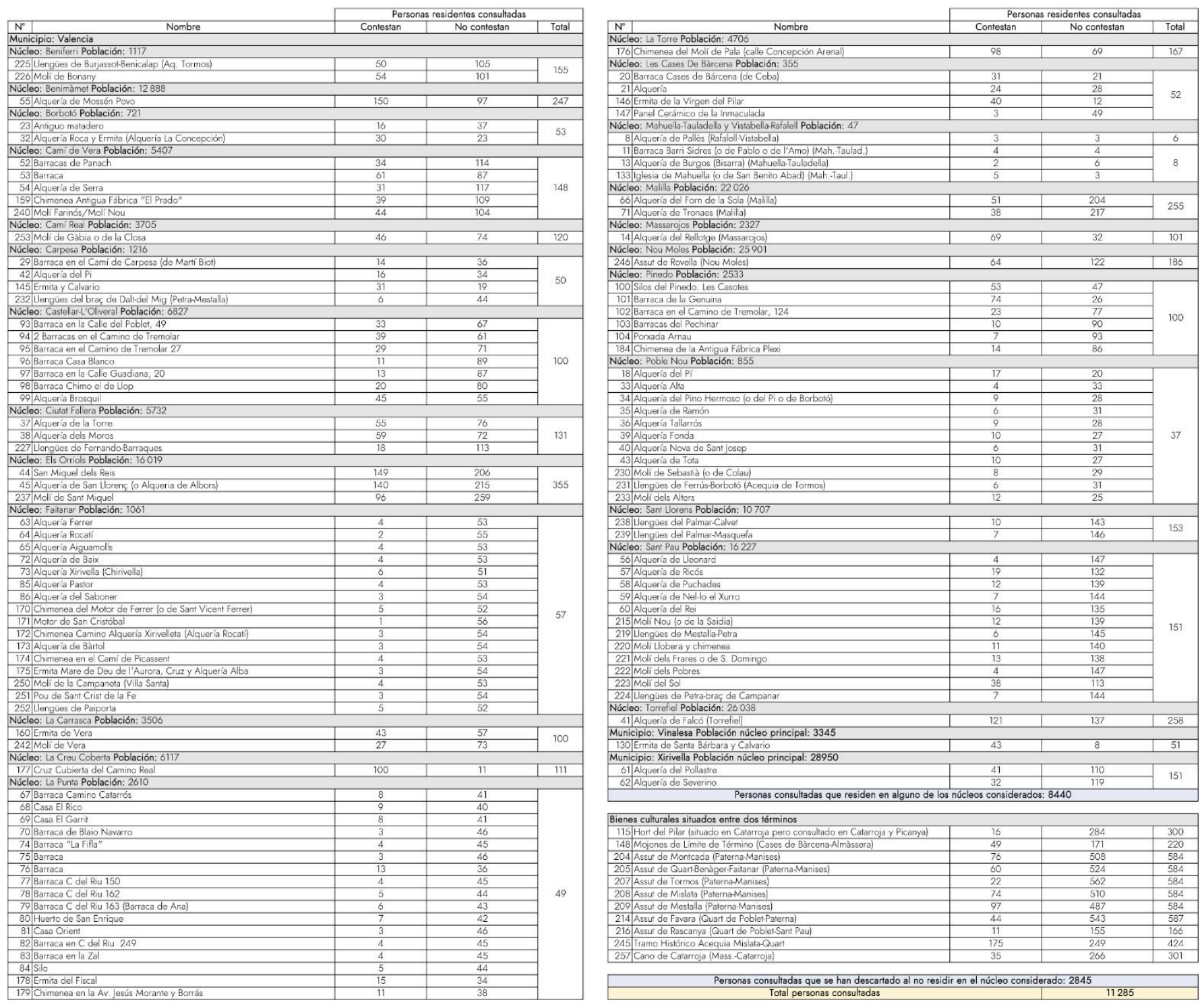

Nota: La fuente consultada para la población de cada núcleo principal es: Instituto Nacional de Estadística (2017).

Fuente: elaboración propia 
Figura 2. Evaluación participativa de cada uno de los bienes seleccionados
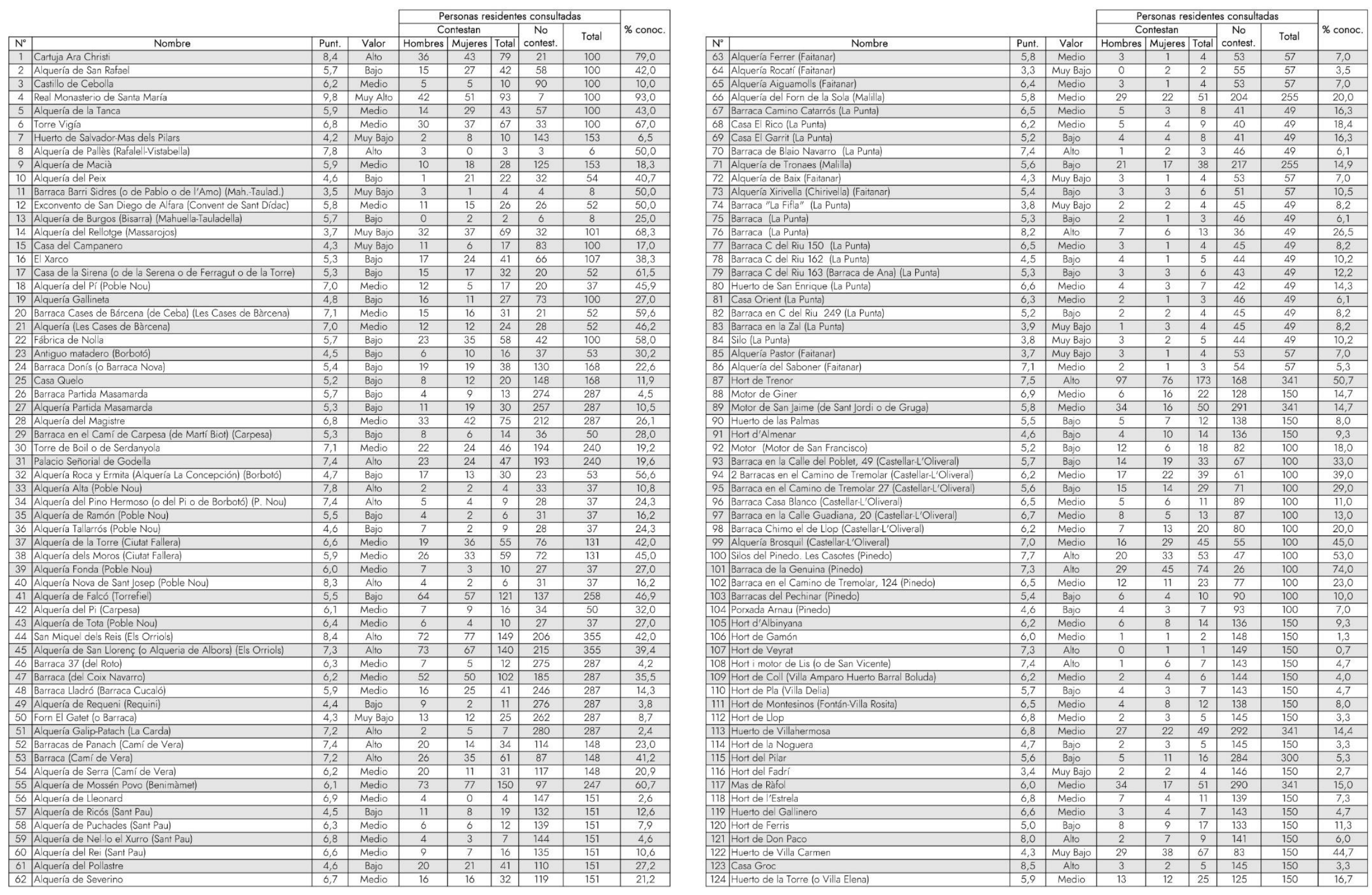

Boletín de la Asociación de Geógrafos Españoles, 82, 2790, 1-57 

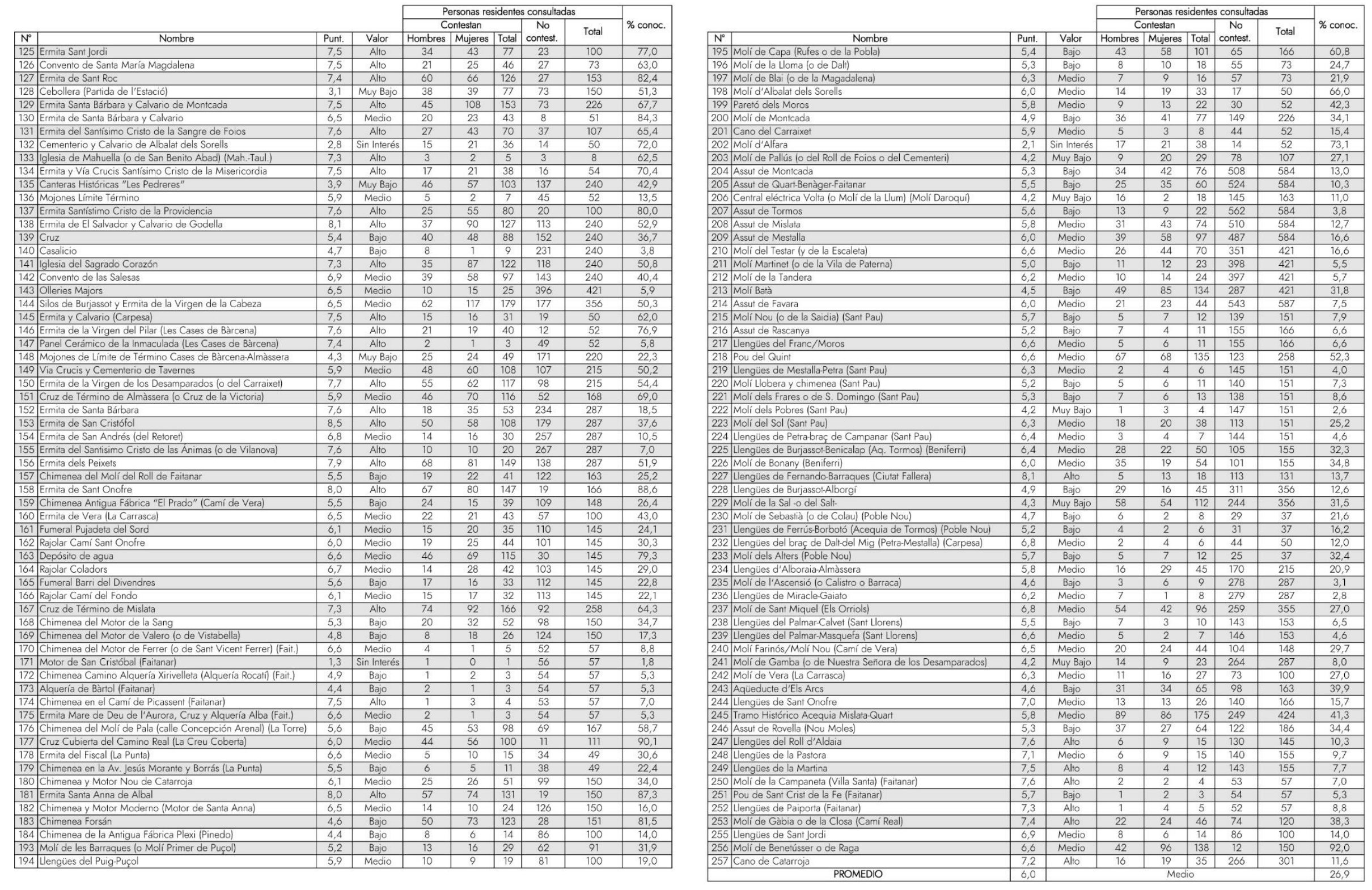

Fuente: elaboración propia

Boletín de la Asociación de Geógrafos Españoles, 82, 2790, 1-57 